\title{
STRUCTURAL BEHAVIOUR OF REINFORCED HIGH-PERFORMANCE CONCRETE JOINTS IN FRAMES SUBJECTED TO LATERAL CYCLIC LOADING
}

\author{
By \\ Ahmed Monjid Abdulmajeed \\ Bachelor of Civil Engineering (BEng), \\ Ryerson University, Toronto, ON, 2018 \\ An MRP \\ presented to Ryerson University \\ in partial fulfillment of the \\ requirements for the degree of \\ Master of Engineering \\ in the program of \\ Civil Engineering
}

Toronto, Ontario, Canada, 2020

(C)Ahmed Monjid Abdulmajeed 2020 


\section{Author's Declaration}

I hereby declare that I am the sole author of this MRP. This is a true copy of the MRP, including any required final revisions, as accepted by my examiners.

I authorize Ryerson University to lend this MRP to other institutions or individuals for the purpose of scholarly research.

I further authorize Ryerson University to reproduce this MRP by photocopying or by other means, in total or in part, at the request of other institutions or individuals for the purpose of scholarly research.

I understand that my MRP may be made electronically available to the public. 


\title{
Structural Behaviour of Reinforced High-Performance Concrete Joints in Frames Subjected to Lateral Cyclic Loading
}

\author{
Ahmed Monjid Abdulmajeed, Master of Engineering (MEng), 2020 \\ Civil Engineering \\ Ryerson University, Toronto, Canada
}

\begin{abstract}
This project involves experimental and theoretical investigations on the structural behavior of different reinforced beam-column frame specimens made of different concrete materials and reinforcement configurations subjected to cyclic lateral loading to failure. This research is intended to develop high performance self-consolidating concrete (SCC) frames with Engineered Cementitious Composite (ECC) and Ultra-High-Performance Concrete (UHPC) joints with better seismic resistance and load carrying capacity as alternatives to conventional concrete frames. Four ECC and UHPC jointed shear and flexure critical SCC frames were tested and their performance was compared based on hysteretic load-deformation response, rebar/concrete strain development, cracking characteristics, stiffness degradation, energy absorption and failure modes. Comparison between code-based and experimental strength capacities is also conducted. The ECC jointed frames illustrated higher ductility, energy absorbing capacity and durability compared to their UHPC counterparts.
\end{abstract}




\section{Acknowledgments}

I would like to express my profound gratitude to my supervisor Dr. Khandaker M. Anwar Hossain for his guidance throughout the completion of this degree. His extensive knowledge in the area has enabled me to gain valuable insights in the course of this research work. His constant encouragement and enthusiasm has inspired me to undertake this research. I am very grateful for his time, patience and unconditional support that motivated me to assert my maximum potential into this research.

Sincere gratitude is extended to the research team members at Ryerson especially Mr. Ali Ehsani Yeganeh for his continuous support and guidance throughout this project, without which this study would not have been accomplished. I would like to also acknowledge Nidal Jaalouk- Lead Technical Officer, Bilal Baradie - Civil Technologist and Khaleel Stoney- Civil Technologist for their help and support in the structural lab during testing. 


\section{Table of Contents}

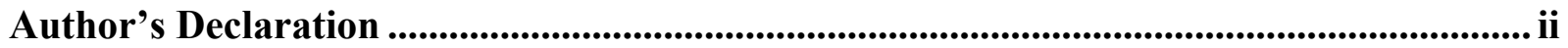

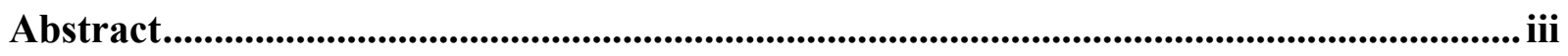

Acknowledgments ................................................................................................................................. iv

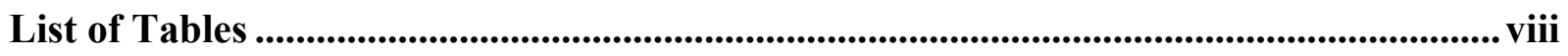

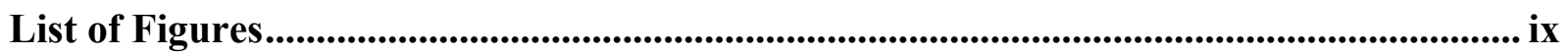

List of Symbols \& Abbreviations.............................................................................. xii

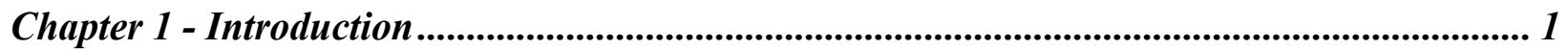

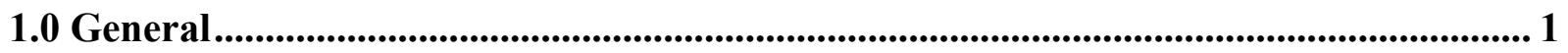

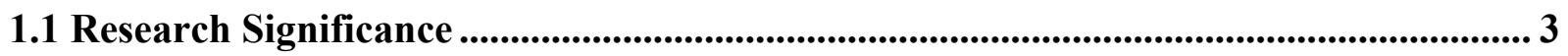

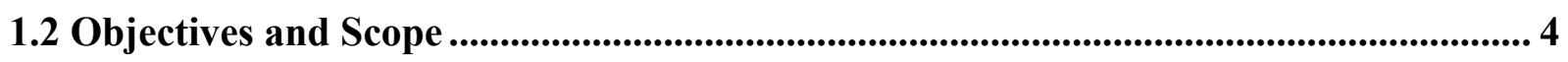

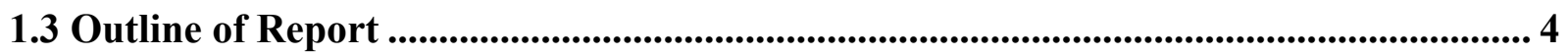

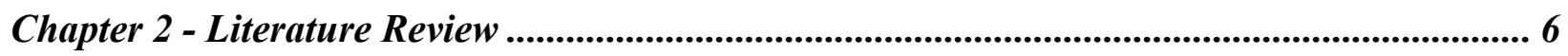

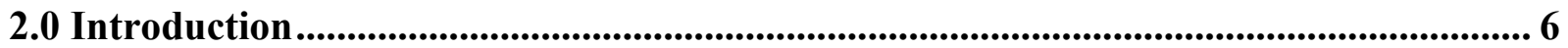

2.1 Advancements in Research on Engineered Cementitious Composite (ECC)............... 6

2.1.1 Material Properties of ECC ................................................................................. 6

2.1.2 Structural Applications of ECC …................................................................... 11

2.2 Advancements in Research on Self-Consolidating Concrete (SCC) ............................ 15

2.2.1 Material Properties of SCC ........................................................................ 15

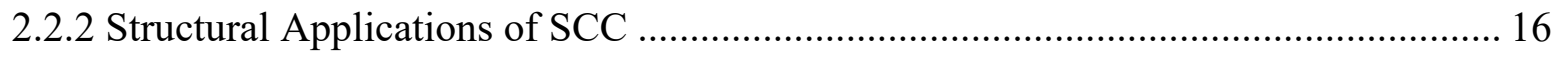

2.3 Advancements in Research on Ultra-High-Performance Concrete (UHPC) .............. 18

2.3.1 Material Properties of UHPC .............................................................................. 19

2.3.2 Structural Applications of UHPC …........................................................... 22

2.4 Research on Completed High Performance Beam-Column Frames .......................... 24

2.5 Design of High-Performance Concrete Beam-Column Members ................................. 26

2.5.1 Shear strength of SCC beam/column ................................................................ 26

2.5.2 Shear strength of ECC and UHPC joints ....................................................... 27

2.5.3 Flexural strength of SCC beam/column.................................................................. 28

2.5.4 Flexure strength of ECC beam/column................................................................ 29

2.5.5 Flexure strength of UHPC beam/column........................................................... 30

2.6 Chapter Review ...................................................................................................................... 31

Chapter 3 - Experimental Investigation ...................................................................... 32 
3.0 Introduction .................................................................................................................................. 32

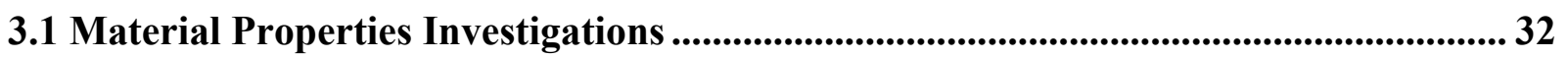

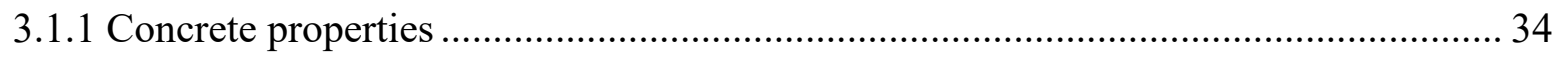

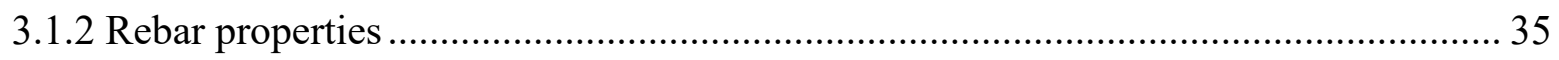

3.2 Beam-Column Frame and Joint Details ............................................................................. 36

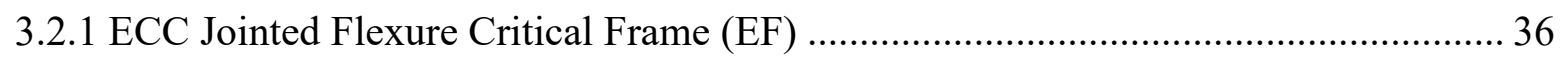

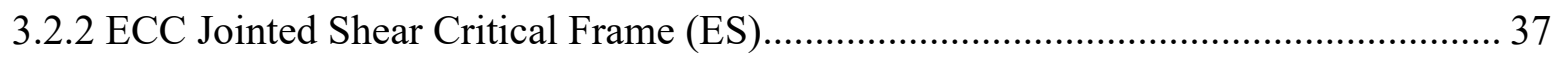

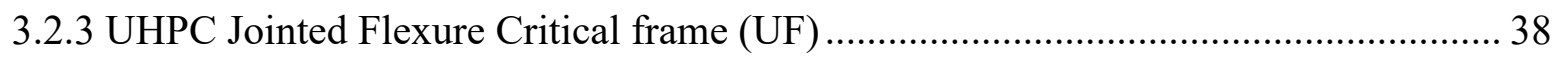

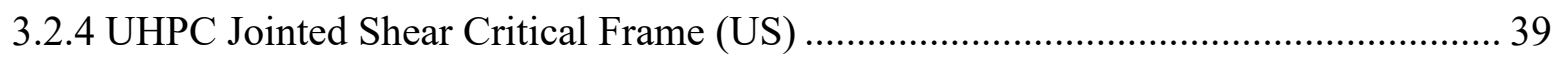

3.3 Test Setup and Procedure ............................................................................................................... 44

3.4 Chapter Review .............................................................................................................................. 47

Chapter 4 - Results and Discussion ................................................................................... 48

4.0 Introduction ....................................................................................................................................... 48

4.1 Test Observations........................................................................................................................... 48

4.1.1 ECC Jointed Flexure Critical Frame (EF) ……….............................................. 48

4.1.2 ECC Jointed Shear Critical Frame (ES) ................................................................... 51

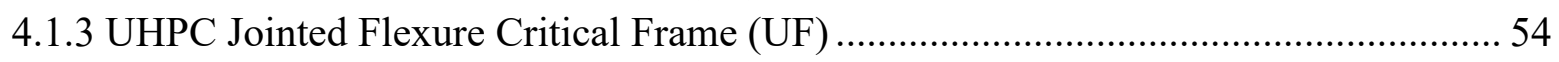

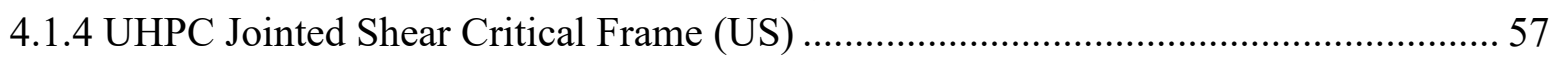

4.2 Crack development and Propagation......................................................................................... 62

4.3 ECC and UHPC Jointed Flexural Critical Frames Comparison .................................... 68

4.4 ECC and UHPC Jointed Shear Critical Frames Comparison.......................................... 73

4.5 Summary of Strain Development ........................................................................................... 79

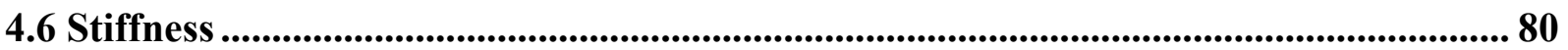

4.7 Energy Absorption.................................................................................................................. 82

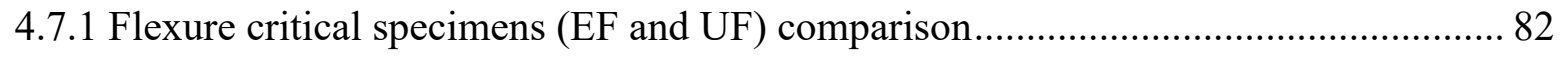

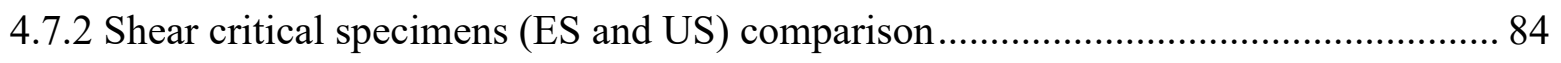

4.8 Experimental and Theoretical based Results and Discussion............................................ 86

4.9 Chapter Review ................................................................................................................................. 89

Chapter 5 - Conclusion and Future Recommendations.................................................................. 90

5.1 Conclusion ........................................................................................................................................... 90

5.2 Future Recommendations ........................................................................................................... 92

Appendix A- Capacity Calculations .............................................................................................. 93

A.1 Code-based Shear Capacity: .................................................................................................... 93 


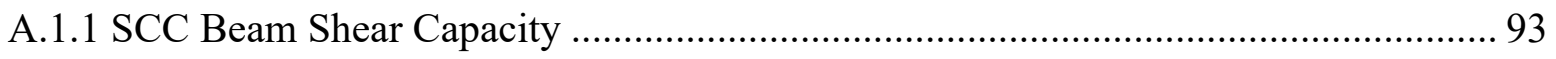

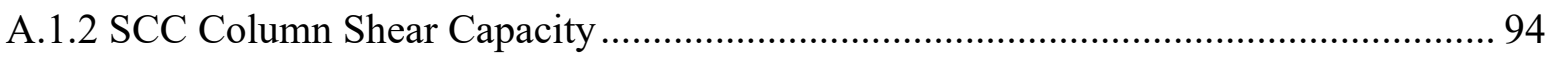

A.1.3 ECC \& UHPC Joint Shear Strength.................................................................... 95

A.2 Code-based Flexural Capacity:........................................................................................... 96

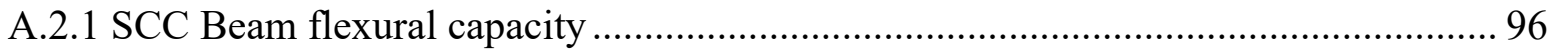

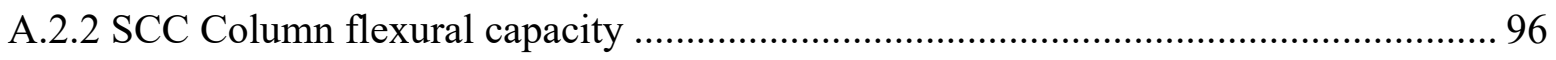

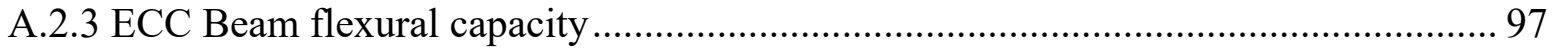

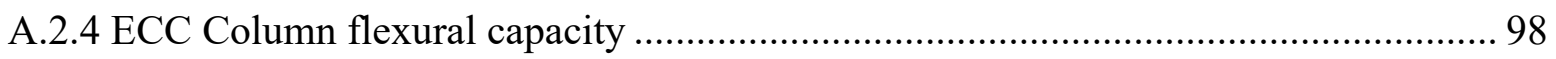

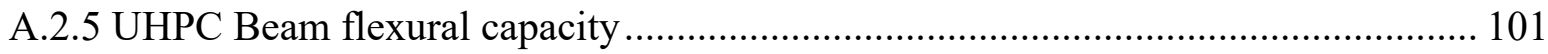

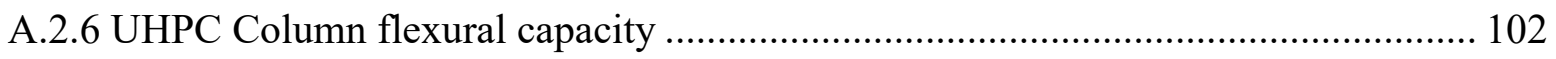

A.3 Experimental Flexural \& Shear Capacity: .................................................................... 103

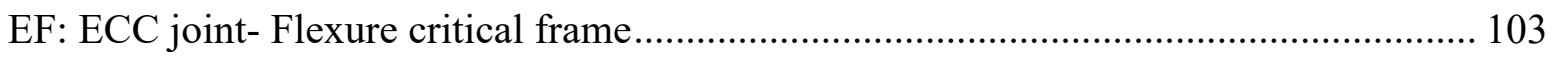

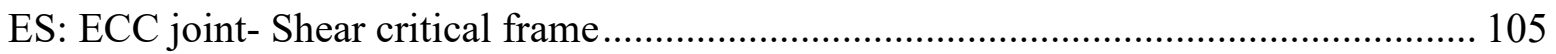

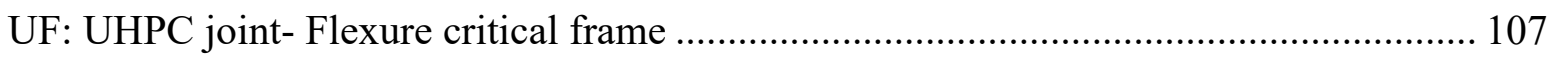

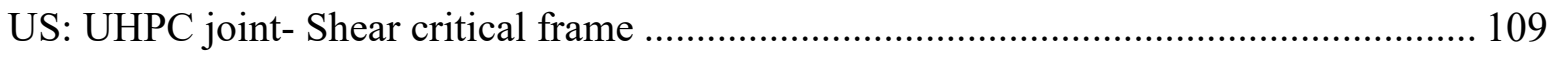

References........................................................................................................................................ 111 


\section{List of Tables}

Table 3.1: Mix design details for ECC and UHPC mixes (Yeganeh, 2015) ........................... 32

Table 3.2: Average Concrete Compressive Strength $\left(f c^{\prime}\right)$ for SCC, ECC and UHPC.............. 35

Table 3.3: Concrete flexural strength $(f t)$ for SCC, ECC and UHPC concrete types (Yeganeh,

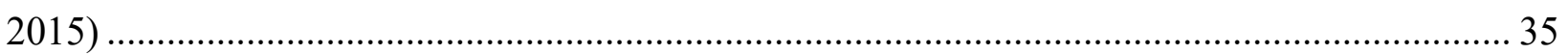

Table 3.4: Rebar reinforcement properties (Yeganeh, 2015) …........................................... 36

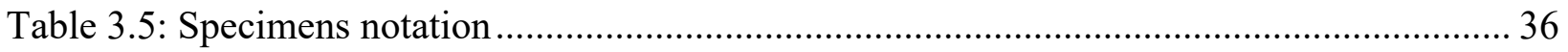

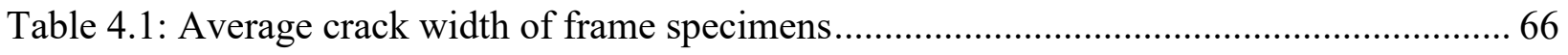

Table 4.2: Strain values at corresponding maximum load for frame specimens ...................... 79

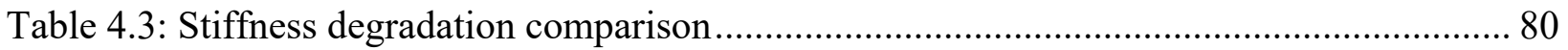

Table 4.4: Energy Absorption, Initial stiffness and peak load (strength) of frame specimens..... 85

Table 4.5: Experimental and theoretical shear member capacity results comparison ................. 86

Table 4.6: Experimental and theoretical flexural member capacity results comparison ............. 88 


\section{List of Figures}

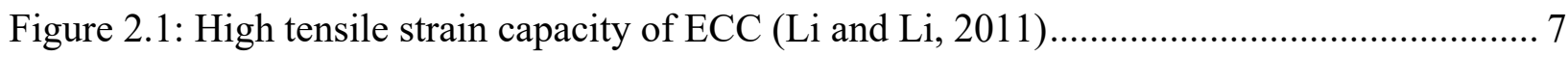

Figure 2.2: Tensile strain capacity comparison of ECC a) without fiber coating, b) with fiber

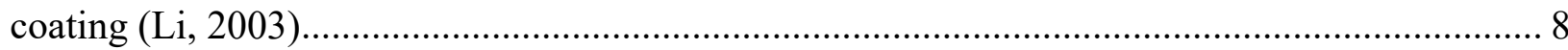

Figure 2.3: Tensile strain capacity of PVA-ECC (Yu et al. 2018) ……………........................... 8

Figure 2.4: ECC microcracking characteristics during uniaxial tensile test ( $\mathrm{Li}$ and $\mathrm{Li}, 2011)$...... 9

Figure 2.5: Drying shrinkage comparison between varying ECC mixtures (Özbay et al. 2012) 11

Figure 2.6: ECC link slab application in bridge decks (Hossain and Anwar, 2014) .................... 12

Figure 2.7: ECC link slab component definition (Hossain and Anwar, 2014) ............................. 12

Figure 2.8: ECC link slab with FRP reinforcement (Zheng et al. 2018) ...................................... 13

Figure 2.9: Load vs. deflection envelope at midspan of the ECC link slab specimens under

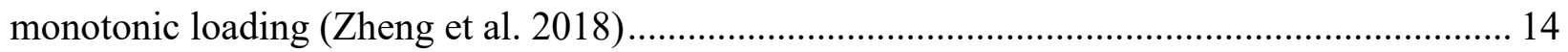

Figure 2.10: Anchorage 4A of Akashi-Kaikyo Bridge (Ouchi) …............................................ 17

Figure 2.11: Comparison of mix compositions of normal concrete, SCC and various UHPCs

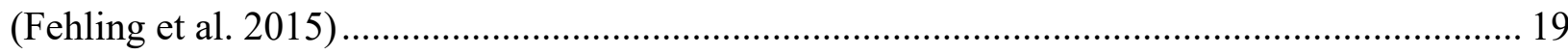

Figure 2.12: Comparison between normal concrete and reactive powder concrete (RPC) (Zdeb, 2013) 20

Figure 2.13: First UHPC bridge constructed in the United States (United States Department of

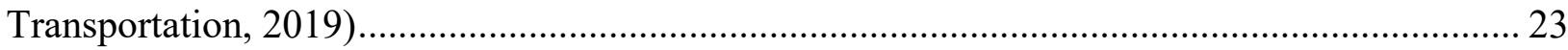

Figure 2.14: Application of UHPC in bridge girder connection (United States Department of

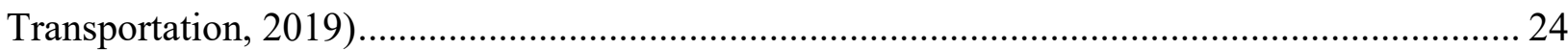

Figure 2.15: $\gamma$ constant for type 2 connections (ACI-ASCE Committee 352, 2002) ................... 28

Figure 2.16: Factors: $b j, b c, b b$ and $h c$ (ACI-ASCE Committee 352, 2002) ……………......... 28

Figure 2.17: Stress-strain distribution of reinforced ECC member (Yeganeh, 2015) ................... 29

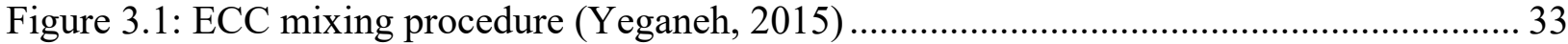

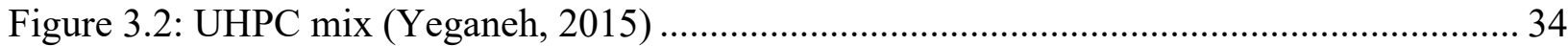

Figure 3.3: Concrete cylinder cross-section; 1: SCC, 2: ECC, \& 3: UHPC …………………....... 34

Figure 3.4: Details of ECC Jointed Flexure Critical frame (EF) ................................................. 37

Figure 3.5: Details of ECC Jointed Shear Critical frame (ES) …………………………............ 38 
Figure 3.6: Details of UHPC Jointed Flexure Critical frame (UF)............................................. 39

Figure 3.7: Details of UHPC Jointed Shear Critical frame (US) .............................................. 40

Figure 3.8: Beam and Column cross-section and reinforcement detailing .................................. 41

Figure 3.9: Foundation cross-section reinforcement detailing ………………………............ 42

Figure 3.10: Frame component illustration, Left: Flexure critical, Right: Shear critical ............. 43

Figure 3.11: Frame details and test set-up ............................................................................ 43

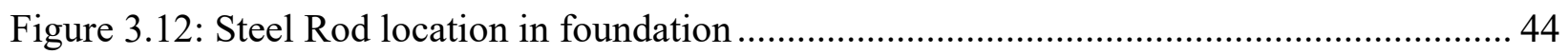

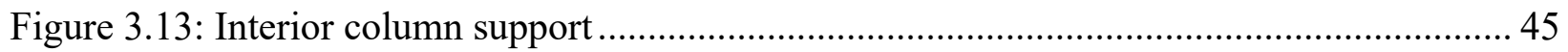

Figure 3.14: Frame test setup, Left: Actuator machine, Right: End plate fixed by steel rods...... 46

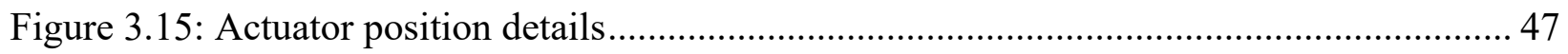

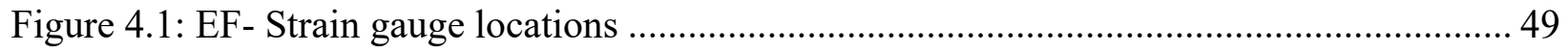

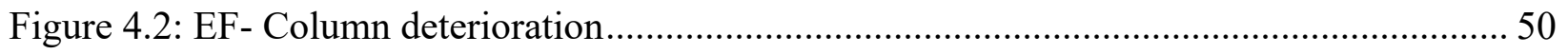

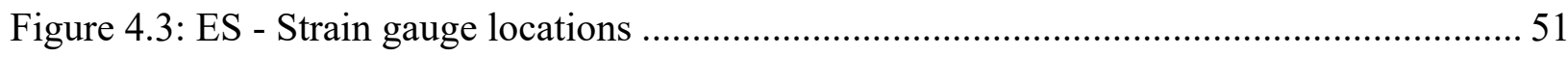

Figure 4.4: ES- a) Shear crack development in the SCC column, b) SCC column \& ECC joint

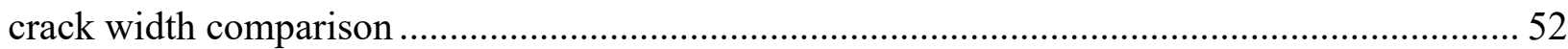

Figure 4.5: ES- shear critical deterioration comparison between SCC column \& ECC joint ...... 53

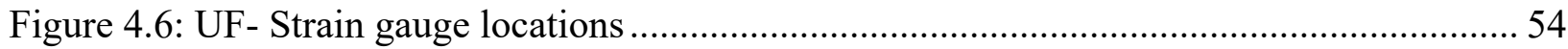

Figure 4.7: UF- Shear crack initiation in SCC columns ........................................................... 55

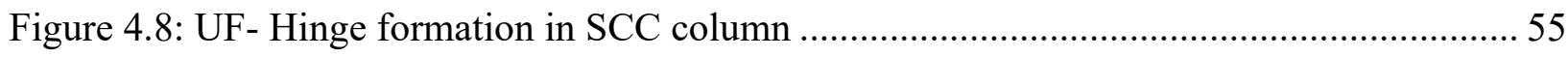

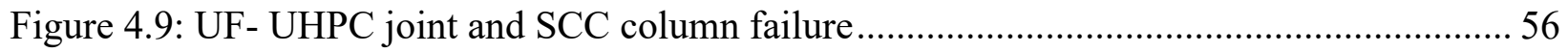

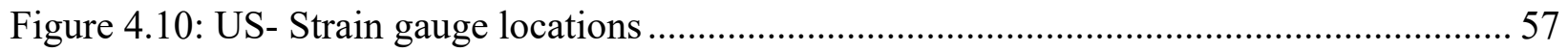

Figure 4.11: US- Shear critical UHPC joint- crack locations ...................................................... 58

Figure 4.12: US- Shear crack location in columns at failure ....................................................... 59

Figure 4.13: US- Slippage between the UHPC joint \& SCC column layers ................................ 59

Figure 4.14: US- a) Concrete crushing of interior SCC column, b) UHPC joint \& SCC column

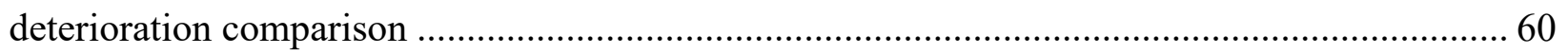

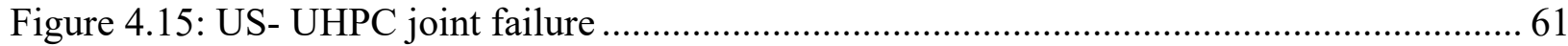

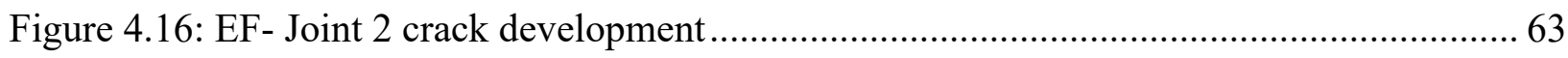

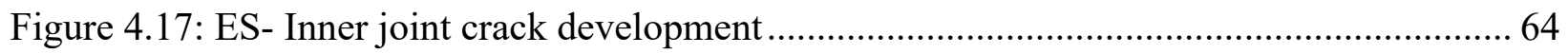

Figure 4.18: UF- a) Outer joint, b) Inner joint's crack development .......................................... 65

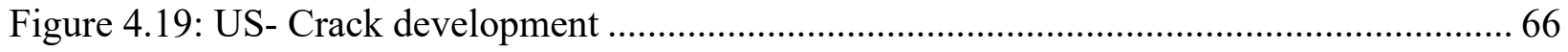




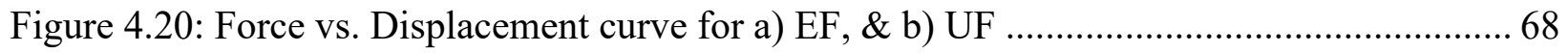

Figure 4.21: Steel and Concrete strain gauge location of a) EF, \& b) UF .............................. 69

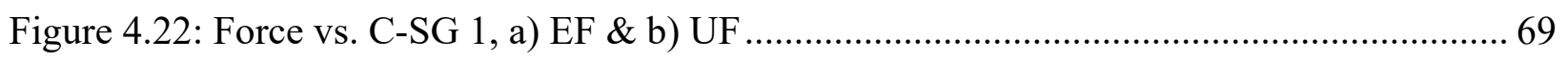

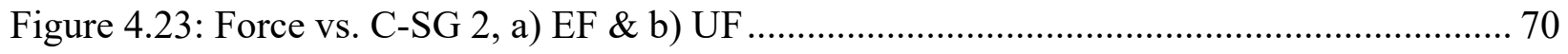

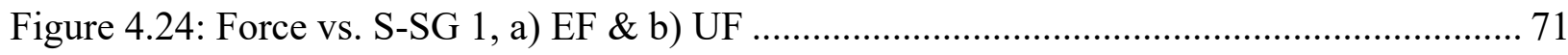

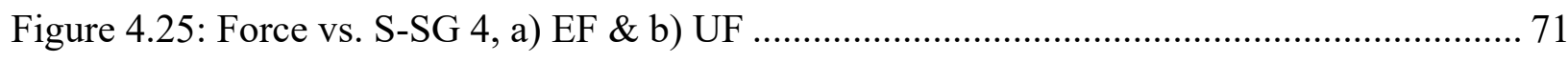

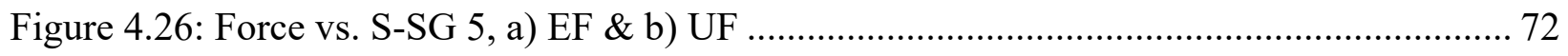

Figure 4.27: Force vs. Displacement curve for a) ES, \& b) US .............................................. 73

Figure 4.28: Steel and concrete strain gauge location of ES \& US for reference...................... 74

Figure 4.29: Force vs. C-SG 1, a) ES \& b) US ............................................................... 74

Figure 4.30: Force vs. C-SG 2, a) ES \& b) US ................................................................... 75

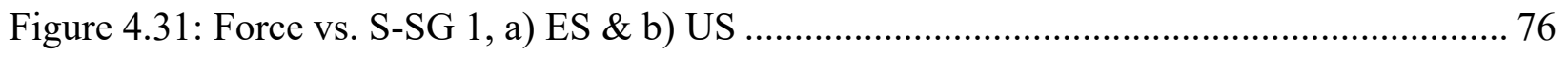

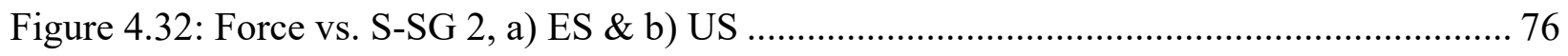

Figure 4.33: Force vs. S-SG 3, a) ES \& b) US .................................................................... 77

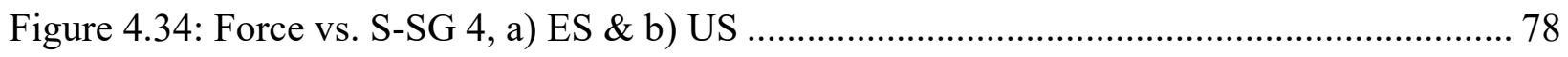

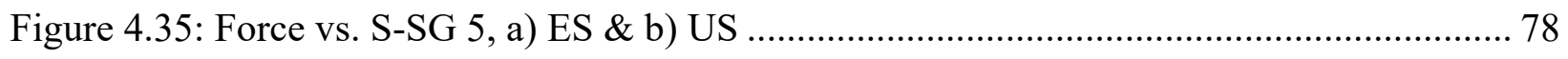

Figure 4.36: Flexure critical specimens, EF \& UF, Stiffness $(\mathrm{K})$ comparison .......................... 81

Figure 4.37: Shear critical specimens, ES \& US, Stiffness (K) comparison ........................... 81

Figure 4.38: Energy Absorption comparison for flexure critical specimens, EF \& UF ............. 83

Figure 4.39: Energy Absorption comparison for both ECC joint specimens, EF \& ES ............. 83

Figure 4.40: Energy absorption comparison of shear critical specimen's ES \& US ................. 84

Figure 4.41: Energy absorption comparison of UHPC joints, UF \& US ................................ 85

Figure 4.42: Location of calculating experimental \& theoretical flexure capacities .................. 89 


\section{List of Symbols \& Abbreviations}

$a$ : Depth of the equivalent rectangular stress block

$A_{s}:$ Area of tensile steel bars

$A_{s, \min }$ : Minimum area of tensile reinforcement

$A_{v}:$ Area of shear reinforcement

$b_{b}$ : Width of longitudinal beam

$b_{c}:$ Joint width

$b_{w}:$ Width of beam

$b_{j}$ : Effective joint width

$c$ : Distance from extreme tension fiber to centroid of reinforcement

$C_{E C C}$ : ECC concrete compressive force

$d$ : Effective depth of section

$d_{f}$ : Diameter of fibers

$d_{v}$ : Effective depth of concrete block

$E_{f}$ : Modulus of elasticity of steel fibers

$f_{c}^{\prime}$ : Compressive strength of concrete

$f_{c f}^{\prime}$ : Compressive strength of fibrous concrete

$f_{y}$ : Yield strength of reinforcement

$f_{t}$ : Tensile stress of ECC

$h$ : Overall height of beam

$h_{c}$ : Depth of column in the direction of the joint shear being considered

$l_{f}$ : Length of fibers

$M_{r}$ : Moment resistance of beam/column member

$n_{\varepsilon}:$ Strain modular ratio

$r_{f}:$ Radius of steel fibers

$s$ : Spacing between shear reinforcement

$T_{E C C-1}$ : ECC concrete tensile force

$T_{E C C-2}$ : ECC concrete tensile force 
$T_{\text {STEEL }}$ : ECC tensile force of steel

$t_{s}$ : Depth of beam section

$V_{r}$ : Member total shear resistance

$V_{c}$ : Concrete shear contribution

$V_{f}$ : Volume fraction of steel fiber

$V_{s}$ : Steel shear contribution

$V_{p}$ : Prestressed steel shear contribution

$V_{n}$ : Joint shear strength

$V_{r, \text { max }}$ : Maximum shear resistance

$\alpha_{1}$ : Concrete stress block parameter

$\beta_{1}$ : Concrete stress block parameter

$\varepsilon_{c}$ : Concrete strain

$\varepsilon_{f}$ : Fiber tensile strain

$\varepsilon_{y}$ : Reinforcement strain

$\varepsilon_{y-E C C}$ : Yield strain of ECC

$\varepsilon_{y-s t e e l}$ : ECC yield strain of steel

$\sigma_{t}$ : Ultimate tensile strength of the fiber reinforced concrete

$\varphi_{c}$ : Concrete reduction factor

$\varphi_{s}:$ Steel reduction factor

$\lambda$ : Modification factor for concrete density

$\eta_{o}$ : Orientation factor

$\eta_{b}$ : Bond efficiency factor

$\eta_{l}$ : Length of efficiency factor

$\gamma$ : Connection classification factor

$\theta$ : Cracks angle

$\tau_{f}$ : Bond strength between the fiber and matrix 


\section{Chapter 1 - Introduction}

\subsection{General}

The use of high performance concretes (HPCs) have gained wide popularity over the last decades. That is due to the high mechanical properties achieved with their application, in addition to costeffectiveness and lower life cycle cost attributed to the high durability and strength of such materials. There are many different material compositions that classify as HPCs, this report will focus on the use of self-consolidating concrete (SCC), engineered cementitious composite (ECC) and ultra-high performance concrete (UHPC). Each HPC has its own unique material composition and mechanical properties that allow for their different applications.

SCC is a new generation of highly flowable concrete that can achieve consolidation in the absence of vibration, without the occurrence of segregation or bleeding. This type of concrete resolves the issue of durability in normal concrete. Careful material composition of high-range water reducer (HRWR), coarse aggregate volume, water content, water-to-powder (w/p) ratio and viscosityenhancing admixture (VEA) allow for control of the deformability of the paste, flowability and level of cohesion (Khayat 1999, Hwang et al. 2006, Long et al. 2014, Hossain et al. 2020, Lotfy et al. 2016, Hossain and Lachemi 2010, Lachemi et al. 2004). The unique flowability and deformability of SCC with high durability properties allow for many applications. SCC is capable of reaching densely reinforced areas in formwork in many types of structures such as in tunnels, columns, foundations and more. Not requiring any vibration reduces construction time and labor cost (Paultre et al. 2005, Long et al. 2014, Khayat 1999).

ECC classifies as a high performance fiber reinforced cementitious composite, with many properties such as high durability, ductility and micro-cracking capability (Li and Li 2011, Li 2003, Yu et al. 2018, Özbay et al. 2012, Hossain 2018, Hossain et al. 2019, Hossain et al. 2018, Sherir et al. 2017). ECC is capable of reaching a strain capacity of 5\%, which is approximately 500 times higher than normal concrete, in addition to having high ductility due to exhibiting high tensile strain capacity of more than $2.5 \%$ in the long term (Li et al. 2011, Hossain 2018, Hossain et al. 2019, Hossain et al. 2018, Sherir et al. 2017, Hossain 2020). Micro-cracking capability of ECC 
mean that average crack widths range from 50 to $80 \mu \mathrm{m}$ even under high deformations, its tight crack width properties decrease the permeability of the concrete, thus reducing the ability of aggressive agents to enter. ECC material composition utilizes polyvinyl alcohol (PVA) fiber which provides the high ductility and tensile strain capacity of the concrete mix. In addition, the use of fly ash in ECC results in increasing the strain hardening characteristics of ECC and improving the tensile strain capacity. Fly ash also reduces the crack width, thus further increasing the density of the concrete matrix (Sahmaran and Li 2009). The aforementioned ECC material properties and structural behavior allow for a wide range of structural applications. Application includes ECC link slabs in joint free bridges, which replaces the need of expansion joints in bridges and their common associated deficiencies (Li et al. 2011, Hossain and Anwar 2014, Zheng et al. 2018). Oher applications include coupling slab in coupled shear wall structures, in beam-column frames, joint-free bridges and many more (Issani 2012, Issani and Hossain 2013, Hossain et al. 2015, Hossain 2014, Gencturk 2013).

UHPC is a fairly new type of concrete that falls under the high performance fiber reinforced concrete group. UHPC has many impressive material properties that vary from high compressive strength that ranges from 150 to $200 \mathrm{MPa}$, high stiffness, delay in crack formation and high dynamic tensile strength (Hossain et al. 2017, Hossain et al. 2017, Yeganeh and Hossain 2019, Zdeb 2013, Khalil et al. 2013, Schmidt et al. 2015). The use of steel fibers provides the high dynamic tensile strength and ductility characteristics. The use of ultra-fine particles such as silica fume, quartz powder, fine sands and reactive powder concrete contribute to the high density and stiffness of the concrete matrix, leading to high durability and strength of the mix (Yoo et al. 2020, Köksal et al. 2007, Slater et al. 2011). Given the mentioned properties of UHPC, there are many structural applications such as its use in foundations, frames, high rise buildings, bridge structures and more (Xu et al. 2012, Hussein et al. 2016, Hossain et al. 2012).

This research will utilize three different concretes namely SCC, ECC and UHPC in beam-column frames and analyze the structural behavior of the ECC and UHPC beam-column joints in building frames under cyclic loading. Reinforced beam-column frames made of both SCC and ECC as well as frames made of SCC and UHPC will be tested where combination of these materials will be used at critical sections (such as in the joints) in order to utilize their high-performance properties 
to improve ductility, energy absorbing capacity and strength. Previous research has been conducted over the past several years on this topic, which involved investigating the performance of beam-column frames under monotonic loading with varying material composition. Researches used different concrete materials such as ECC, SCC, UHPC and normal concrete (NC) with steel fiber, varying beam-column dimensions and reinforcement composition and finite element (FEM) modeling in addition to experimental testing (Hossain and Yeganeh 2019, Changwang and Jinqing 2010, Tawfik et al. 2014, Yeganeh 2015, Said and Razak 2016, Melnikov and Hossain 2017, Candido and Micelli 2018, Abbas et al. 2018, Kang et al. 2019). To the author's knowledge, the combination of using SCC to make up a portion of the beam and column members of the frame with utilization of ECC and UHPC at joints has not been previously researched.

\subsection{Research Significance}

The research conducted on the use of the high-performance materials namely SCC, ECC and UHPC in beam-column frame joints is warranted in raising awareness on the benefits associated with the use of such materials. Inducing common benefits such as high durability, ductility, deformability and long service life are vital for frames subjected to cyclic loading leading to an increase in their seismic resistance. It is observed that the use of ECC and UHPC joints in beamcolumn frame made of SCC has not been optimized and performance criteria has not also been defined till now. In addition, guidelines on their design and performance are not available in codes. The lack of research justifies the need for formulation of design guidelines and specifications for ECC and UHPC jointed SCC frames. The proposed research on the structural behaviour of ECC and UHPC jointed flexure and shear critical reinforced SCC frames subjected to lateral cyclic loading to formulate design guidelines is justified and warranted. The outcomes of this research will be beneficial for engineers and designers in understanding the structural behaviour, designing UHPC/ECC jointed reinforced building frame and realizing the benefits associated with the use of $\mathrm{ECC} / \mathrm{UHPC}$ as substitute for normal concrete. 


\subsection{Objectives and Scope}

The main objectives of this research are to:

- Evaluate the structural performance on four frame specimens with varying material composition and reinforcement composition. Two specimens (specimen 1 and specimen 2) are made of ECC joints with beam-column frame made of SCC. The other two specimens, (specimen 3 and specimen 4) are SCC frames with UHPC joints. Specimens 1 and 3 are flexure critical and specimens 3 and 4 are shear critical frames. The specimens were instrumented with steel/concrete strain gauges (installed at strategic locations over the frame and joint regions) to record rebar/concrete strain development during cyclic loading to failure for analysis of the performance of these flexure/shear critical frames. The performance is analyzed based on cyclic load-deformation response, crack development and propagation, stiffness, energy absorption and failure modes.

- Compare the performance of the ECC/UHPC jointed flexure and shear critical frames based on the criteria mentioned above.

- Compare results obtained from experiments and code/other existing design formulations and make recommendations on design of ECC/UHPC jointed SCC flexure and shear critical frames.

\subsection{Outline of Report}

This report consists of five chapters that discuss and analyze structural behaviour of reinforced SCC shear and flexure critical frames with ECC and UHPC joints subjected to cyclic loading. The outline of the report is as follows:

Chapter 1 presents a brief introduction on beam-column frames and a brief summary on the advances on the high-performance concrete materials used namely SCC, ECC, and UHPC. Research significance, scope and objectives are discussed in this chapter, with the outline of the report presented.

Chapter 2 presents the literature review presenting advancements in research on the high performance concrete materials and research already performed in this area. Design procedures for flexural and shear member capacities made of SCC, ECC and UHPC are presented based on code provisions and design guidelines. 
Chapter 3 presents the experimental investigation, which discusses in detail the material properties, beam-column frame composition, reinforcement details, test setup and procedure.

Chapter 4 presents the results and discussion of this research, which outlines the test observations on the failure modes of the frame specimens, cyclic/hysteretic load-deformation response, rebar/concrete strain developments, crack development and propagation, and performance comparison of flexure and shear critical frames. This chapter also discusses the stiffness degradation and energy absorption capacity of the frames, in addition to comparing theoretical and experimental member capacities.

Chapter 5 presents the conclusions drawn from this research project and future recommendations. 


\section{Chapter 2 - Literature Review}

\subsection{Introduction}

This chapter discusses the background information on the development and use of the different high performance concrete (HPC) materials such as self-consolidating concrete (SCC), engineered cementitious composite (ECC) and ultra-high-performance concrete (UHPC) in structural applications. The following section will discuss research on the advancements of each type of HPCs including their material properties and structural applications. In addition, design guidelines based on codes and other existing formulations are presented for calculating the flexural and shear capacities of the HPC frame members.

\subsection{Advancements in Research on Engineered Cementitious Composite (ECC)}

ECC is a fairly new type of concrete that solves the common issues with normal reinforced concrete structures, which is durability. ECC represents a class of high-performance fiber reinforced cementitious composites, in which ECC has high ductility properties due to its microcracking capability and high tensile strain capacity. The advancements in research on the material properties and structural applications of ECC are discussed in this section.

\subsubsection{Material Properties of ECC}

ECC can achieve a strain capacity of approximately $5 \%$, which is significantly higher than normal concrete, almost 500 times higher. A paper by Li and Li (2011) discusses the high ductility and tensile capacity properties of ECC. Their research investigated the ECC's durability characteristics in repair material applications. It was observed that the ECC mix presented with strain hardening behavior at different ages that ranged from just 3 days of casting to 28 days. The tensile strength capacity of ECC increased with age, in which it ranged from $4 \mathrm{MPa}$ to $7 \mathrm{MPa}$. It was also observed that even in the long-term, ECC still exhibited high tensile strain capacity of more than $2.5 \%$, illustrating its high durability and ductile properties ( $\mathrm{Li}$ and $\mathrm{Li}, 2011)$. The high tensile strain capacity of ECC is illustrated in figure 2.1. The figure illustrates the comparison in tensile strain capacity between NC and ECC, the high ductility properties of ECC are also presented ( $\mathrm{Li}$ and $\mathrm{Li}$, 2011). ECC's high durability properties are due to its tight crack width properties and strain 
hardening characteristics. Even at ultimate load the crack width approximately ranges between 50 to $80 \mu \mathrm{m}$.

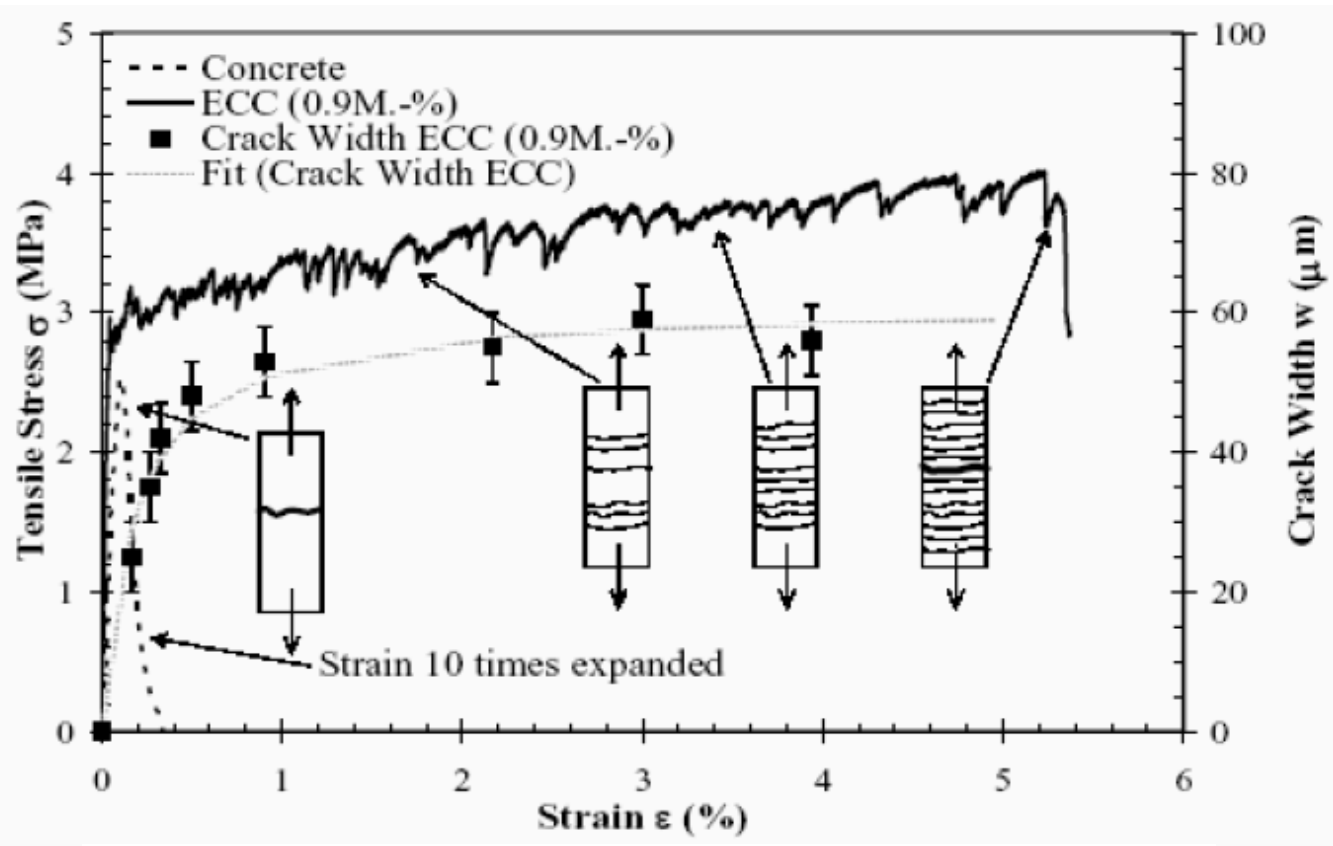

Figure 2.1: High tensile strain capacity of ECC ( $\mathrm{Li}$ and $\mathrm{Li}, 2011)$

A paper by $\mathrm{Li}$ (2003) researched the importance of micromechanics in the material design strategy of ECC. Micromechanics allows for the "systematic microstructure tailoring of ECC as well as materials optimization" ( $\mathrm{Li}, 2003)$. One of the factors investigated is the tailoring of the Polyvinyl alcohol (PVA) fiber used in ECC, which involved tailoring the interfacial bond of the fiber and its effect on the tensile strain capacity. The tailoring of the fiber occurred by providing surface coating on the surface of the PVA fiber, oil coating is often used for such applications. Figure 2.2 illustrates the comparison in the ductility and tensile strain capacity of ECC with and without fiber coating. In figure 2.2(a) it can be seen that without the presence of fiber coating, fiber rupture and high bond strength results in limiting the tensile strain capacity. However, in figure 2.2(b), a noticeable increase in the strain hardening characteristics is observed when the PVA fiber is coated. 

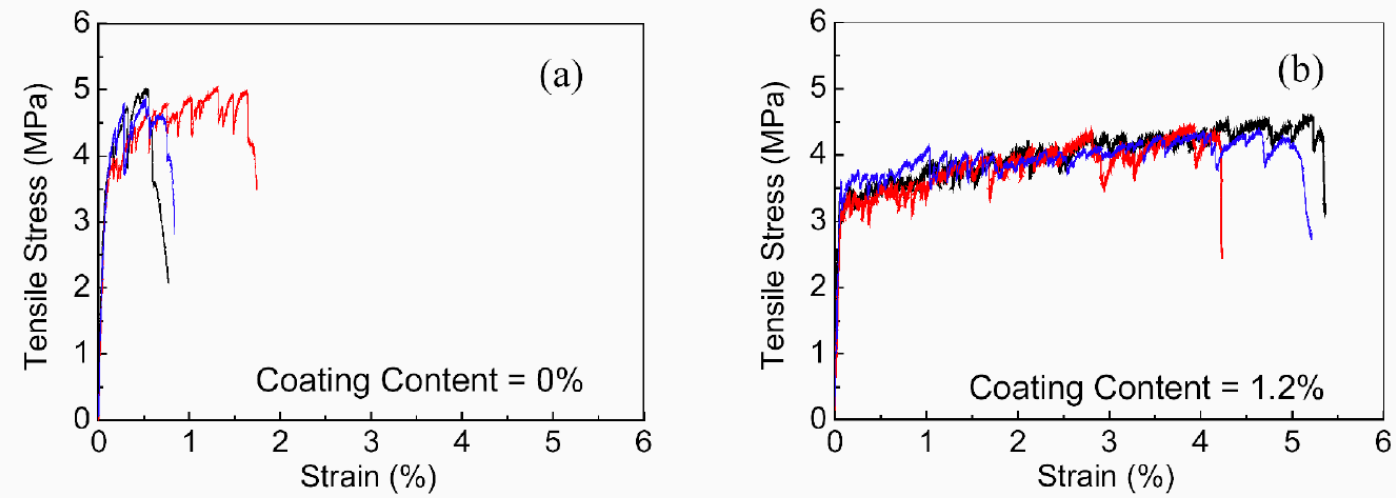

Figure 2.2: Tensile strain capacity comparison of ECC a) without fiber coating, b) with fiber coating $(\mathrm{Li}, 2003)$

$\mathrm{Yu}$ et al. (2018) researched the direct tensile properties of ECC. Their research focused on the factors affecting the tensile properties of ECC such as fiber properties, specimen geometry, strain rate, and factors affecting durability of ECC were also investigated such as the mechanical behavior of ECC in the long term and its effects under fatigue loading. The high ductility properties of ECC were observed due to the continuous hydration process of cementitious materials and the constantly changing fiber-matrix interface properties. It can be seen in figure 2.3 the ductility observed in the PVA-ECC mix over a period of 200 days. The strain capacity was observed to peak at approximately 10 days, however, a steady ductile decline in the tensile strength is observed due to the increase in chemical bond strength which is attributed to the hydrophilic properties of the PVA fiber used in the ECC mix (Yu et al. 2018). The influence of high temperatures was also

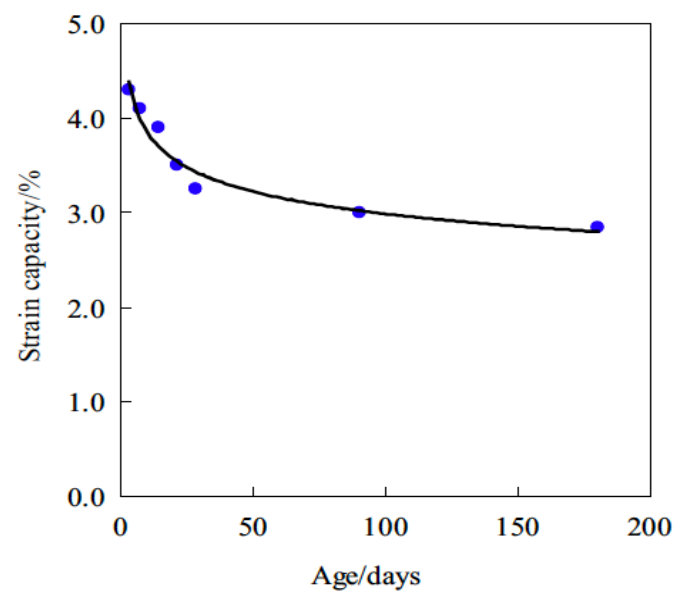

Figure 2.3: Tensile strain capacity of PVA-ECC (Yu et al. 2018) 
investigated on the tensile properties of ECC. The melting point of PVA fiber is observed to be $273^{\circ} \mathrm{C}$, which makes ECC susceptible to high temperatures. It was observed that at approximately $150^{\circ} \mathrm{C}$, the strain hardening characteristics of ECC were diminished with reduction in strength as well, with the tensile strain almost completely disappearing after $250^{\circ} \mathrm{C}$. The fatigue properties of ECC were also investigated, in which it was observed that the tensile strain capacity of ECC remained unchanged under cyclic tension-compression loading when the compressive strength of the material was not exceeded. Once the compressive strength of ECC is exceeded, the tensile capacity is reduced, however, a ductile response is observed (Yu et al. 2018). Li and Li (2011) discussed the material properties and high durability characteristics of ECC. The high durability characteristics of ECC due to the low permeability of the material was illustrated. Since ECC has tight crack width and microcracking properties, which usually result in crack widths of less than $100 \mu \mathrm{m}$, the material has a very high resistance to penetration from any damaging external agents. The microcracking properties of ECC during a uniaxial tensile test at different ages is presented in figure 2.4. The performance of the ECC specimen during the uniaxial tensile test at 4 hours, 24 hours, 3 days and 28 days are presented in the figure. It was observed that the crack width at 4 hours is $10 \mu \mathrm{m}$ with tensile strain capacity of $6 \%$ observed. The crack width increased as the age increased to approximately 30 to $60 \mu \mathrm{m}$ at 28 days. It is clear that the microcracking characteristics of ECC illustrates the high durability of the material (Li and Li, 2011).
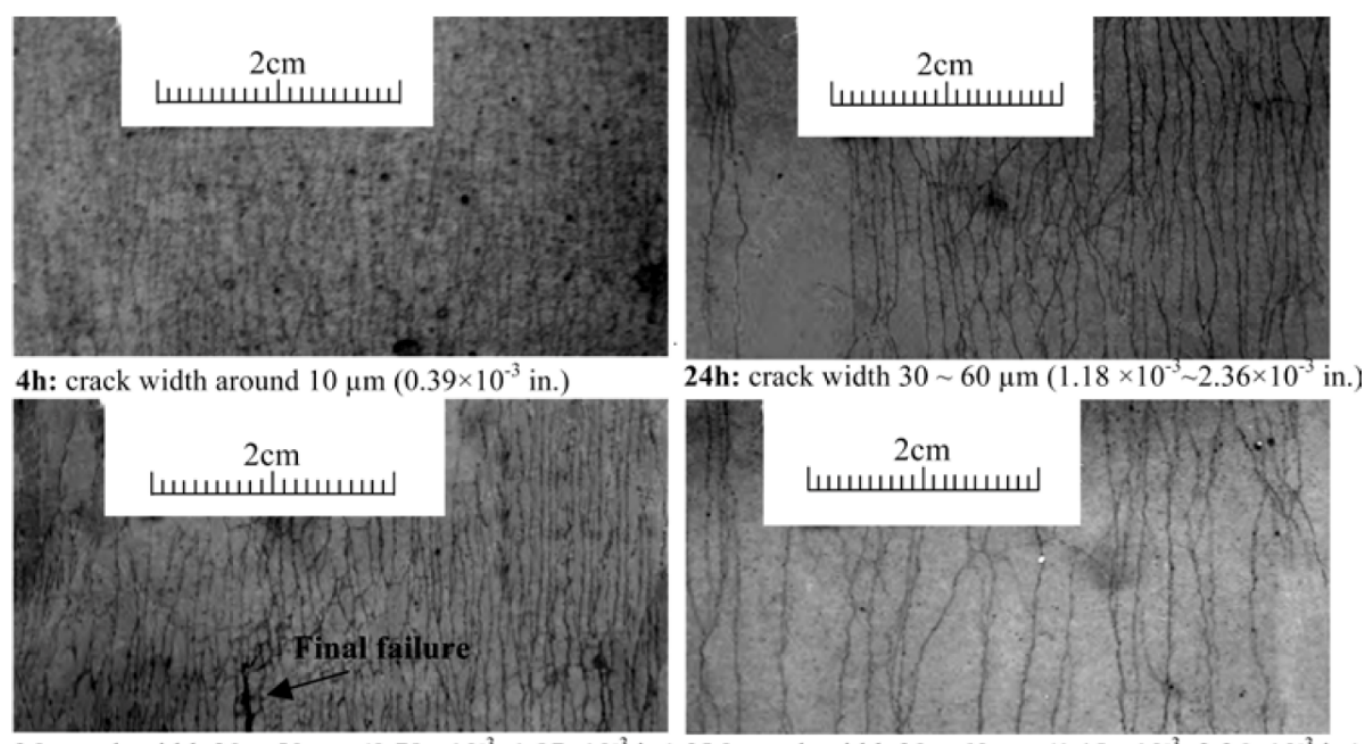

3d: crack width $20 \sim 50 \mu \mathrm{m}\left(0.79 \times 10^{-3} \sim 1.97 \times 10^{-3}\right.$ in. $) 28 d$ : crack width $30 \sim 60 \mu \mathrm{m}\left(1.18 \times 10^{-3} \sim 2.36 \times 10^{-3}\right.$ in. $)$

Figure 2.4: ECC microcracking characteristics during uniaxial tensile test (Li and Li, 2011) 
Research is also conducted on ECC containing high volumes of fly ash (Sahmaran and Li 2009, Özbay et al. 2012). Sahmaran and Li (2009) discussed the durability properties of micro-cracked ECC containing high volumes of fly ash. It was observed that ECC mixes containing fly ash resulted in improvement to the tensile properties, specifically the tensile strain capacity and strain hardening characteristics of ECC, in addition to reductions in crack width (Sahmaran and Li, 2009). For example, a chloride ponding test was conducted and compared the average crack width and diffusion coefficient between a standard ECC mix (M45) and an ECC mix with higher volume of fly ash. The number of cracks observed were reduced in addition to reduction in average crack width that ranged from 10 to $35 \mu \mathrm{m}$, when compared to the standard ECC mix that obtained an average crack width of $50 \mu \mathrm{m}$. Özbay et al. (2012) investigated the properties of ECC incorporating high volumes of fly ash and metakaolin to be able to achieve low drying shrinkage and high composite strength without compromising durability and ductility. The research involved comparing the performance of an ECC mix that incorporated a blend of metakaolin and fly ash and was compared to a standard ECC mix and a high-volume fly ash ECC mix. It can be seen from figure 2.5 that the drying shrinkage over time is reduced with the increase in volume of fly ash, when comparing ECC-1+FA/PC=1.2 and $\mathrm{ECC}-2+\mathrm{FA} / \mathrm{PC}=2.2$, however, the blend of metakaolin and fly ash resulted in a further decrease in drying shrinkage. The research concluded that the use of high-volume fly ash and blend of fly ash and metakaolin resulted in reducing drying shrinkage, porosity, chloride-ion permeability and sorptivity. In which, using the blend did not result in reducing the strain-hardening properties or high ductility of ECC (Özbay et al. 2012). It should be noted that the type of ECC mix used in this project consists of fly ash. 


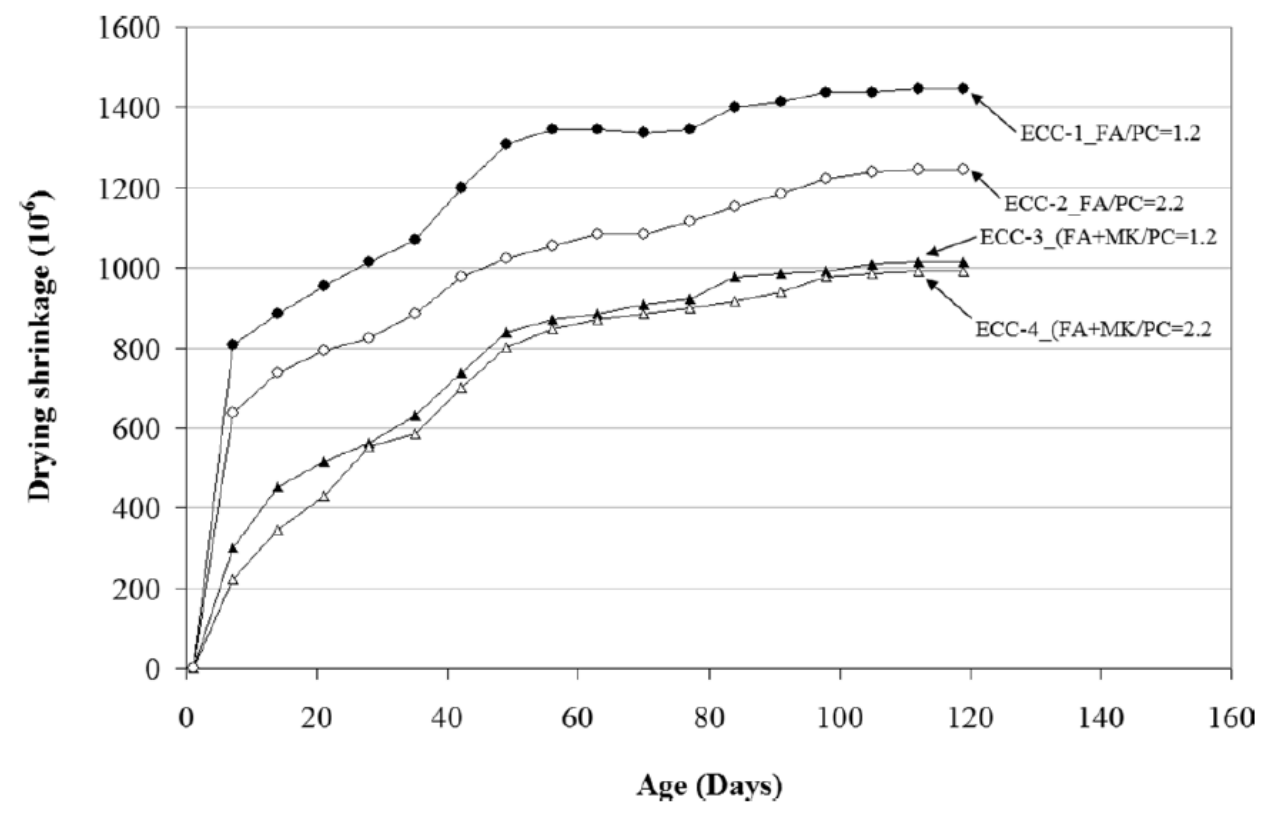

Figure 2.5: Drying shrinkage comparison between varying ECC mixtures (Özbay et al. 2012)

\subsubsection{Structural Applications of ECC}

Due to ECC's high durability and ductility characteristics, there are endless structural applications that can utilize such material. Examples of applications include ECC link slabs in joint-free bridges, shear walls in buildings with ECC coupling slab, beam-column frame elements, and can be utilized as a repair material to existing deteriorated structural elements. A bridge deck located in southern Michigan applied ECC in a patch repair job of a portion of the bridge deck. The ECC patch was placed in 2006 and over the span of 5 years, only microcracks were observed with crack widths less than $60 \mu m$ ( $\mathrm{Li}$ and $\mathrm{Li}, 2011)$. The tight crack width properties and high durability properties of ECC make it a suitable material to be used in such repair jobs. Other applications in bridges include the use of durable ECC link slab. Common issues that appear in conventional joints used in bridges is leaking expansion joints, debris accumulation, cracking and corrosion. This deterioration results in billions of dollars being spent in the repair, rehabilitation and maintenance of bridges in North America. The use of a durable ECC link slab instead of conventional joints is a promising alternative. Hossain and Anwar (2014) investigated the strength and deformation characteristics of ECC link slab in joint-free bridge decks. Figure 2.6 illustrates the concept of the 
durable ECC link slab, in which the link slab replaces the conventional expansion joint and instead extends into a portion of the deck. Eliminating the use of expansion joints in decks eliminates all

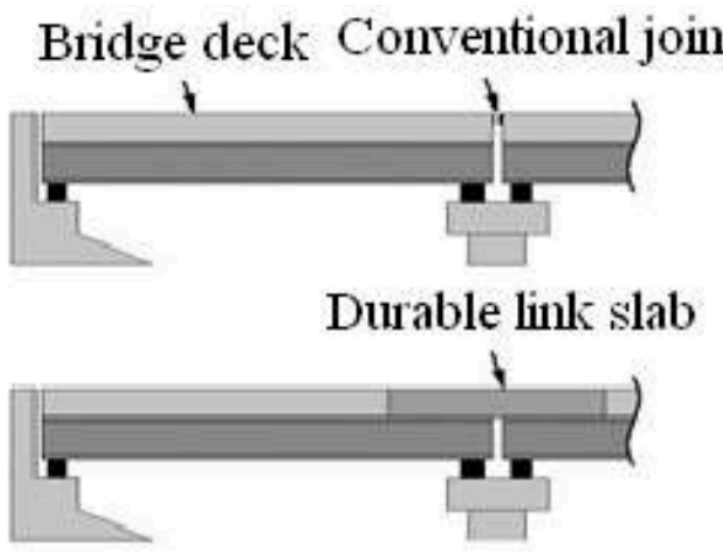

Figure 2.6: ECC link slab application in bridge decks (Hossain and Anwar, 2014)

the common deficiencies associated with it such as corrosion and leaking due to aggressive agents ability to penetrate such joints. The use of ECC with its tight crack width, high ductility and durability characteristics resolve the mentioned issues and is cost effective due to eliminating the need for constant maintenance and repair. From the research conducted it was observed that it was necessary for a portion of the link slab to extend into the adjacent deck to allow for proper load transfer from the girders to the link slab. This is done by the use of shear connectors, in which it is specified that $2.5 \%$ of the span length is to be used as the transition zone on each side of the link slab to allow for proper load transfer. The paper indicated that to achieve the desired performance from the ECC link slab, the length of the link slab is to be $7.5 \%$ of the span length as seen in figure 2.7. Testing was performed on several link slab specimens, which consisted of 4 different type of

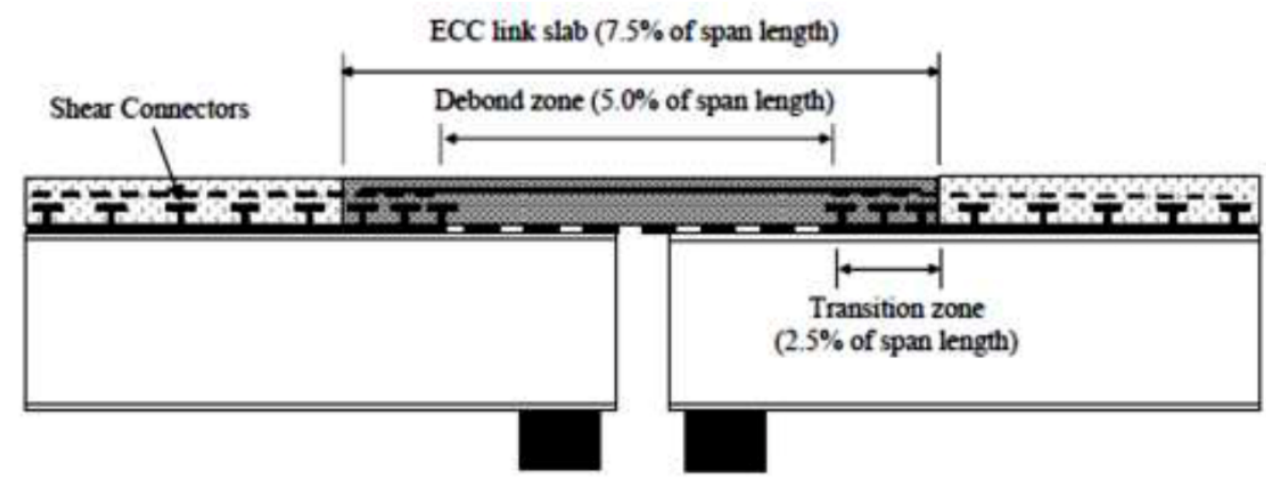

Figure 2.7: ECC link slab component definition (Hossain and Anwar, 2014) 
link slabs. The specimens were made out of ECC with varying material composition such as silica sand, crushed sand, fly ash and ground pumice and one control link slab made out of normal concrete (NC) was tested as well. The link slabs were tested under monotonic loading to mimic the fatigue loading observed in real bridge structures. Results indicated that all the different ECC types of link slabs outperformed the normal concrete link slab. The ECC specimens formed multiple microcracks when compared to one major crack that resulted in brittle failure in the NC specimen. In addition, higher ductility is observed due to the large deflection observed in the ECC sample, which reached $9.81 \mathrm{~mm}$ (LS-VP-CS-ECC sample) when compared to $1.93 \mathrm{~mm}$ in the NC specimen. Double the energy absorption is also observed of 101 joules when compared to 56 joules in its NC counterpart (Hossain and Anwar, 2014). The high strain hardening characteristics, ductility and durability characteristics prove the effectiveness of the use of this technology in link slabs as a replacement to conventional expansion joints.

Zheng et al. (2018) investigated the behavior of flexible and ductile ECC link slab reinforced with fiber reinforced polymer (FRP). The combination of the ultra-ductile ECC material and noncorrosive FRP reinforcement provide a unique combination to tackle the common deficiencies associated with expansion joints When compared to the previous paper discussed, the use of FRP reinforcement is used instead of normal steel. The link slab investigated is provided in figure 2.8, in which the proposed link slab required to maintain the "structural integrity and durability while conforming to crack width limitations and having sufficient deformation capacity" (Zheng et al. 2018). The link slab is also required to have low stiffness to allow for unrestrained deformations

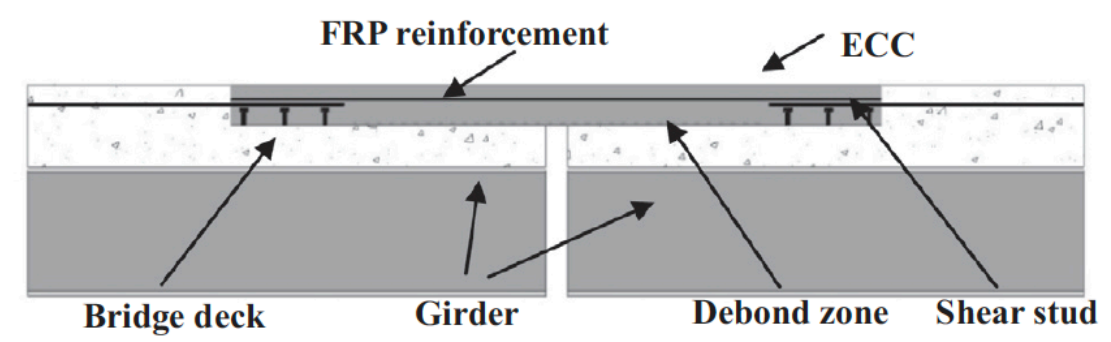

Figure 2.8: ECC link slab with FRP reinforcement (Zheng et al. 2018)

of the adjacent deck spans. Monotonic loading was tested on several specimens with varying reinforcement composition, one specimen was made of ECC without any reinforcement (LS1), ECC link slab reinforced with FRP grid (LS2) and ECC link slab reinforced with FRP bars (LS3). It was observed that the ECC link slab with FRP bars had significant ductility and its bending stiffness increased without any degradation during the testing process, in addition to observing 
good bond behaviour between ECC and the FRP bars. Figure 2.9 illustrates the load vs. deflection envelope at midspan of the ECC link slabs. It can be seen that as discussed, the ECC link slab with FRP bars portrayed high ductility and high stiffness throughout the monotonic loading cycles, which is attributed to the high flexural stiffness and high percentage of FRP reinforcement of $1.4 \%$. The other ECC link slab specimens did not portray the high stiffness and ductility properties as seen in the ECC link slab with the FRP bars. The crack width formation and development were also observed in the 3 specimens. The two specimens that involved FRP materials had lower maximum crack width and average crack width when compared with the ECC link slab without any reinforcement. It was concluded that the use of FRP reinforcing materials, especially FRP bars result in better crack-control and reduced permeability in ECC link slabs (Zheng et al. 2018).

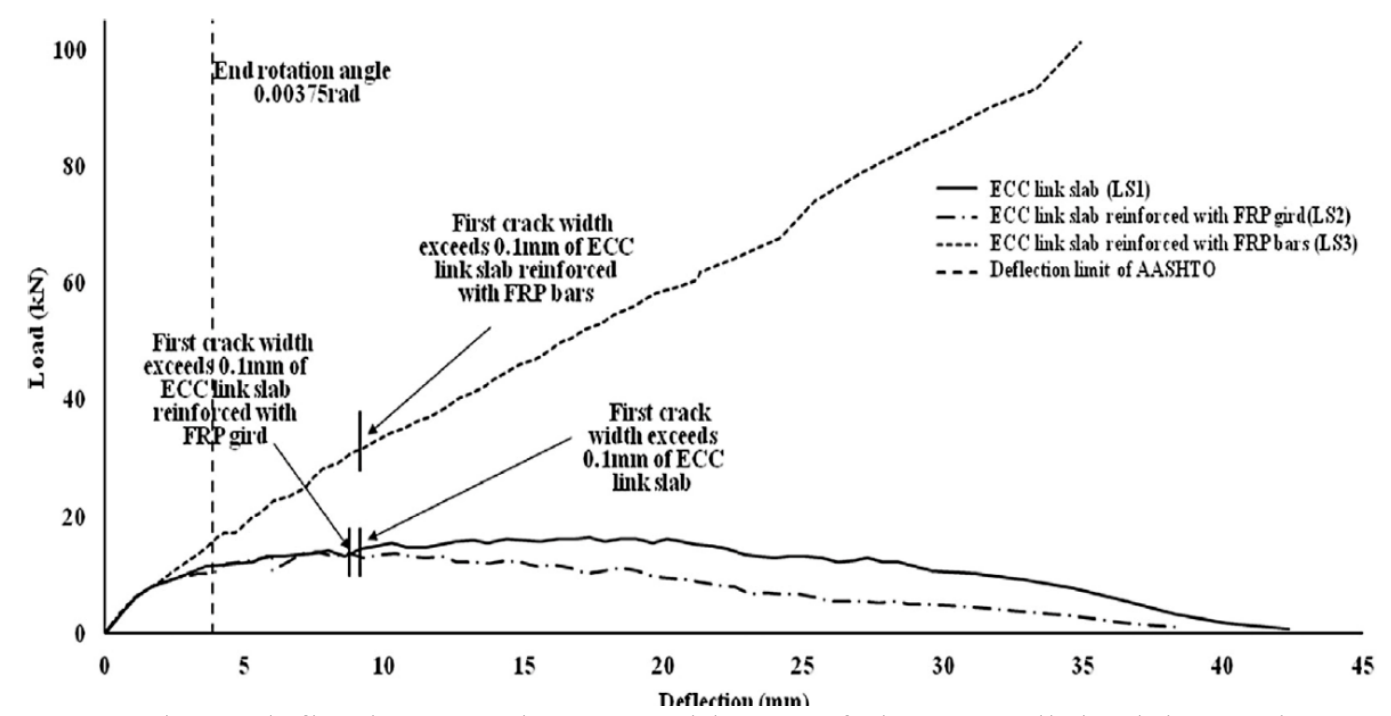

Figure 2.9: Load vs. deflection envelope at midspan of the ECC link slab specimens under monotonic loading (Zheng et al. 2018)

Other applications of ECC include its use in coupling slab in coupled shear wall structures. Issani (2012) researched the flexural behavior of ECC coupling slab in coupled shear wall structure. The use of ECC in coupled shear wall (CSW) system can significantly improve its performance in the service stage with increased ductility and durability. The use of ECC in CSW system is compared to SCC counterparts and it was observed that the ECC coupling slab portrayed higher tensile/compressive strain, had better crack formation, yielding and ultimate loading were higher more importantly higher ductility than its SCC counterpart (Issani, 2012). Lastly, research 
conducted by Gencturk (2013) investigated the life-cycle cost assessment of reinforced concrete and compared it to ECC frames using structural optimization. Since using ECC is more expensive, the life cycle cost assessment will help justify the benefits of the investment in this highperformance concrete due to its adequate performance in the long haul. The research conducted considered the use of ECC in beam-column sections of frames and compared them to normal reinforced concrete $(\mathrm{RC})$. The ECC members considered did not contain any shear reinforcement, which resulted in reducing the initial construction cost due to lower material and labor costs. In the long-term, the benefits of using ECC to its RC counterpart were observed in seismic design. That is attributed to the higher structural capacity, ductility and durability of the ECC frame (Gencturk, 2013).

\subsection{Advancements in Research on Self-Consolidating Concrete (SCC)}

Self-Consolidating Concrete (SCC) is a new generation of concrete known for being a highly flowable concrete that can flow without any segregation or bleeding and can achieve consolidation in the absence of vibration (Khayat, 1999). This type of high-performance concrete resolves the issue of durability found in normal concrete. One of its unique features is its ability to reach inaccessible areas such as dense reinforcement areas and filling of those voids. No external vibration is needed when SCC concrete is used. The material properties and structural applications of SCC will be discussed in this section.

\subsubsection{Material Properties of SCC}

To achieve the high flowability and workability properties of SCC without bleeding or segregation several factors need to be considered in the mix design. Factors include; the use of high-range water reducer (HRWR) to increase deformability of the paste, low coarse aggregate volume to reduce the inter-particle friction and reduce separation of solids, low water content to minimize bleeding and the use of a viscosity-enhancing admixture (VEA) to enhance cohesiveness and reduce aggregate segregation (Khayat, 1999). The combination of all these factors result in an SCC mix that is capable of self-consolidating and meeting durability and strength requirements. The coarse aggregate content is usually reduced by $50 \%$ when compared to normal-concrete mixes. To compensate for the reduction in coarse aggregate, the cement paste is to be increased, thus we need 
to replace the coarse aggregate content with fine aggregate. To achieve the high deformability of the paste, the use of the superplasticiser is necessary to be able to lower the water-to-powder ratio (w/p). The advantage of using superplasticizer is its capability of improving flowability without compromising the viscosity, however, a balance is needed of the w/p since if it's too high it can result in high deformability but will reduce cohesiveness of the paste, thus will result in segregation between the particles. The reduction in cohesiveness will result in segregation since the concrete "cannot maintain proper suspension of aggregate to insure uniform deformation around obstacles" (Khayat, 1999). Therefore, it is important to increase the cohesion of the mix to ensure proper bond between the mortar and coarse aggregate. Another important factor that should be considered is the use of high-quality material such as high-quality coarse aggregates, any compromise in quality will result in affecting the overall performance of the SCC mix and hindering on the capability of achieving the strength and durability requirements desired. There are several tests that can be conducted to measure the self-compatibility, deformability, flowability and its other performance-based specifications of SCC. Research done by Hwang and Khayat (2006) focused on the performance-based specifications of SCC used in structural applications. Their research consisted of $70 \mathrm{SCC}$ mixtures made with varying w/c ratio and other varying material properties and they tested the workability characteristics using varying test methods. The significance of their research was to provide reliable test methods and performance specifications for the SCC, to ensure adequate quality control. Tests conducted included slump flow test, to test the deformability and flow rate thus ensuring the filling ability is adequate and there is an unrestricted flow. Vfunnel, L-box, U-box and J-Ring tests were also conducted on SCC to measure the passing ability of the concrete. This is vital in narrow openings and heavily dense reinforced areas of formwork. Filling vessel (Caisson) was used to measure the filling capacity of the mix, and lastly, surface settlement, visual stability index and GTM screen stability tests were conducted to measure the static ability of the SCC mix, which is the mixes resistance to bleeding segregation and settlement (Hwang et al. 2006).

\subsubsection{Structural Applications of SCC}

Advantages of using SCC in structures includes; reduction in construction time and labor cost, high durability and flowability. Reduction in labor cost and construction time is due to not requiring vibration, which leads to reduced exposure to its noise. SCC allows the proper filling of 
densely reinforced areas and access to restricted areas of the member to be casted. These advantages allow for many structural applications of SCC. SCC is mainly used in structures with densely congested reinforcement such as in tunnels, columns, foundations and so on. SCC can also be used in the rehabilitation of structures, which can be used to wrap existing deteriorated columns for example. SCC will provide the necessary durability and can be casted with minimal labor if used. Due to the high flowability of this concrete, it manages to reach densely reinforced areas of structures. For example, it can be used in filling and casting of tunnel-lining sections, which commonly have restricted access to consolidation. In addition, SCC can also be used in uncongested structures, due to the lack of requirement in vibration, reduction in construction costs and noise are observed, which is important in urban areas (Khayat, 1999). Examples of the use of SCC in existing structures include the Akashi-Kaikyo Bridge located in Japan. The suspension bridge with the longest span of the world opened in 1998. SCC was used in the two anchorage sites of the bridge, a photograph of one of the anchorage sites is provided in figure 2.10. The anchorage sites required $290,000 \mathrm{~m}^{3}$ of SCC to be pumped. A new system was developed for this project which involved mixing the concrete at a batch plant nearby and pumping it using a network of 200-meter-long pipes to the site. The use of SCC for this project managed to shorten the anchorage construction period by $20 \%$, approximately from 2.5 years to 2 years (Ouchi).

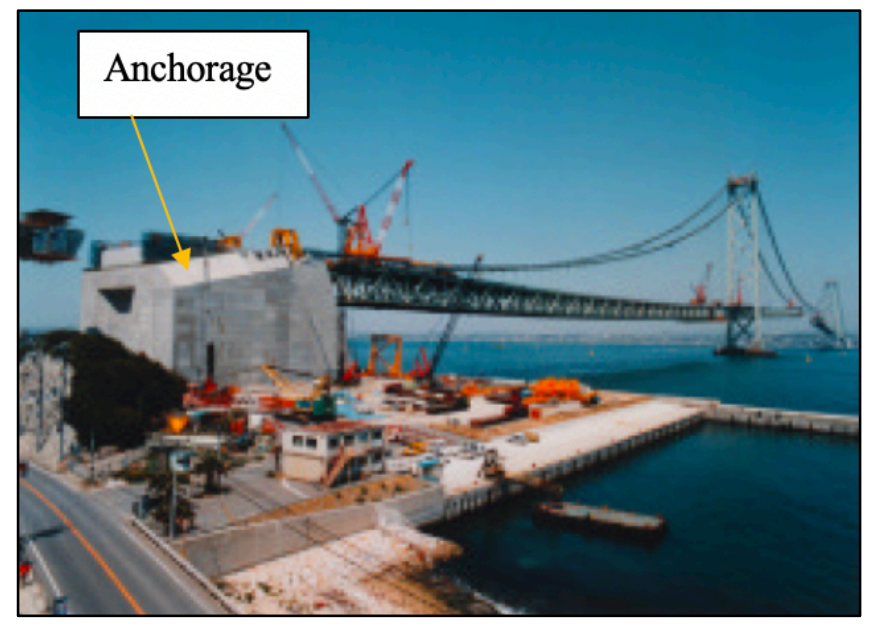

Figure 2.10: Anchorage 4A of Akashi-Kaikyo Bridge (Ouchi)

Other applications of SCC include prestressed structural members such as in prestressed beams, as well as in precast architectural panels. Research was conducted on the workability characteristics of prestressed and precast SCC members by Long et al. (2014). The research 
consisted of measuring the workability characteristics of SCC in such prestressed and precast members, a total of 33 SCC mixtures were conducted with varying material composition such as aggregate maximum size, type of aggregate, type of binder, water-to-cement (w/c) ratio and more. It was concluded that in densely reinforced prestressed and precast beams, that SCC should have a slump flow that ranges between $635-760 \mathrm{~mm}$, with other specifications outlined such as the range of plastic viscosity of 100-225 Pa's. From the research conducted, these ranges defined lead to achieving desired workability and deformability of SCC in such members without compromising the durability and strength requirements (Long et al. 2014). Another paper by Paultre et al. (2005) compared the structural performance of SCC in highly confined columns and compared them to the use of normal concrete (NC) in such members. The research conducted involved testing a total of 16 columns, with 11 columns made out of either SCC and ECC, and 5 columns were cast without reinforcement. The columns without reinforcement were tested for uniaxial compression and some were cored to allow for understanding on the distribution of the in site compressive strength along the column height (Paultre et al. 2005). It was observed that SCC portrayed higher ductility than it's NC counterpart, however a slightly lower compressive strength was achieved. For the cored unreinforced column members, it was observed that SCC had a more homogenous distribution of the in-situ properties throughout the column height when compared to $\mathrm{NC}$, which illustrates the higher durability and deformability properties.

\subsection{Advancements in Research on Ultra-High-Performance Concrete (UHPC)}

Ultra-high-performance concrete (UHPC) is a new type of concrete that falls under the highperformance fiber reinforced concrete group. UHPC is known for its high compressive strength and stiffness. Advancements in research on UHPC, including material properties and structural applications are discussed in this section. 


\subsubsection{Material Properties of UHPC}

The UHPC mix mainly consists of fine grains, which have a maximum particle size of approximately $1 \mathrm{~mm}$. The use of fine particles makes the internal microstructure significantly homogenous when compared to normal concretes (Fehling et al. 2015). The high stiffness and homogeneity help UHPC reach compressive strengths of about 150 to $200 \mathrm{MPa}$. However, without the use of fiber in UHPC, the mix exhibits a brittle failure and result in an explosive failure with no warning due to its limited post-cracking behavior. Therefore, the use of steel fibers is necessary in UHPC to ensure proper tensile strength and improve cracking deformation characteristics (Khalil and Tayfur, 2013). The high strength and stiffness of the concrete is attributed to its low water-to-binder $(\mathrm{w} / \mathrm{b})$ ratio of approximately 0.20 . The very dense microstructure of the mix is achieved by the use of ultrafine particles such as cement, quartz, silica fume and other reactive fillers that have grain size of $<125 \mu \mathrm{m}$, which allows them to be packed in a specific way that makes them packed densely together (Fehling et al. 2015). Figure 2.11 illustrates a comparison of different concrete mix compositions by volume between NC, SCC, and various types of UHPC. If

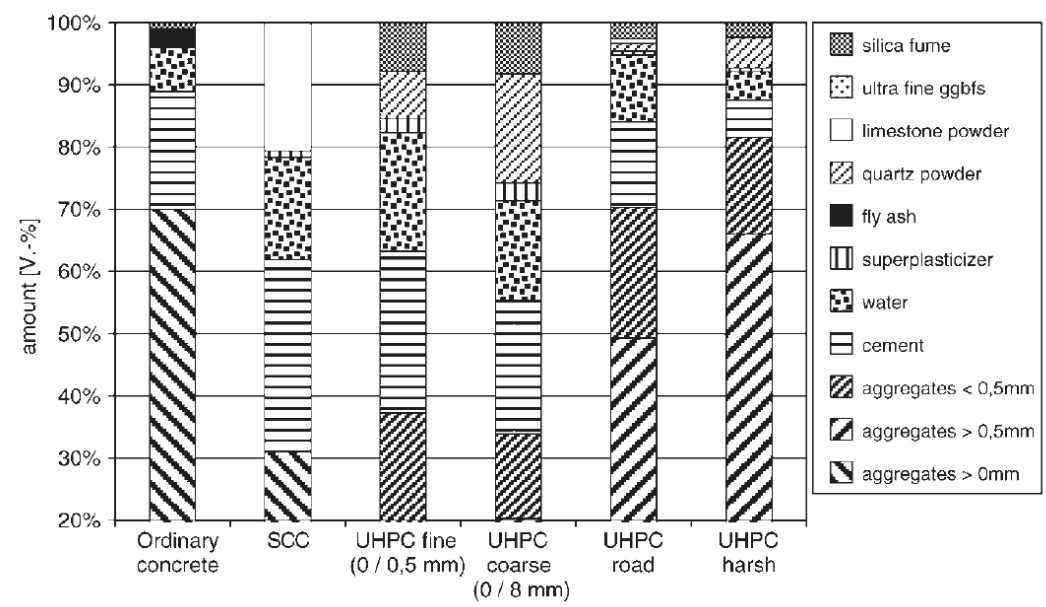

Figure 2.11: Comparison of mix compositions of normal concrete, SCC and various UHPCs (Fehling et al. 2015)

we compare the UHPC fine mix with SCC, you can see that UHPC mainly consists of ultrafine particles such as silica fume and quartz powder when compared to large size aggregates and more cement in SCC. The use of high-quality aggregates is also important to be able to achieve the desired durability and strength properties. In UHPC the use of ground quartz as a high-quality aggregate is used as an alternative that helps achieve the very high strength and durability properties of HPCs. UHPC also consists of an advanced cementitious composite called reactive 
powder concrete (RPC). The compressive strength of UHPC varies and it depends on the composition of material properties and on the curing conditions (Zdeb, 2013). For example, steam cured, or heat cured specimens yield better results than untreated specimens. The very dense structure of UHPC is also illustrated in figure 2.12, which shows a comparison between a normal concrete microstructure and an RPC structure, UHPC. RPC uses quartz aggregate instead of a coarse aggregate in normal concrete (NC), and uses fine sands as a filler to reduce porosity in the structure of the concrete and to increase the homogeneity of the material (Zdeb, 2013). In addition, the reduced w/b ratio is achieved by using a superplasticizer. The main properties of UHPC is high compressive strength, higher strain at ultimate stress, delay in crack formation, and high dynamic tensile strength due to the presence of steel fibers (Yeganeh and Hossain, 2019).

Research conducted by Khalil and Tayfur (2013) investigated the flexural strength of fibrous UHPC beams. Their research consisted on testing several UHPC beams with varying type of steel fibers such as hooked and crimped, in addition to varying volume fractions of steel fibers, $0.5 \%$ and $0.75 \%$. It was observed that the ultimate moment capacity for the beam members are significantly improved with the use of steel fiber in the mix, a 27\% increase was observed from the control specimen (without steel fibers), it was also observed that full-depth fiber dispersion

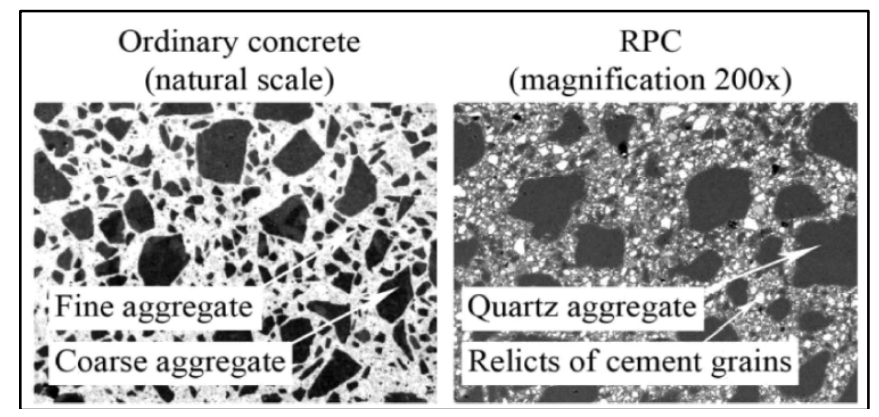

Figure 2.12: Comparison between normal concrete and reactive powder concrete (RPC) (Zdeb, 2013)

resulted in an increase in ultimate moment capacity when compared to half-depth fiber dispersion. In addition, it was observed that beam members with hooked steel fibers provided higher flexural strength than members with crimped (Khalil and Tayfur, 2013). Another research paper by Yoo et al. (2020) observed the enhanced tensile performance of UHPC through the use of half-hooked steel fibers. The research conducted involved the use of 4 different steel fibers, smooth-straight, hooked-end, half-hooked and straightened half-hooked. Pullout tests were conducted to evaluate the tensile performance and bond performance of UHPC, it was observed that the hooked-end fiber 
performed the best out of the 4 types of steel fibers, in which the tensile strength observed was 3.7 times higher in the hooked-end fiber than in the smooth-straight fiber. In which the bond strength is observed to be 4.7 times higher than in the smooth-straight fiber. Furthermore, it was also observed that hybrids of two types of steel fibers such as a hybrid of hooked-end and smoothstraight fibers resulted in increasing the tensile performance of the UHPC mix (Yoo et al. 2020).

An experimental study by Köksal et al. (2007) researched the effect of silica fume and steel fiber on the mechanical properties of high strength concretes. It was observed that the combination of silica fume and steel fiber in the UHPC mix resulted in an increase in compressive strength and in splitting and flexural strengths of the concretes. The use of the steel fibers counteracts the brittleness associated with the use of silica fume, which results in a more ductile behavior and higher energy absorption capacity of the concrete. It was also observed that the addition of silica fume reduced the workability of the concrete mix, however, the addition of the superplasticizer provided the desired workability/flowability of the mix. One major benefit to the use of silica fume is its capability of improving the cement paste-aggregate interface, due to its filling effect. This area is known to be the weakest zone in the concrete matrix, thus it results in increasing the mechanical properties (Köksal et al. 2007). The composition of the steel fibers used need to be carefully considered to be able to achieve the performance required in UHPC. For example, different fiber type (shape), aspect ratio (length/diameter), volume fraction, orientation of fibers and tensile strength of fibers are all important parameters that need to be carefully chosen to achieve the desired properties (Köksal et al. 2007). When it comes to beam-column frames, high ductility is of great importance to be able to have high seismic resistance and high lateral load capacity. It should be noted that a common disadvantage of UHPC is its poor fire resistance. Due to the very low permeability of the UHPC paste, it is observed that at high temperatures a risk of explosion is evident due to buildup in pore pressure, in which the moisture is not able to escape, thus leading to explosion in UHPC members.

Nonetheless, given that there are currently no code provisions on the shear strength of UHPC members, research conducted by Slater et al. (2011) obtained viable shear strength models on the prediction of shear strength of steel fiber reinforced concrete beams. Their research indicated the need for such modeling and equations that would predict the response of such high-performance 
concrete members. The research conducted provided viable equations and models using both linear and non-linear regression analysis. The equations developed managed to predict the shear strength of steel fiber UHPC adequately with considering varying parameters such as the span to depth ratio, concrete compressive strength and fiber shape (Slater et al. 2011). The need for such accurate modeling is also illustrated later in this report.

\subsubsection{Structural Applications of UHPC}

Given the high mechanical properties discussed of UHPC there are many structural applications that can utilize this high-performance concretes advanced properties. Applications vary from UHPC's use in foundations, frames, high rise buildings, bridge structures and more. Xu et al. (2012) discussed the application of high-performance concretes such as UHPC in ultra-high-rise buildings. The paper discussed that such high-performance concretes have a large pumping resistance, making it difficult to pump at required heights in high rises. The high pumping resistance is due to the high viscosity of UHPC. Therefore, research was conducted on altering the UHPC properties, so it is capable of reaching incredible heights in projects without compromising any of its mechanical properties. For example, this was performed in the West Tower Project in Guangzhou, a known landmark in Pearl River New Town. This tower consists of a height of 440.7 $\mathrm{m}$, making the pumping of the UHPC to the 103 floors a challenge. The UHPC properties were altered and was used in core structural components of the 103-floor tower (Xu et al. 2012).

UHPC has many applications in bridge structures, in fact the first bridge built made out of UHPC in the United States is located in Iowa. Figure 2.13 illustrates the UHPC bridge, which consists of three UHPC prestressed I-girders spanning over a creek. The combination of prestressing which manages to achieve long span-to-depth ratio and the high stiffness and tensile properties of UHPC make it a suitable material to be used in such structures. 


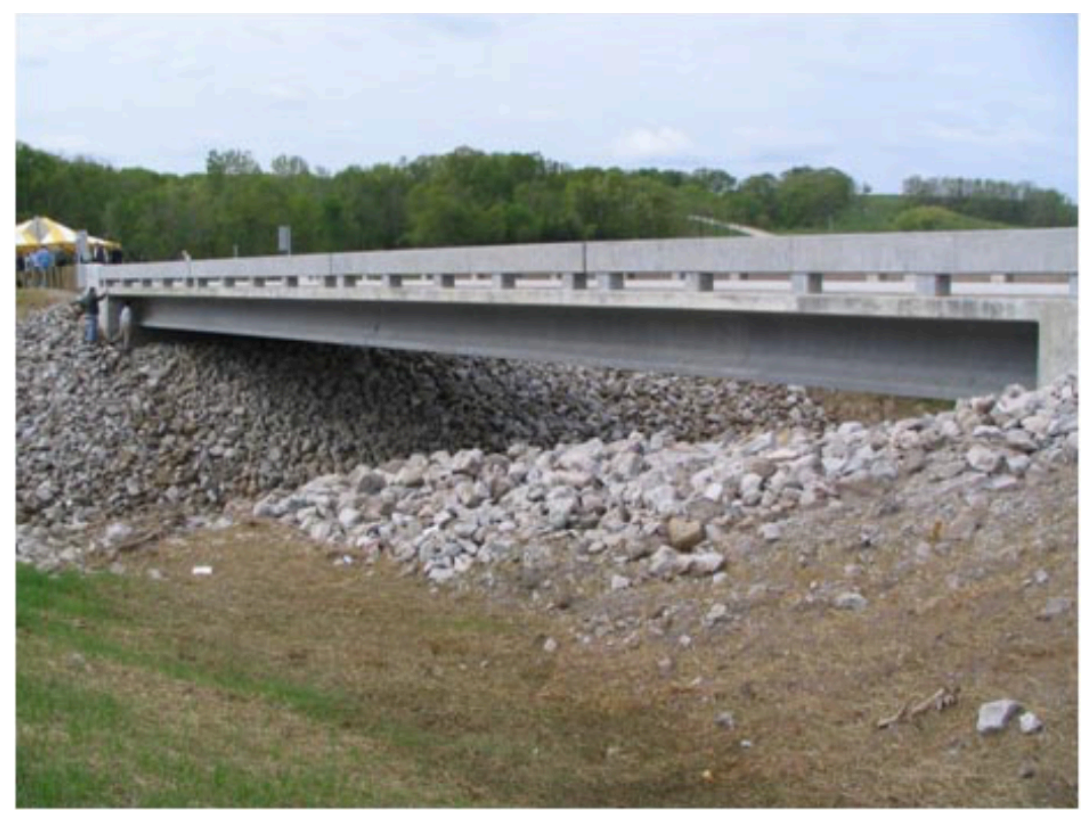

Figure 2.13: First UHPC bridge constructed in the United States (United States Department of Transportation, 2019)

A paper by Hussein et al. (2016) researched the performance of UHPC in concrete bridge connections. The performance of bridge connections significantly depends on the strength of the material used and mainly on the adhesion and friction between the connected materials. These requirements make UHPC a clear candidate to its application in bridge connections. It was observed that the high strength and durability properties of UHPC resulted in reduced joint cracking and improved transverse load transfer (Hussein et al. 2016). In addition, the use of steel fiber provided adequate ductility, resulting in a high fatigue resistance of the connection. Another example is the use of UHPC in longitudinal connections between deck-bulb-tee girders, which was observed in a bridge located in Lyons, NY. The UHPC is casted in the longitudinal connection to enhance the tensile strength transfer between the girders and its high stiffness and strength properties are vital in such application as seen in figure 2.14. It can be seen that the reinforcement in the longitudinal section is very dense, in which the UHPC mix used was altered to have selfconsolidating properties to be able to flow smoothly in the narrow space observed in the connection. Hybrids of UHPC and SCC prove to be beneficial since the benefits of both type of high-performance concretes are utilized. 


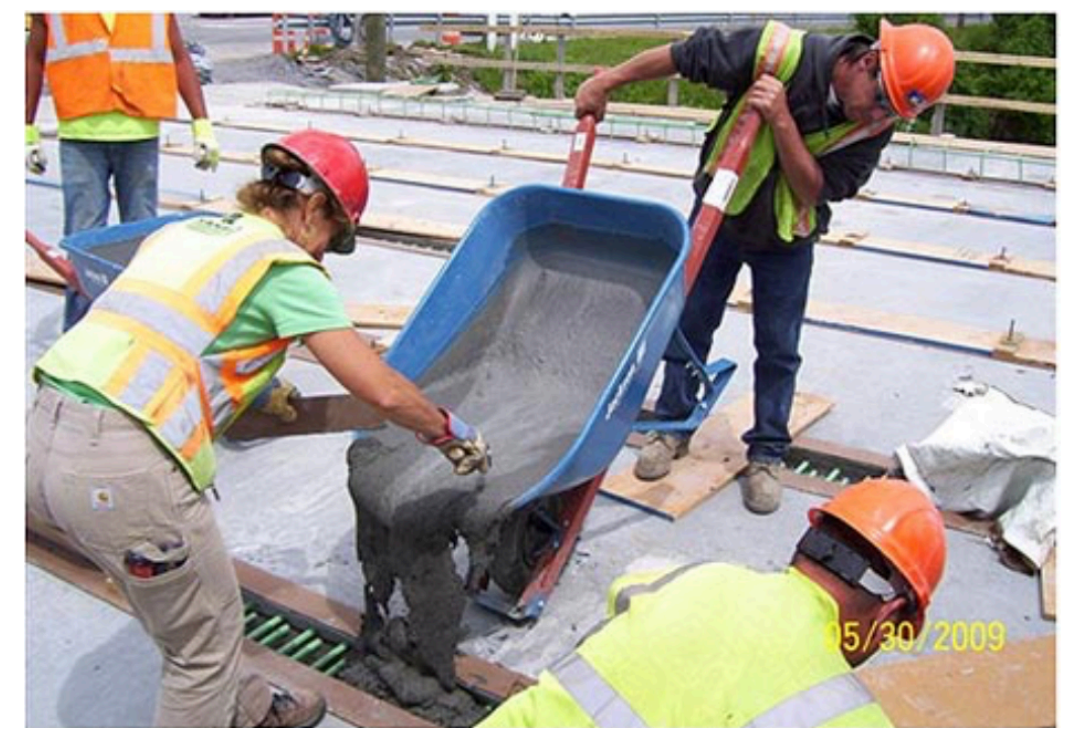

Figure 2.14: Application of UHPC in bridge girder connection (United States Department of Transportation, 2019)

\subsection{Research on Completed High Performance Beam-Column Frames}

Researches on the structural behavior of high performance beam-column frames under monotonic/cyclic loading have been performed over the past several years. The need for more ductile and durable reinforced concrete frames is clear. Changwang and Jinqing (2010) investigated the seismic performance of steel reinforced ultra-high-strength concrete composite frame joints. Their research involved testing interior beam-column frame specimens that consisted of ultra-high-strength concrete columns and steel reinforced concrete beams under low cyclically lateral loading (Changwang and Jinqing, 2010). Research by Tawfik et al. (2014) investigated the behavior and ductility of high strength reinforced concrete frames. Their research focused on the comparison of the performance of different frame compositions under lateral loading, which involved changing beam and column dimensions, changing the aspect ratio (height to length of panel) and changing beam-column connection reinforcement (spacing of shear reinforcement) (Tawfik et al. 2014). Research conducted by Yeganeh (2015) involved investigating the structural behavior of reinforced high-performance concrete frames subjected to monotonic lateral loading. Current research is a continuation of ongoing research conducted by research group at Ryerson University (Yeganeh, 2015; Yeganeh and Hossain 2019). Yeganeh (2015) tested three different exterior beam-column joints made of SCC, ECC and UHPC. Each frame was tested under 
monotonic loading and their structural behaviors were analyzed and compared (Yeganeh, 2015). Research conducted after that by Said and Razak (2016) involved investigating the structural behavior of RC ECC exterior beam-column joints under reversed cyclic loading. Their research involved comparing a NC specimen and ECC joint specimen under reversed cyclic loading and their structural behavior such as load-deflection relationship, crack propagation, energy absorption capacity and other factors were investigated (Said and Razak, 2016). Research done by Melnikov and Hossain (2017) involved investigating the numerical modeling of reinforced ECC building frames. Numerical modeling using ABAQUS Implicit was performed on SCC and ECC frames using research data from Ali Yeganeh's thesis. The finite element modeling (FEM) was subjected to monotonic loading and allowed for better understanding of the behavior of the high-performance concrete frames (Melnikov and Hossain, 2017). Research conducted by Candido and Micelli (2018) involved investigating the seismic behavior of regular reinforced concrete plane frames with fiber reinforced concrete in joints. Which involved researching the benefits of using fiber reinforced concrete in the joint portion of frames through numerical modeling (Candido and Micelli, 2018). Abbas et al. (2018) investigated the behavior of reinforced concrete frames with different beam-column joint types. Their research involved testing four different types of beamcolumn joints which involved the use of normal concrete mix with varying amounts of steel fiber $(0 \%, 0.5 \%$ and $1 \%)$. The addition of steel fiber to the normal concrete mix is to improve ductility and energy dissipation capacity of the beam-column joints (Abbas et al. 2018). Lastly, the most recent research to the author's knowledge conducted on this research area was performed by Kang et al. (2019). The research involved investigating the seismic behavior of exterior beam-column connections with high-strength materials and steel fibers. 3 beam-column frame specimens were tested, two are roof-exterior joints and one exterior joint with a continuous column. The frames were tested under quasi-static reversed cyclic loading and the material used consisted of reinforced concrete, and high performance fiber reinforced concrete (Kang et al. 2019). The research previously conducted did not contain the combination of the use of different material composition consisting of SCC being a primary material in a portion of the beam/column and ECC and UHPC making up the joint portion of the frame. The use of this combination is more economical due to the use of the high-performance concretes (ECC and UHPC) in the joint portion of the frame, utilizing their strength and durability characteristics. The structural behavior of the reinforced high performance concrete frames under monotonic loading will be investigated in this report. 


\subsection{Design of High-Performance Concrete Beam-Column Members}

This section will outline the procedure for the theoretical member capacity calculations, the calculations of the capacities are provided in appendix A, section A.1 and A.2. The equations and procedure used to calculate the shear strength of the SCC and ECC beam, column and joint strength are shown (Appendix A, section A.1). In addition, to the flexural capacity of the ECC, UHPC, and SCC beam/column capacities (Appendix A, section A.2). The theoretical capacities are calculated based on different code provisions and design formulations.

\subsubsection{Shear strength of SCC beam/column}

To calculate the shear resistance $\left(V_{r}\right)$ of the beam/column section, equation 2.1 is to be used as according to clause 11.3.3 of CSA A23.3-14 (CSA, 2014) and (CSA, 2016). In which, the shear resistance $\left(V_{r}\right)$, is calculated by adding the contribution of the concrete shear resistance $\left(V_{c}\right)$, steel shear resistance $\left(V_{S}\right)$ and prestressing steel shear resistance $\left(V_{p}\right)$ as per equation 2.1:

$$
V_{r}=V_{c}+V_{s}+V_{p}
$$

the concrete shear contribution is calculated based on equation 2.2 (CSA, 2014):

$$
V_{c}=\varphi_{c} \lambda \beta \sqrt{f_{c}^{\prime}} b_{w} d_{v}
$$

In which, the factored concrete strength, $\varphi_{c}$, is taken as 0.65 as according to clause 8.4.2. The modification factor for concrete density, $\lambda=1.00$ for normal density concrete, $\beta$ factor taken as 0.21 as noted in clause 11.3.6.2, the concrete compressive strength, $f_{c}^{\prime}$, of the SCC, ECC, and UHPC material. $b_{w}$ is the width of the section, effective shear depth, $d_{v}$, which is taken as the greater of $0.9 d$, and $0.72 h . d$ is the effective depth, measured from the top of the cross-section to the center of the tensile reinforcement, and $h$ is the depth of the beam/column cross-section.

The steel shear contribution can be calculated using equation 2.3 (CSA, 2014). In which the steel resistance factor of $\varphi_{s}$, is taken as 0.85 (8.4.3), the area of shear reinforcement, $A_{v}$, the shear reinforcement yield stress, $f_{y}$, the $\theta$ factor taken as $42^{\circ}$ (11.3.6.2), and the shear reinforcement spacing, $s$. 


$$
V_{s}=\left(\varphi_{s} A_{v} f_{y} d_{v} \cot (\theta)\right) / s
$$

According to clause 11.3.3, the shear resistance is to be less than the maximum shear resistance $\left(V_{r} \leq V_{r, \max }\right)$, in which $V_{r, \max }$ is calculated using equation 2.4 (CSA, 2014).

$$
V_{r, \max }=0.25 \varphi_{c} f_{c}^{\prime} b_{w} d_{v}
$$

\subsubsection{Shear strength of ECC and UHPC joints}

For joint strength calculations of the ECC and UHPC material, ACI 352R-02 is used, which outlines "recommendations for design of beam-column connections in monolithic reinforced concrete structures" (ACI-ASCE Committee 352, 2002). It is outlined that the nominal shear strength of the joint can be calculated by equation 2.5 :

$$
V_{n}=0.083 \gamma \sqrt{f_{c}^{\prime}} b_{j} h_{c}(\mathrm{MPa})
$$

where $f_{c}^{\prime}=$ Joint concrete compressive strength (UHPC/ECC), $b_{j}=$ the effective joint width, $h_{c}=$ depth of the column in the direction of the joint shear being considered and $\gamma$ is a constant which depends on the connection classification (ACI-ASCE Committee 352, 2002). $b_{j}$ can be calculated by equation 2.6 , which the effective joint width, $b_{j}$, cannot exceed the smallest of the three factors:

$$
b_{j} \ll\left\langle\frac{b_{b}+b_{c}}{2},\right| b_{b}+\sum \frac{m h_{c}}{2} \text {, and }\left|b_{c}\right\rangle
$$

where $m=0.5, b_{b}=$ width of longitudinal beam, and $b_{c}=$ joint width. The factors, $b_{j}, b_{c}, b_{b}$ and $h_{c}$ are illustrated in figure 2.15. The $\gamma$ constant depends on the beam-column connection classification. Given that the frame composition tested in this paper is an external joint with one beam connected to the column through the joint as seen in figure 2.16 , according to the code, this case of connection classifies as type 2 connection, classification A.3, which classifies that the $\gamma$ constant equals to $12(\gamma=12)$ for the type of beam-column joint connection used in this project. 


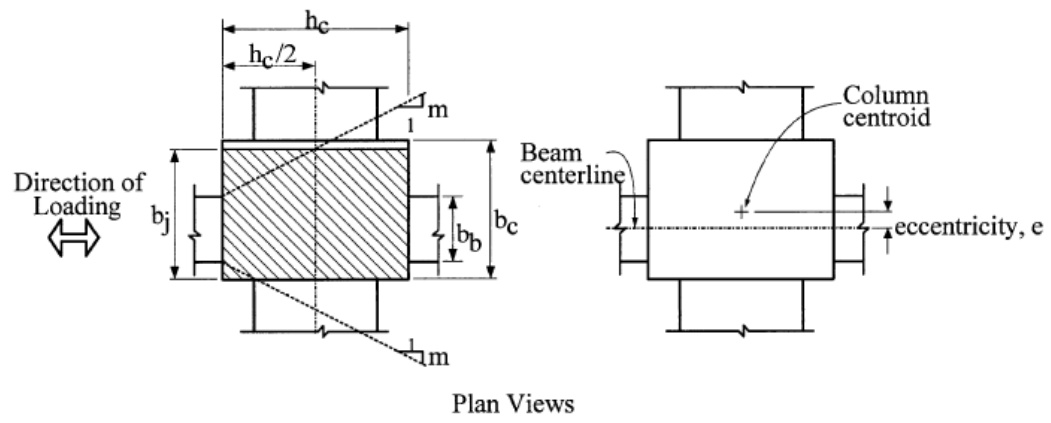

Figure 2.15: $\gamma$ constant for type 2 connections (ACI-ASCE Committee 352, 2002)

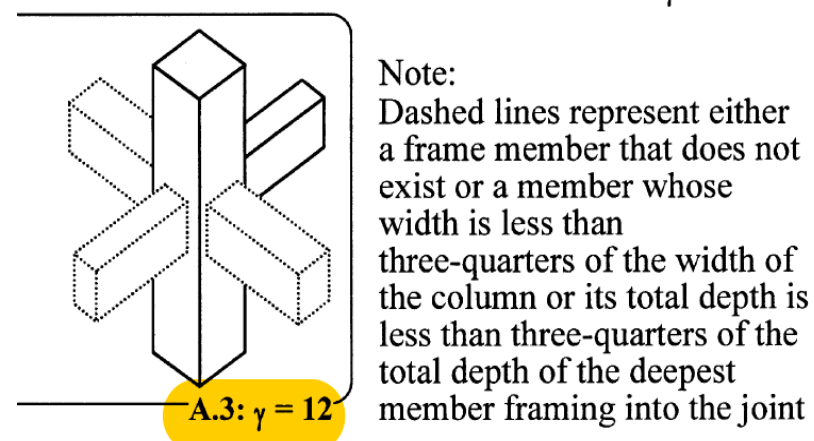

Figure 2.16: Factors: $b_{j}, b_{c}, b_{b}$ and $h_{c}$ (ACI-ASCE Committee 352, 2002)

\subsubsection{Flexural strength of SCC beam/column}

The flexural capacity of the SCC beam and column sections are calculated using equation 2.7 based on CSA A23.3-14 (CSA, 2014). In which, $A_{s}$ is the area of flexural reinforcement, $f_{y}$ is the yield stress of the flexural reinforcement, $d$, the effective depth, and $a$, is the depth of equivalent rectangular stress block, calculated using equation 2.8 .

$$
\begin{aligned}
& M_{r}=\varphi_{s} A_{s} f_{y}\left(d-\frac{a}{2}\right) \\
& a=\frac{\varphi_{s} A_{s} f_{y}}{\alpha_{1} \varphi_{c} f_{c}^{\prime} b}
\end{aligned}
$$




\subsubsection{Flexure strength of ECC beam/column}

To calculate the flexural capacity of the ECC portion of the beam and column, equation 2.9 will be used as per Lepech and Li (2009). Figure 2.17 illustrates the stress-strain distribution of the reinforced ECC member. In which, B represents the beam width, $t_{s}$ represents the beam depth, $\mathrm{C}$ is the distance from the tension face to the center of the reinforcing bars, and $\mathrm{d}$ is the distance from the neutral axis (N.A) to the center of the bars.
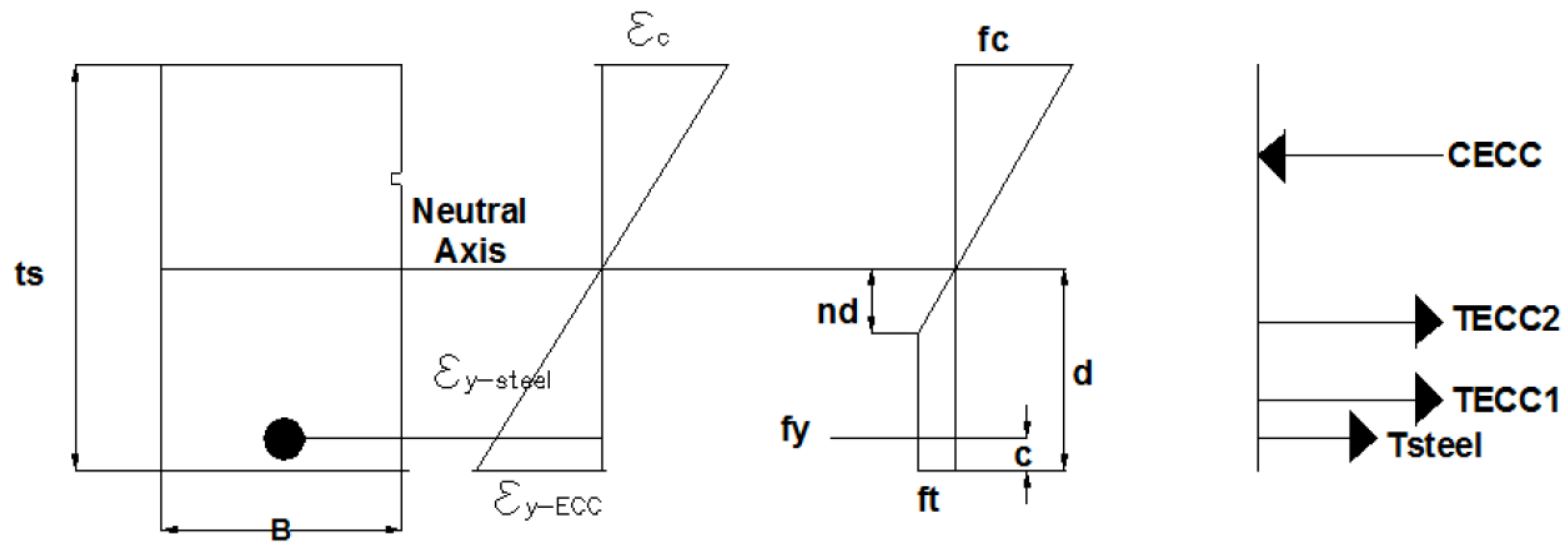

Figure 2.17: Stress-strain distribution of reinforced ECC member (Yeganeh, 2015)

$M_{r}=\left[T_{\text {steel }} d+T_{E C C-1}\left(\frac{\left(1-n_{\varepsilon}\right) d+c}{2}+n_{\varepsilon} d\right)+T_{E C C-2}\left(\frac{2}{3}\right) n_{\varepsilon} d+C_{E C C}\left(\frac{2}{3}\right)\left(t_{s}-d-c\right)\right]\left(\frac{1}{1000}\right)$

In which, the force in the steel, $T_{\text {steel }}$ can be calculated using equation 2.10 where $f_{y}$ is the yield stress of the flexural reinforcement and $A_{s}$ is the area of steel reinforcement.

$$
T_{\text {steel }}=0.4 f_{y} A_{s}
$$

The tensile force of the ECC material, is calculated by $T_{E C C-1}$ and $T_{E C C-2}$ using equations 2.11 and 2.12, respectively. In which, $f_{t}$ is the tensile stress of the ECC, $d$ is the effective depth, $c$ is the distance from tensile steel to extreme tension fiber and $n_{\varepsilon}$ is the modular ratio - which is calculated by using equation 2.14. The compressive strength contribution of ECC, $C_{E C C}$, is calculated using equation 2.13 . 


$$
\begin{aligned}
& T_{E C C-1}=f_{t}\left[\left(1-n_{\varepsilon}\right) d+c\right] b \\
& T_{E C C-2}=0.5 f_{t} n_{\varepsilon} d b \\
& C_{E C C}=0.5 f_{t}\left(\frac{1}{n_{\varepsilon} d}\right)\left(t_{s}-d-c\right)^{2} b
\end{aligned}
$$

The modular ratio $\left(n_{\varepsilon}\right)$ is calculated using the equation 2.14 in which $\varepsilon_{y-E C C}$ is the yielding strain of the ECC material and $\varepsilon_{y-s t e e l}$ is the yield strain of the flexural reinforcement.

$$
n_{\varepsilon}=\frac{\varepsilon_{y-E C C}}{0.4 \varepsilon_{y-s t e e l}}
$$

\subsubsection{Flexure strength of UHPC beam/column}

The flexural strength of the UHPC portion of the beam and columns in the UHPC specimens is calculated by the moment of resistance equation provided in equation 2.15 (Yeganeh, 2015). The flexural strength is derived by taking into consideration of the contributions from the reinforcement and the ultimate tensile strength of the fiber reinforced concrete, $\sigma_{t}$.

$$
M_{n}=A_{s} f_{y}\left(d-\frac{a}{2}\right)+\sigma_{t} b(h-c)(h+c-a) / 2
$$

The equivalent rectangular stress block, $a$, can be calculated using equation 2.16:

$$
a=\frac{\left(A_{s} f_{y+} \sigma_{t} b h\right)}{\lambda f_{c f}^{\prime} b+\sigma_{t} b}
$$

The ultimate tensile strength of the fiber reinforced concrete, $\sigma_{t}$ can be calculated using equation 2.17 (Yeganeh, 2015). In which, $\eta_{o}$, is the orientation factor taken as $0.41, \eta_{b}$ is the bond efficiency factor taken as 0.5 (round fibers), $\eta_{l}$, is the length efficiency factor taken as $0.86, V_{f}$, volume fraction of steel fiber is taken as $0.021 \%, \tau_{f}$, is the bond strength between the fiber and matrix

(MPa) calculated by $0.66 \sqrt{f_{c}^{\prime}}, l_{f}$, length of the fibers is taken as $14 \mathrm{~mm}$ and $d_{f}$, the diameter of fibers is taken as $0.4 \mathrm{~mm}$. 


$$
\sigma_{t}=2 \eta_{o} \eta_{b} \eta_{l} V_{f} \tau_{f}\left(l_{f} / d_{f}\right)
$$

\subsection{Chapter Review}

The literature review presented the advancements in the high performance concrete (HPC) materials namely SCC, ECC and UHPC. In addition, previous researches conducted on the behaviour of beam-column frame joints are presented with design guidelines based on code-based and other formulations for calculating shear and flexural capacities of members made of different HPC materials. Literature review confirmed that lack of research studies of HPC (ECC and UHPC) jointed reinforced shear and flexure critical building frames and justified the current research. 


\section{Chapter 3 - Experimental Investigation}

\subsection{Introduction}

Experimental research investigation was conducted to analyze the behaviour of reinforced beamcolumn frames subjected to in-plane cyclic lateral loading. Four beam-column frame specimens (two shear critical and two flexure critical) made of SCC with ECC/UHPC joints were tested. This chapter will describe material properties, details of beam-column frame with joint and test setup with testing procedures for the experimental investigation.

\subsection{Material Properties Investigations}

Ryerson developed ECC and UHPC and a commercial SCC were used to construct the frame specimens. The ECC mix (mix composition is presented in table 3.1) consisted of cement, fly ash, silica sand, polyvinyl alcohol (PVA) fibers, and high range water reducer (HRWR). The water to cementitious (w/c) material ratio of 0.30 was used for the ECC mix. The PVA fiber used in the mix consisted of the following properties - "39 microns in diameter, $8 \mathrm{~mm}$ in length, a tensile strength of $1620 \mathrm{MPa}$, modulus elasticity of $42.8 \mathrm{GPa}$, and has a melting point of $225^{\circ} \mathrm{C}$ ' (Yeganeh, 2015). The mixing procedure of the ECC is briefly illustrated in figure 3.1. The mixing procedure

Table 3.1: Mix design details for ECC and UHPC mixes (Yeganeh, 2015)

\begin{tabular}{|c|c|c|c|c|c|c|}
\hline \multirow[b]{2}{*}{ Mixture } & \multicolumn{3}{|c|}{ Ingredients per 1 part of Cement } & \multirow[b]{2}{*}{$\begin{array}{c}\text { PVA } \\
\mathrm{kg} / \mathrm{m}^{3}\end{array}$} & \multirow[b]{2}{*}{$\begin{array}{c}\text { HRWR } \\
\mathrm{kg} / \mathrm{m}^{3}\end{array}$} & \multirow[b]{2}{*}{$\mathbf{w} / \mathbf{b}$} \\
\hline & Cement & Fly Ash (FA) & $\begin{array}{l}\text { Silica } \\
\text { Sand }\end{array}$ & & & \\
\hline ECC & 1 & 1.2 & 0.80 & 26 & 5.4 & 0.27 \\
\hline Mixture & Cement & Silica Fume & $\begin{array}{l}\text { Silica } \\
\text { Sand }\end{array}$ & $\begin{array}{c}\text { Steel fiber } \\
\mathrm{kg} / \mathrm{m}^{3}\end{array}$ & $\begin{array}{c}\text { HRWR } \\
\mathrm{kg} / \mathrm{m}^{3}\end{array}$ & $\mathrm{w} / \mathrm{b}$ \\
\hline UHPC & 1 & 0.25 & 1.10 & 164 & 26 & 0.22 \\
\hline
\end{tabular}

mainly involved placing all the solid contents of the mix into the 120-liter shear drum mixer, except for the PVA fiber. After mixing for 1 minute, $75 \%$ of the water was added with $50 \% \mathrm{HRWR}$ gradually added into the mixer for approximately 2 to 3 more minutes. Afterwards the remaining water and HRWR were gradually added to the mix to ensure a consistent mortar mixture. The PVA fibers were added next and mixed for approximately 3 minutes. 

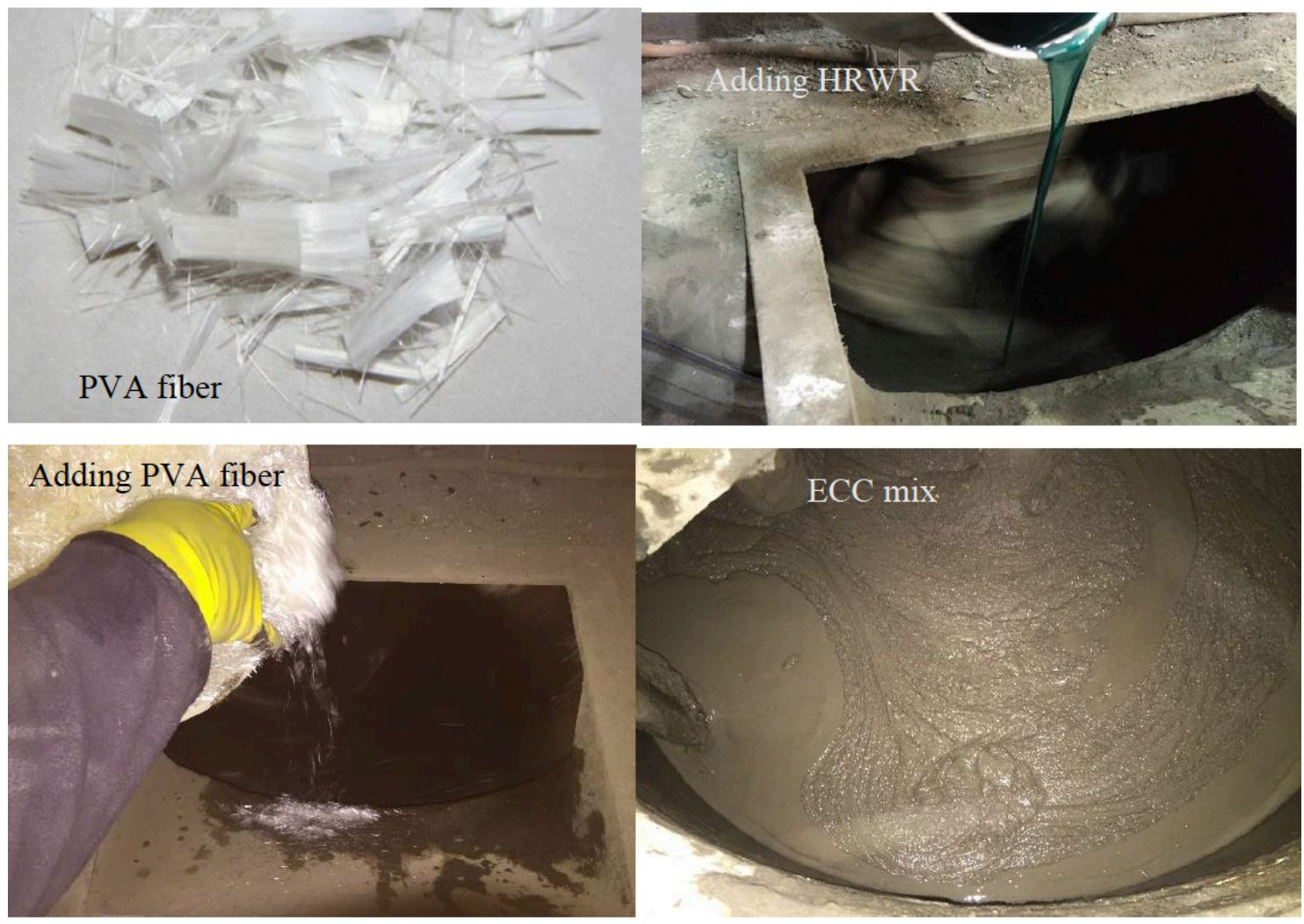

Figure 3.1: ECC mixing procedure (Yeganeh, 2015)

The SCC mix used for a portion of the beam and column sections of the frame specimen consisted of "10 mm maximum size coarse aggregates, crushed sand, Portland cement and admixtures" (Yeganeh and Hossain, 2019). The admixtures consisted of air entraining admixtures and the supplementary cementing materials such as silica fume was used in the mix. The SCC mix required 2.4-liter of water for each pre-packed bag and the mixing procedure required water to be gradually added to the dry mix for several minutes, until required workability and followability were achieved.

The UHPC (composition presented in table 3.1) mainly consisted of cement, silica fume, silica sand, steel fiber and HRWR. This mix had a w/c ratio of 0.22 and a steel fiber content of $9 \%$. The steel fiber used had $0.4 \mathrm{~mm}$ diameter and $14 \mathrm{~mm}$ length with a tensile strength of $2160 \mathrm{MPa}$, modulus of elasticity of $210 \mathrm{GPa}$ and melting point higher than $800^{\circ} \mathrm{C} "$ (Yeganeh, 2015). The substitution of silica fume with fly ash as used in ECC allows the achievement of the dense mixture of UHPC. The use of steel fibers instead of PVA fibers further increase the stiffness of the UHPC 
in addition to the increase of the tensile capacity. The mixing procedure mainly consisted of casting the dry materials into the shear drum mixer, except the steel fibers. After mixing for 2 minutes, $75 \%$ of the water was added into the mixer and mixed for an additional 2 minutes. Afterwards, the remaining water and the HRWR were introduced into the mix, and finally the steel fibers were mixed into the mixture. Figure 3.2 illustrates the steel fibers used in the UHPC mix (on the left) with the flowable UHPC (on the right).

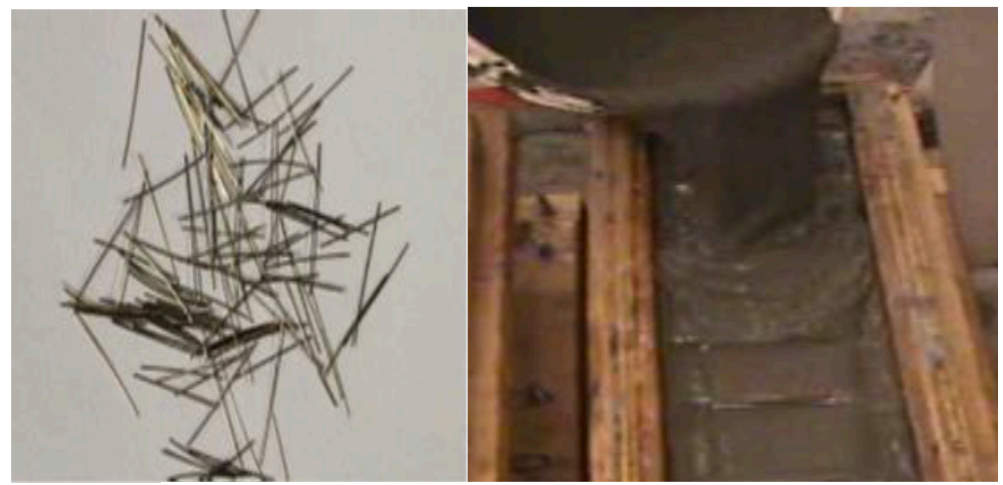

Figure 3.2: UHPC mix (Yeganeh, 2015)

\subsubsection{Concrete properties}

Concrete cylinder specimen for each concrete type were tested to obtain the average concrete compressive strength for each concrete type; SCC, ECC and UHPC. The samples were tested as per ASTM C39 (ASTM International, 2020). The cylinders were casted during casting of the frame specimens, cured similar manners as the frame and were tested at the testing date of frame specimens. Figure 3.3 shows a view of the cross-sections of the cylindrical samples that illustrates the difference in mix properties of each concrete type. For example, the presence of coarse aggregate in SCC, PVA fiber and fine aggregates in ECC and the presence of steel fibers in UHPC.

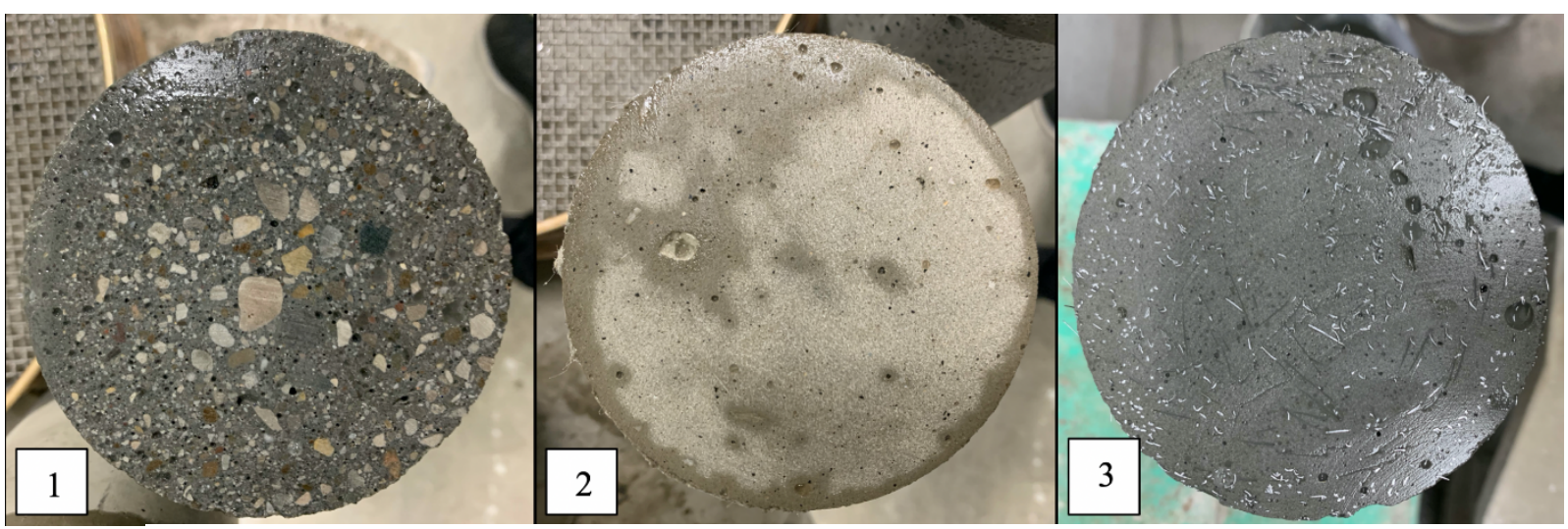

Figure 3.3: Concrete cylinder cross-section; 1: SCC, 2: ECC, \& 3: UHPC 
Table 3.2 presents the average concrete compressive strength $\left(f_{c}^{\prime}\right)$ of SCC, ECC and UHPC tested as per ASTM C39 (ASTM International, 2020). The average concrete compressive strengths at the age of testing are 49.57 MPa, 76.37 MPa, and 113.66 MPa for SCC, ECC and UHPC, respectively.

Table 3.2: Average Concrete Compressive Strength $\left(f_{c}^{\prime}\right)$ for SCC, ECC and UHPC

\begin{tabular}{|l|l|l|l|}
\hline & \multicolumn{3}{|c|}{ Concrete Compressive strength $\left(\boldsymbol{f}_{c}^{\prime}\right)$ - at the age of testing (1 year) } \\
\hline Concrete Type: & SCC & ECC & UHPC \\
\hline & EF*: $56.294 \mathrm{MPa}$ & EF: $76.374 \mathrm{MPa}$ & EF:117.77 MPa \\
& ES: $42.851 \mathrm{MPa}$ & ES**: N/A & ES: $109.54 \mathrm{MPa}$ \\
\hline Average: & $\boldsymbol{f}_{c}^{\prime}=\mathbf{4 9 . 5 7} \mathrm{MPa}$ & $\boldsymbol{f}_{c}^{\prime}=\mathbf{7 6 . 3 7} \mathrm{MPa}$ & $\boldsymbol{f}_{c}^{\prime}=\mathbf{1 1 3 . 6 6} \mathrm{MPa}$ \\
\hline
\end{tabular}

Note: *flexure critical frame, ${ }^{* *}$ shear critical frame

Table 3.3 presents the concrete flexural strength $\left(f_{t}\right)(\mathrm{MPa})$ at the age of testing, which was tested as per ASTM C78 (ASTM International, 2018). It can be seen that the UHPC mix has the highest flexural strength of 15.7 MPa, which is attributed to the presence of steel fibers in the UHPC mix, followed by SCC at 5.9 MPa, and lastly ECC at 5.1 MPa.

Table 3.3: Concrete flexural strength $\left(f_{t}\right)$ for SCC, ECC and UHPC concrete types (Yeganeh, 2015)

\begin{tabular}{|l|c|c|c|}
\hline & \multicolumn{3}{|c|}{ Concrete Flexural strength $\left(\boldsymbol{f}_{\boldsymbol{t}}\right)$ (MPa) } \\
\hline Concrete Type: & SCC & ECC & UHPC \\
\hline Flexural strength & $5.9 \mathrm{MPa}$ & $5.1 \mathrm{MPa}$ & $15.7 \mathrm{MPa}$ \\
\hline
\end{tabular}

\subsubsection{Rebar properties}

Three different types of rebars were used in all four frame specimens; $10 \mathrm{~mm}$ rebar was used as longitudinal reinforcement in the beam sections, $15 \mathrm{~mm}$ rebar was used as longitudinal reinforcement in the column sections and $6 \mathrm{~mm}$ steel rods were used as shear reinforcement. The yield strain $\left(\varepsilon_{y}\right)$ and yield stress $\left(f_{y}\right)$ of each rebar is outlined in table 3.4. 
Table 3.4: Rebar reinforcement properties (Yeganeh, 2015)

\begin{tabular}{|l|c|c|}
\hline Rebar size (mm) & Yield stress $\left(\boldsymbol{f}_{\boldsymbol{y}}\right) \mathbf{( M P a )}$ & Yield strain $\left(\boldsymbol{\varepsilon}_{\boldsymbol{y}}\right)(\boldsymbol{\mu} \boldsymbol{\varepsilon})$ \\
\hline $15 \mathrm{~mm}$ & 527 & 2240 \\
\hline $10 \mathrm{~mm}$ & 478 & 2310 \\
\hline $6 \mathrm{~mm}$ & 429 & -- \\
\hline
\end{tabular}

\subsection{Beam-Column Frame and Joint Details}

For this project, 4 frame specimens of different material and reinforcement composition are tested. All frame specimens consist of beam and column sections made of SCC. However, specimen 1 and 2 consist of ECC joints with a portion of the ECC making up a section of the beam and column, however, specimen 1 is flexure critical (EF) and specimen 2 (ES) is shear critical. The location and amount of shear reinforcement differs between both specimens and will be discussed in detail below. On the other hand, specimen 3 and 4 both consist of UHPC joints with SCC beam and columns, however, specimen 3 is flexure critical (UF) and specimen 4 (US) is shear critical. Table 3.5 illustrates the notation to be used for the 4 specimens in this report.

Table 3.5: Specimens notation

\begin{tabular}{|l|l|}
\hline \multicolumn{1}{|c|}{ Specimens } & \multicolumn{1}{c|}{ Specimens notation } \\
\hline Flexural critical ECC & EF \\
\hline Shear critical ECC & ES \\
\hline Flexural critical UHPC & UF \\
\hline Shear critical UHPC & US \\
\hline
\end{tabular}

\subsubsection{ECC Jointed Flexure Critical Frame (EF)}

Figure 3.4 illustrates the details of the frame specimen showing cross-section and reinforcement for flexure critical frame EF. EF consisted of an ECC joint, with a portion of the ECC making up the beam and column sections, and mainly SCC in the beam and column. This specimen was designed as flexure critical and contained six steel strain gauges (indicated as S-SG) on the flexural reinforcement as shown in the figure 3.4 with two concrete strain gauges (indicated as C-SG) located on the surface of the ECC on the joint opposite of the actuator load location. 


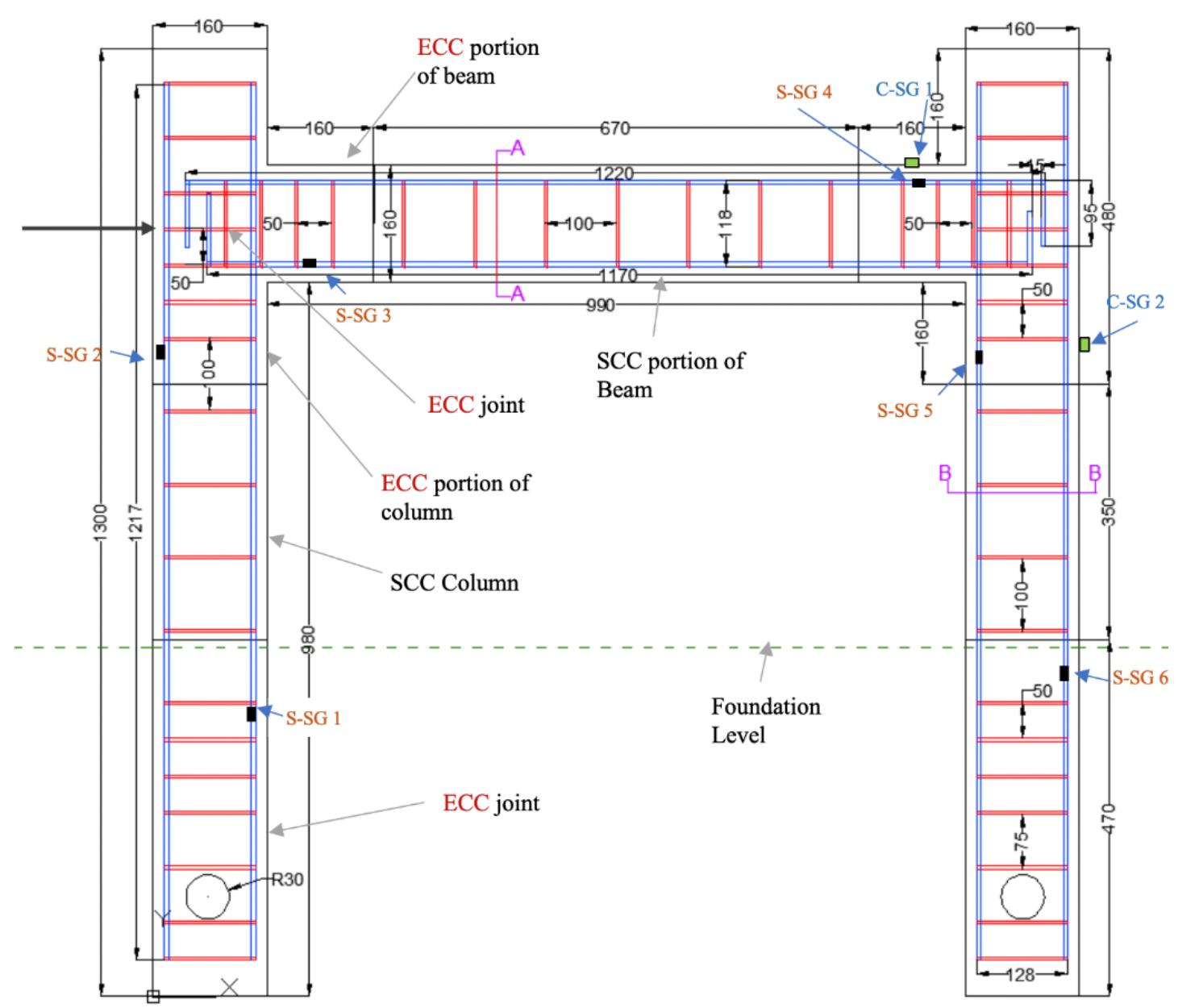

Figure 3.4: Details of ECC Jointed Flexure Critical frame (EF)

\subsubsection{ECC Jointed Shear Critical Frame (ES)}

The frame reinforcement detailing for ES frame is presented in figure 3.5. This specimen also consisted of ECC joint and beam/column made of SCC/ECC. However, this is a shear critical specimen and there was shear reinforcement only located in the joints as labeled in red in the figure. For this specimen there were eight steel strain gauges, 2 additional steel gauges were located in the shear reinforcement located in the joint, with 2 concrete strain gauges also placed on the surface of the concrete on the joint. 


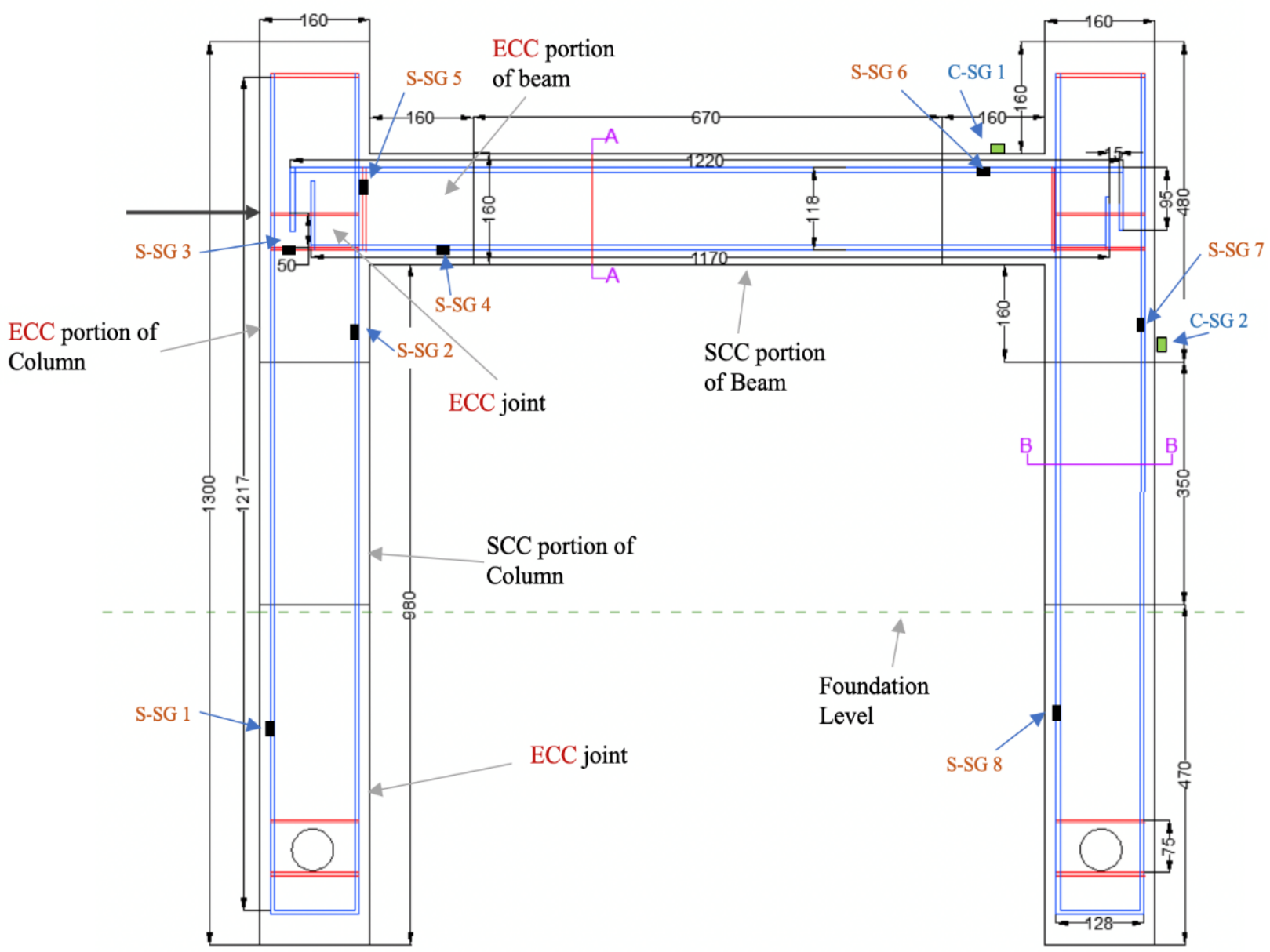

Figure 3.5: Details of ECC Jointed Shear Critical frame (ES)

\subsubsection{UHPC Jointed Flexure Critical frame (UF)}

UF has the same reinforcement detailing as EF, however, the strain gauge locations in the column longitudinal reinforcement differed. This specimen was also flexure critical, however, the material used for the joints was UHPC rather than ECC as shown in figure 3.6. 


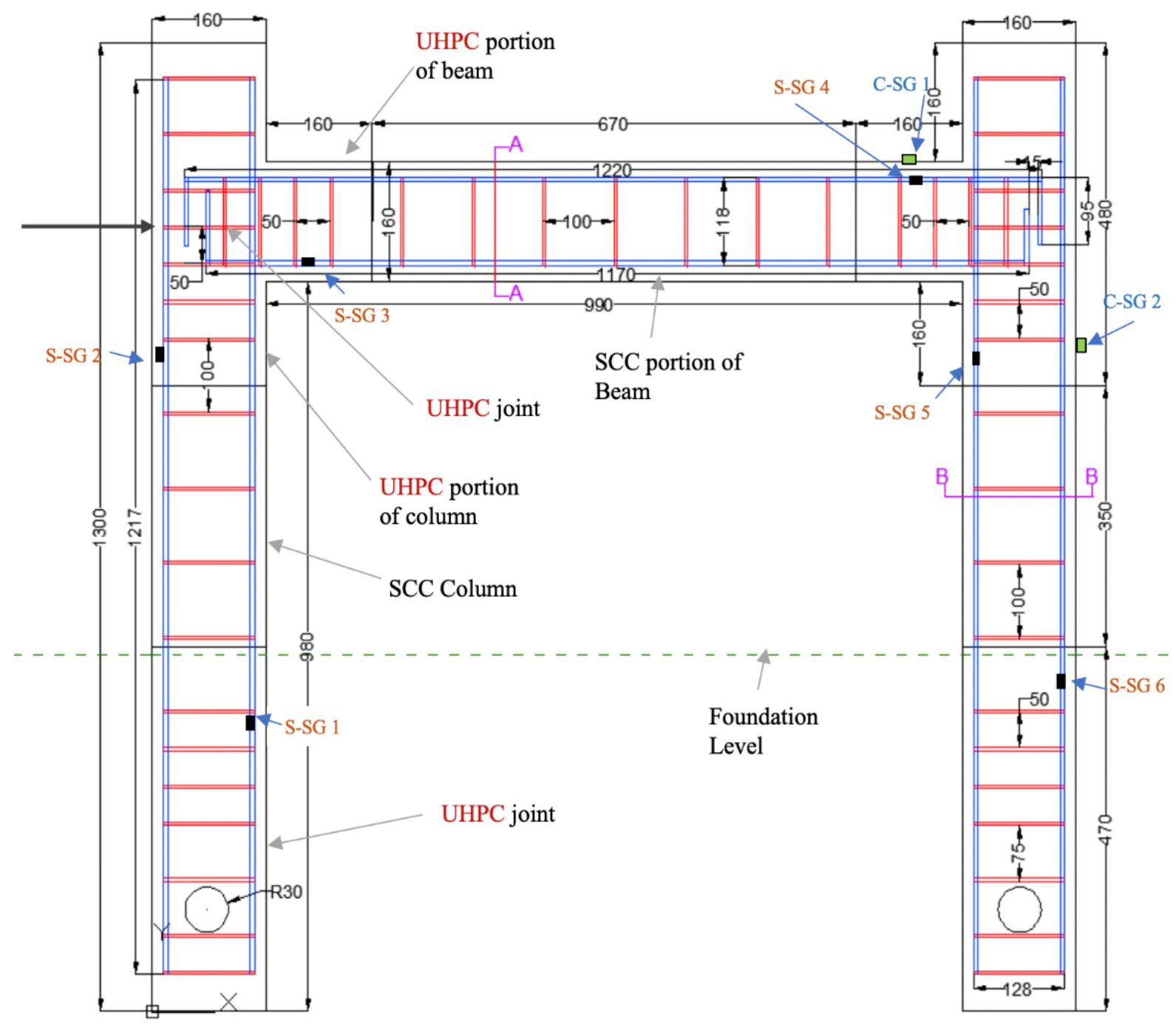

Figure 3.6: Details of UHPC Jointed Flexure Critical frame (UF)

\subsubsection{UHPC Jointed Shear Critical Frame (US)}

US had the same reinforcement detailing and strain gauge locations as ES. However, the material used for the joints was UHPC rather than ECC as shown in figure 3.7. This allowed for the comparison and analysis of the behaviour of both types of frames. 


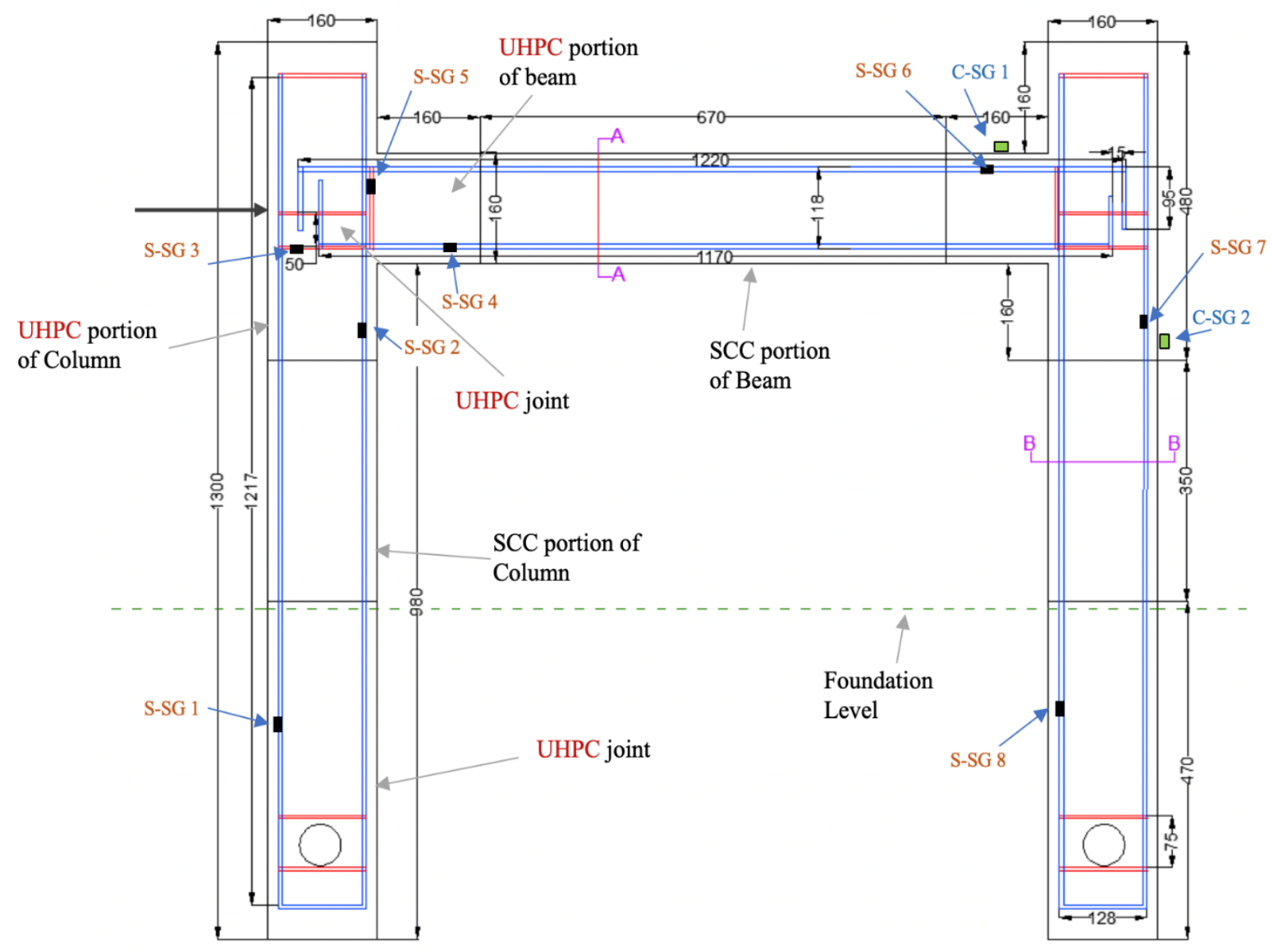

Figure 3.7: Details of UHPC Jointed Shear Critical frame (US)

\subsubsection{Beam and Column detailing}

Figure 3.8 presents the beam and column cross-section and reinforcement detailing. On the left of the figure, the beam cross-section A-A from the figure 3.6 is presented. The beam cross-section was $120 \mathrm{~mm} \times 160 \mathrm{~mm}$, which consisted of 4, $10 \mathrm{~mm}$ longitudinal reinforcing bars in addition to $6 \mathrm{~mm}$ stirrups at $100 \mathrm{~mm} \mathrm{c/c}$ spacing. On the right of figure 3.8, the column cross-section is presented of size $160 \mathrm{~mm}$ x $120 \mathrm{~mm}$, which consisted of 4, $15 \mathrm{~mm}$ longitudinal reinforcing bars and $6 \mathrm{~mm}$ shear reinforcing at $100 \mathrm{~mm} \mathrm{c} / \mathrm{c}$ spacing. This reinforcement detailing applies to the flexure critical specimen. For the shear critical specimen, shear reinforcement was not present in the beam/column sections, only in the joint. 
For the ECC and UHPC joint reinforcement detailing, the same reinforcement detailing was used as seen in figure 3.6, however, the tie reinforcement spacing varied from $50 \mathrm{~mm}, 75 \mathrm{~mm}$ to 100 $\mathrm{mm}$ as seen in the frame detailing in that figure. The shear reinforcement spacing was closely spaced at the area of the joint where the beam reinforcement intersected with the column reinforcement to ensure sufficient load transfer occurred between the members.

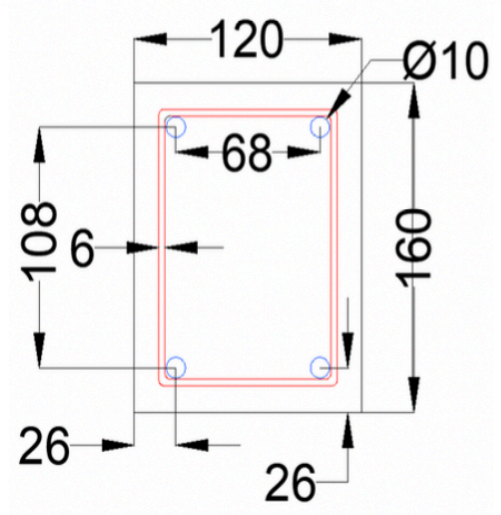

BEAM CROSS-SECTION A-A

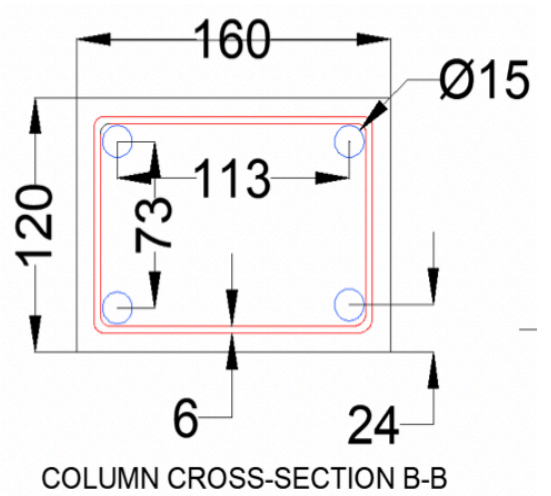

Figure 3.8: Beam and Column cross-section and reinforcement detailing

\section{Foundation cross-section:}

The foundation cross-section is presented in figure 3.9. The foundation is casted from Ultra-HighPerformance Concrete (UHPC) and allows the frame specimen to be inserted into the foundation and secured using rods as to be discussed in the test-setup section. 


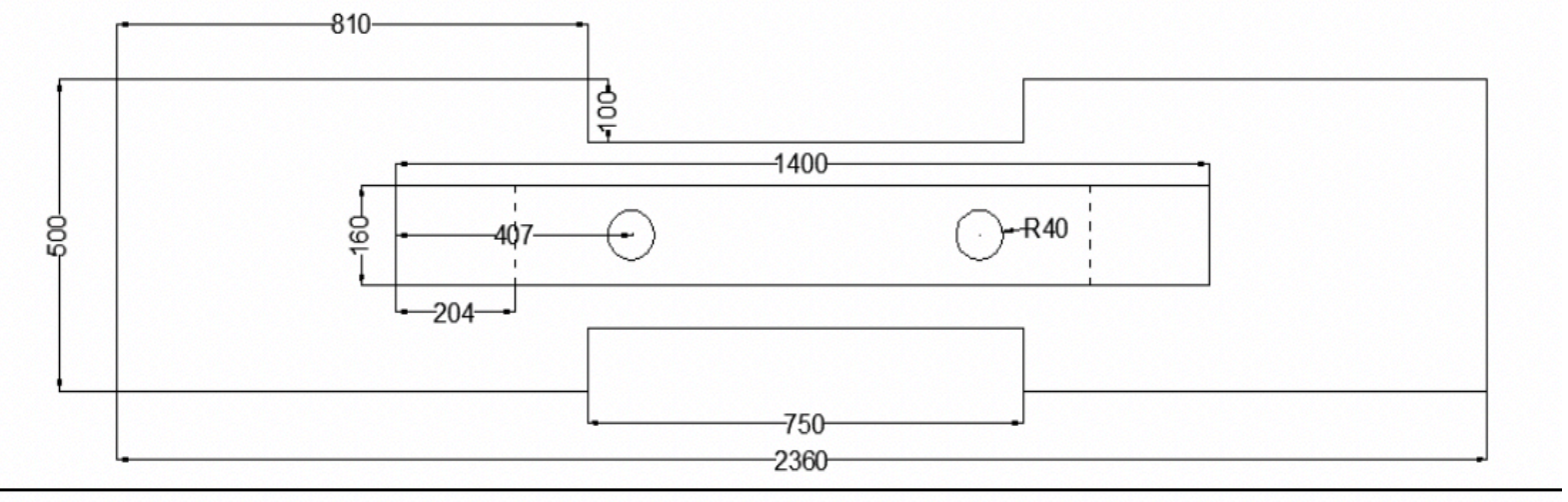

SIDE VIEW OF FOUNDATION

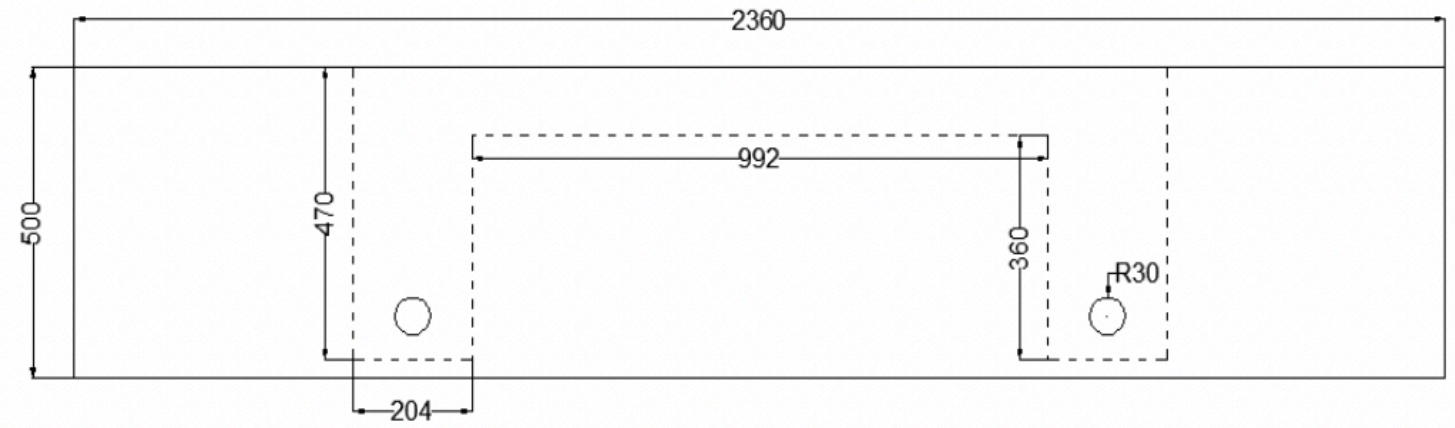

Figure 3.9: Foundation cross-section reinforcement detailing

\section{Frame composition:}

The frame composition for specimens 1 to 4 is illustrated in figure 3.10. On the left, is the flexure critical frame composition for EF and UF. The hatched components of the diagram illustrate the different material used for the joints, i.e. ECC and UHPC. Whereas, the beam and column section of the frame is made of SCC. On the right of the figure, is the shear critical frame composition, ES and US. This frame has the same components as the flexure critical specimen, however, the amount of shear reinforcement differs. 

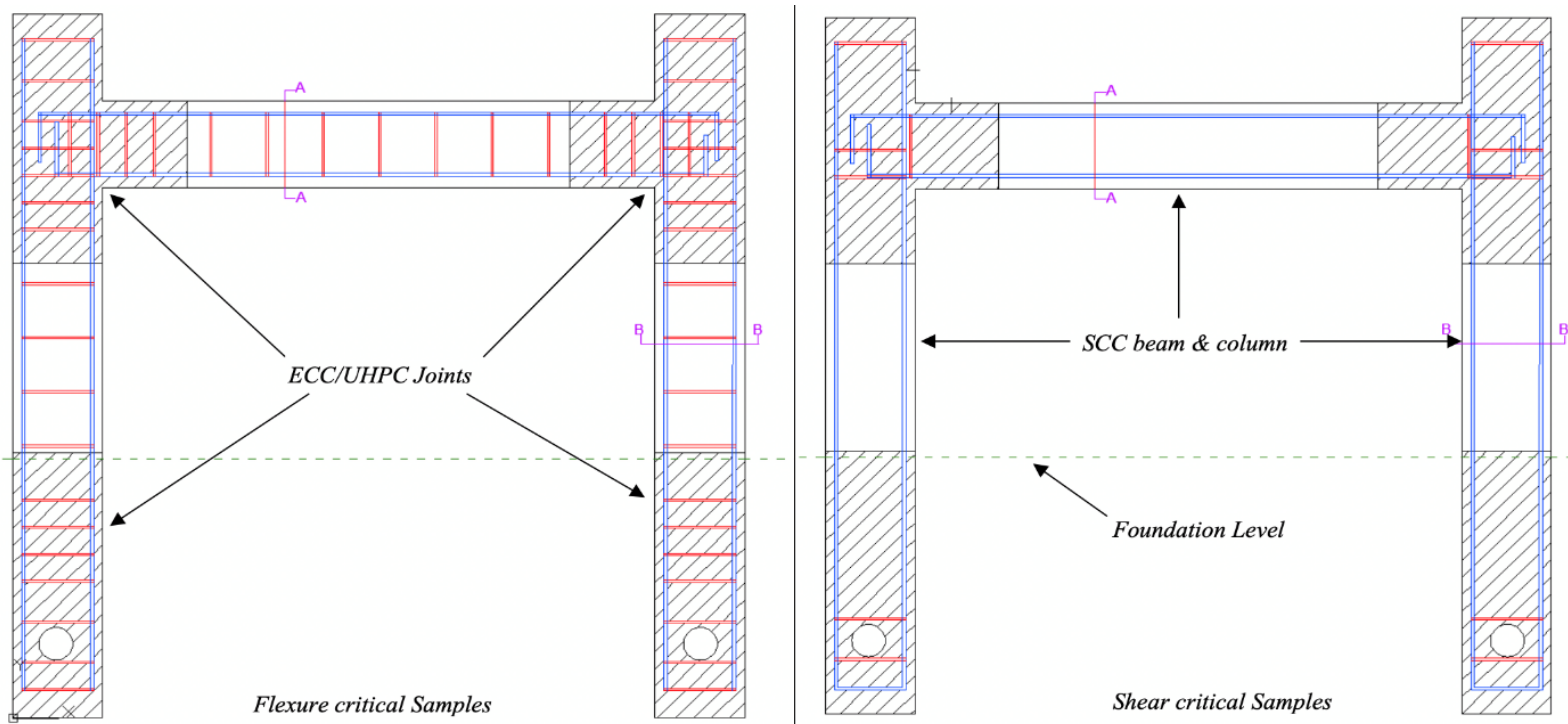

Figure 3.10: Frame component illustration, Left: Flexure critical, Right: Shear critical

The lab test set-up and frame composition are also illustrated in figure 3.11. The different sections of the frame specimen are clearly shown. The beam/column consisted of SCC and the joints consisted of ECC or UHPC.

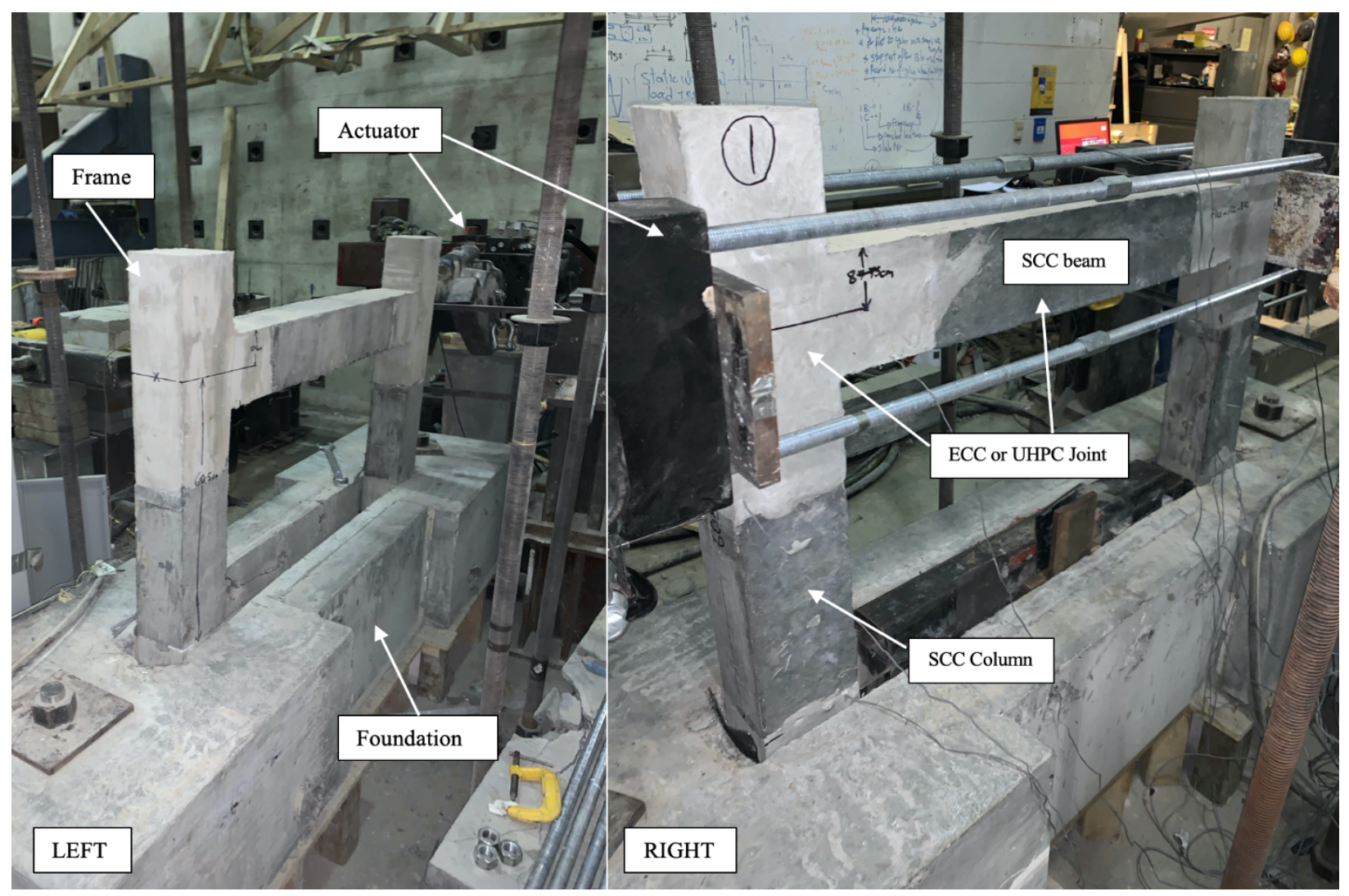

Figure 3.11: Frame details and test set-up 


\subsection{Test Setup and Procedure}

Four SCC frame specimens were tested under lateral cyclic loading to failure - two shear critical and two flexural critical frame with UHPC/ECC joint. The shear critical frame specimens contained tie/shear reinforcement only in the ECC/UHPC joint regions and no shear reinforcement the beam or column as opposed to the flexure critical specimens. The test setup shown in figure 3.11 was similar for all the frames and typical testing procedure followed for all the specimens are described in the following steps:

Step 1: A foundation was already in position with holes of size $20 \mathrm{~cm} \times 16 \mathrm{~cm}$ and $38 \mathrm{~cm}$ deep into the foundation to accommodate the frame columns as shown in figure 3.12. First step was to carry the specimen by crane and placed it into position into the foundation.

Step 2: Second step required to move the actuator machine into position. The actuator needed to be aligned with the centre of the beam section of the frame. Therefore, once the specimen was placed into position, the center of the actuator needed to be positioned at $60.5 \mathrm{~cm}$ from the top of the foundation.

Step 3: The frame specimen was required to be secured into the foundation to mimic fixed condition. The foundation and the bottom of the frame specimen had a circular hole that aligned through both the foundation and frame specimen once the specimen was placed into the foundation. Two 2.5-inch steel rods were hammered into the foundation hole, penetrating through the frame specimen and out the other side of the foundation as shown in figure 3.12. To further

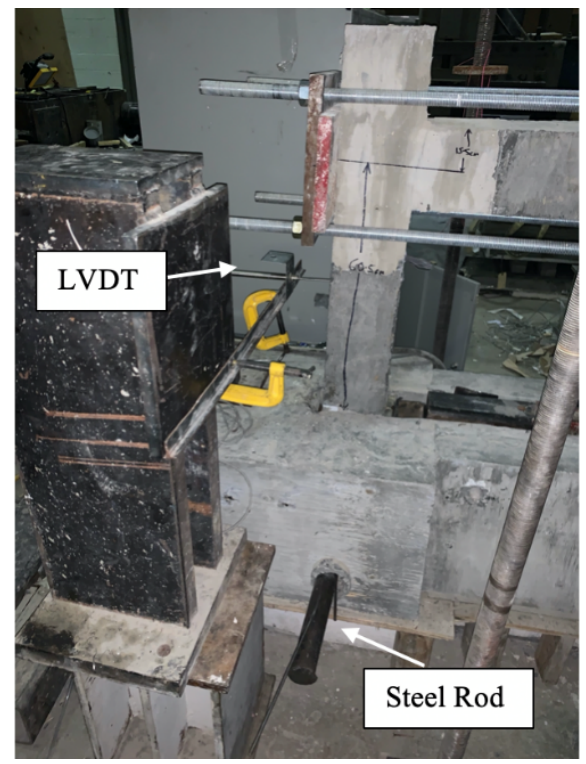

Figure 3.12: Steel Rod location in foundation 
secure the specimen, several $6 \mathrm{~mm}$ steel rods were also forced into the hole to ensure no movement occurs during the fatigue cycles.

Step 4: To ensure that the fixed condition of the frame was aligned (on the same level). From the cross section of the foundation provided in figure 3.9, it can be seen that the foundation was higher at the outer edges with the inner edges of the foundation being lower. Therefore, to ensure that the fixed support condition was aligned, thin steel plates had to be hammered into the outer side of the column in the gap between the foundation and the column. The height of the stuffed plates needed to be aligned to ensure an aligned fixed connection. For the inner column sections, HSS sections and steel plates were inserted to fix and support the inner columns adequately as seen in figure 3.13 .

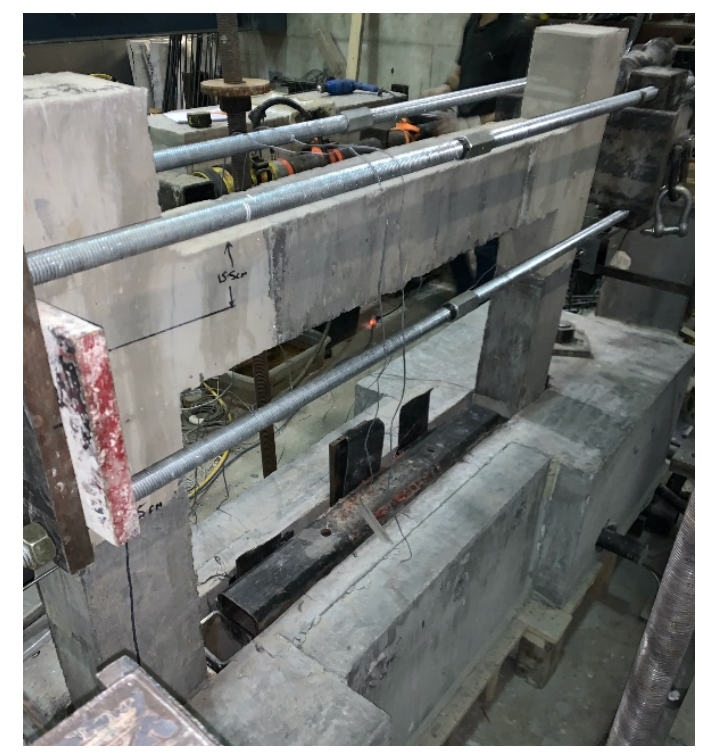

Figure 3.13: Interior column support

Step 5: Looking at figures 3.14 and 3.15 of the actuator, the head of the machine had 4 holes embedded in the plate. The load was applied by steel plates that were held by 4 steel rods holding the specimen throughout the beam. The 4 steel rods were $6 \mathrm{ft}$ long, which were connected by a hinge at the centre. The steel rods went through the actuator and was bolted to an identical plate $(30 \mathrm{~cm} \times 30 \mathrm{~cm} \times 2.5 \mathrm{~cm})$ at the end of the beam. Washers were placed and were fixed into position with 1-inch diameter knots at the side of the actuator to ensure proper pushing and pulling forces were provided during testing. In addition, 2 identical plates $(40 \mathrm{~cm}$ x $20 \mathrm{~cm} \times 2.5 \mathrm{~cm})$ were placed between the actuator and the frame specimen, and the other was placed between the end 4-hole 
steel plate and the specimen. These plates as shown in figure 3.15, which transferred the load and ensured uniform loading was applied on both sides.

Step 6: The actuator was then moved into position, holding the inner steel plates on both sides and the knots were tightened to ensure a uniform connection.

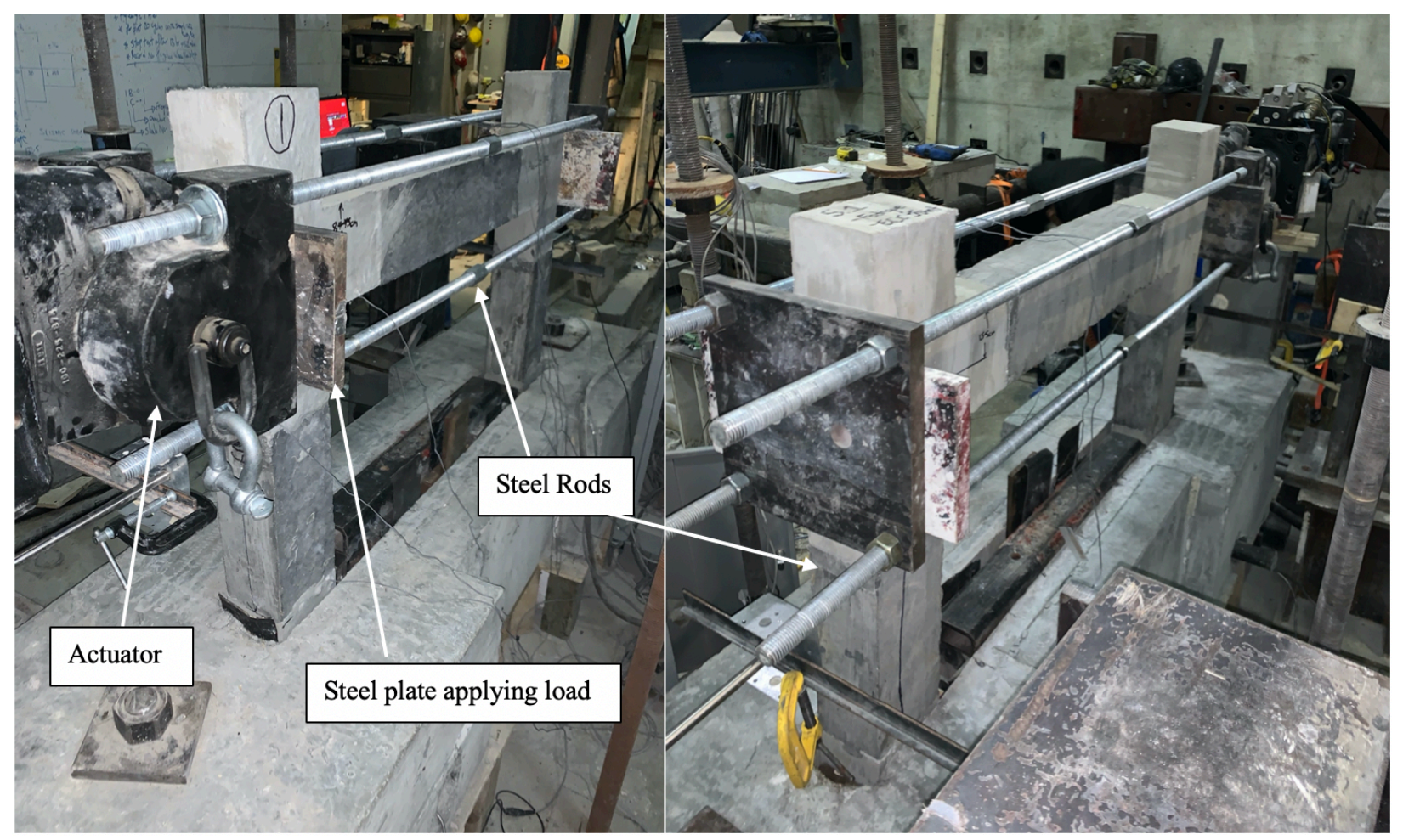

Figure 3.14: Frame test setup, Left: Actuator machine, Right: End plate fixed by steel rods

Step 7: Two $60 \mathrm{~mm}$ concrete strain gauges were installed in each specimen. The concrete strain gauges $(\mathrm{C}-\mathrm{SG})$ were placed at the end joint, the joint located at the other end of the actuator in critical locations.

Step 8: In addition, 6-10 $\mathrm{mm}$ steel strain gauges (S-SG) were embedded into the reinforcement of the flexure critical specimen before casting, whereas $8-10 \mathrm{~mm}$ steel strain gauges were installed in the shear critical specimen also before casting. The strain gauges were placed in the reinforcement located in the ECC/UHPC joints. The location and details of reinforcement can be found in the joint and reinforcement details in figures 3.4 to 3.7 .

Step 9: The steel strain and the concrete strain gauges were connected to the computer and the data was collected through a data acquisition system during testing. The specimens were tested under cyclic loading until failure. 
Step 10: The cyclic loading was applied through the hydraulic actuator at $0.2 \mathrm{kN} / \mathrm{s}$.

Step 11: While the test was running, crack development in the UHPC/ECC joints, beam/columns was visually observed and marked at the cycle crack appeared in. Afterwards, the average crack width in the joints was calculated by measuring the crack width using a crack scope.

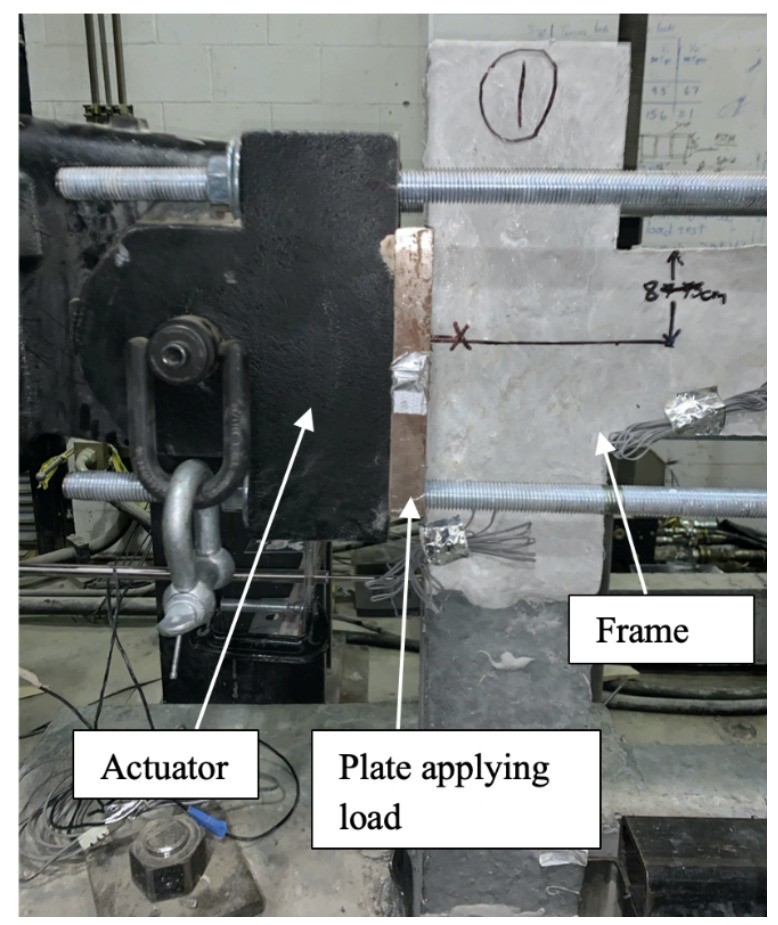

Figure 3.15: Actuator position details

\subsection{Chapter Review}

This chapter discussed the experimental investigation of the beam-column frame joints in detail. The SCC, ECC and UHPC material properties and mixing procedure were explained, in addition to outlining the concrete and rebar properties. The beam-column frame and joint reinforcement details of the four specimens were also outlined and differentiated. Finally, the process for test setup and testing procedure under cyclic loading to failure were illustrated. The next chapter, chapter 4, will present the results obtained from testing and analysis of test results with discussion to explain the structural behaviour of the frames. 


\section{Chapter 4 - Results and Discussion}

\subsection{Introduction}

The test results of the four frame specimens are presented and analyzed in this chapter. Test observations for each specimen, crack width measurements of the joint, stiffness degradation, energy absorption, load-deformation responses and concrete/steel strain development are described and performance of the flexure and shear critical frames is compared taking into consideration of the effect of ECC/UHPC material at joints.

\subsection{Test Observations}

This section analyzes the test observations and failure modes of the four beam-column frame specimens. The observations mentioned were noted down as the cycles of loading commenced with observations on each part of the frame - joint, beam and columns.

\subsubsection{ECC Jointed Flexure Critical Frame (EF)}

Test observations for ECC jointed flexure critical frame (EF) is discussed. Figure 4.1 presents the steel strain gauge (S-SG) and concrete strain gauge (C-SG) locations for reference. During pulling action S-SG 2 was observed to have the highest tensile strain when compared to all the other strain gauges. This can be linked to the critical location of that reinforcement, which is next to the location where the load is being applied. For this reason, cracking in the joint was initiated within the first couple of cycles, which also included interface cracks between the ECC and beam/column joint. Major cracks and deterioration observed throughout the cyclic test are as follows:

- After approximately cycle 30 , cracks in the joint stopped forming as the load was transferred to the columns.

- Cracking in the columns initiated at cycle 37 at approximately $+60 \mathrm{kN}$ load. Significant deterioration was noticed occurring in the outer column (opposite actuator load) at cycle $37-40$ during pushing action. Afterwards, at cycle 40 at a pulling load of $-56 \mathrm{kN}$ the inner column started to crack. 


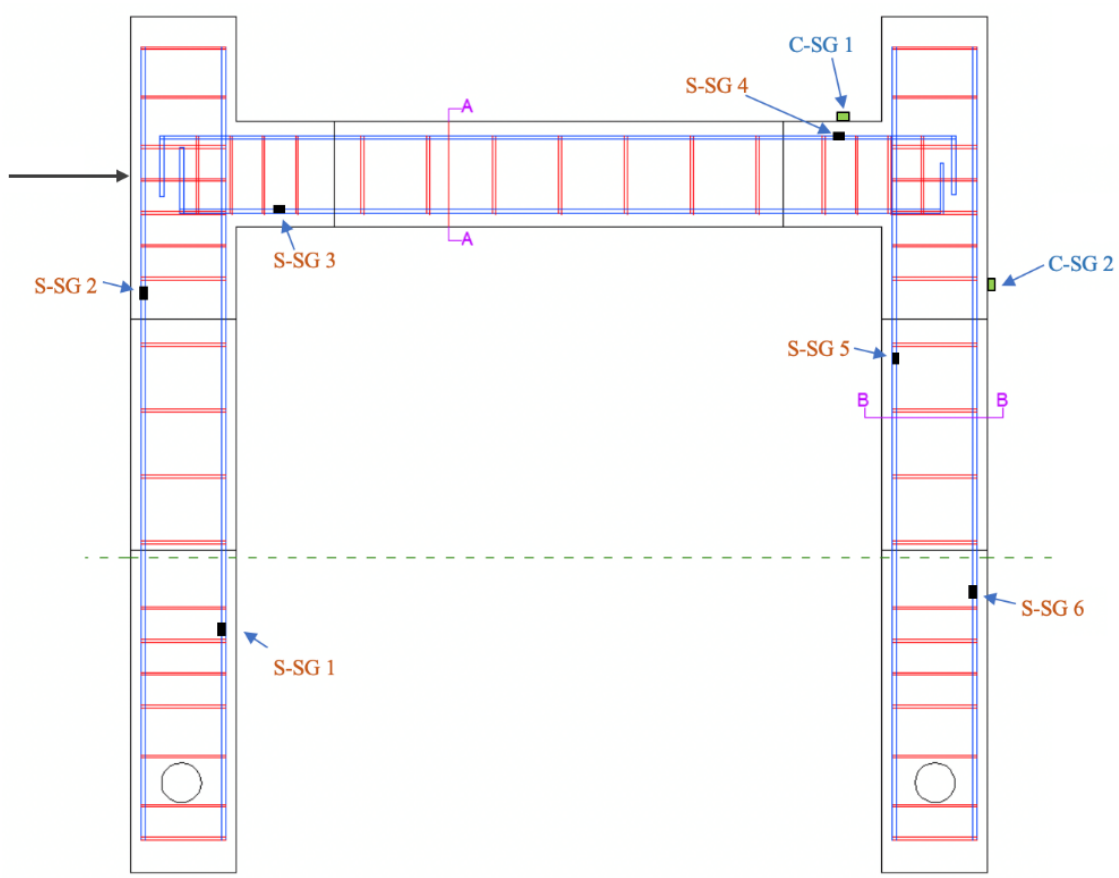

Figure 4.1: EF- Strain gauge locations

- During cycle 43 , displacement increased from $-25 \mathrm{~mm}$ to $-31.37 \mathrm{~mm}$ during pulling at a force of $-67.22 \mathrm{kN}$. At this cycle a large diagonal crack ( $2 / 3 \mathrm{~mm}$ thick) formed at the corner of the outer joint (opposite of actuator).

- It was observed that at the higher loads the pulling action caused more deterioration than pushing. At approximately cycle 43, a large crack formed at the top of the outer column near the joint interface. This occurred at a pulling load of $+83.07 \mathrm{kN} /-67.22 \mathrm{kN}$ at a displacement of $31.35 \mathrm{~mm}$. Shortly after the crack in the corner of the joint mentioned above, migrated to the column and created a slip between the joint and column. At this point the concrete cover broke off and reinforcement was exposed.

- At cycle 43 shear cracks were observed in the beam that initiated from the beam/joint interface. However, no flexure cracks were observed.

- At cycle 46 , at $+84 \mathrm{kN}$ during pushing action, a large crack formed on the side of the column under initial break off exposing more reinforcement and crushing of concrete occurred. At this point, the specimen had reached its peak load of $+84.26 \mathrm{kN}$ and -71.23 $\mathrm{kN}$ and significant stiffness degradation is observed afterwards due to failure of the joint and columns. Figure 4.2 shows the deterioration to the column at this point, which also shows how the column was tilting during the pulling action. 


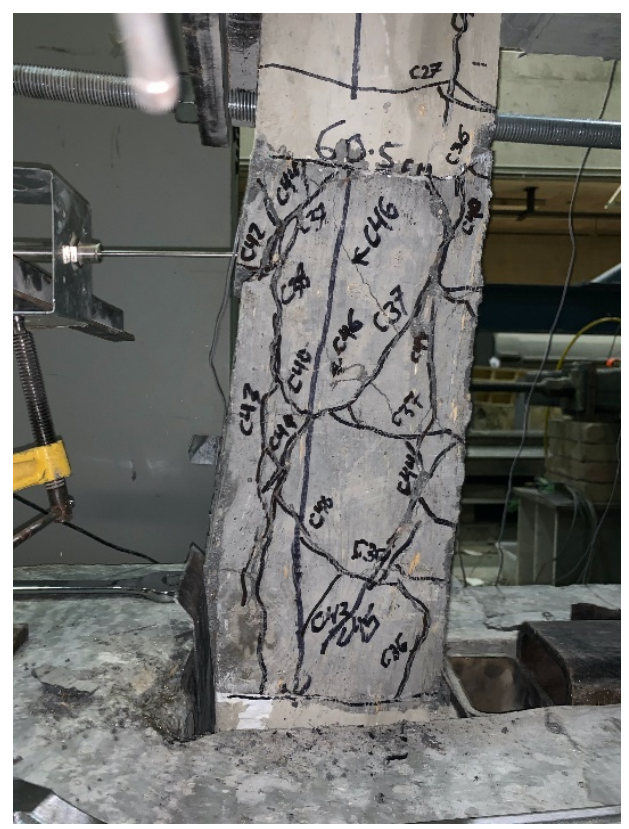

Figure 4.2: EF- Column deterioration

- It should be noted that minimal deterioration observed on the foundation ECC concrete

- At cycle 48, concrete crushing of the column occurred, further exposing of ties and rebar. Most crushing occurred as actuator adjusted from pushing to pulling.

- At cycle 48 , test terminated, load only reached $+57 \mathrm{kN}$ at this cycle, where maximum peak load was $+84.26 \mathrm{kN}$. 


\subsubsection{ECC Jointed Shear Critical Frame (ES)}

This ECC jointed specimen is shear critical with no shear (tie) reinforcement in the beam or column sections of ECC and SCC as seen in figure 4.3. Four ties are available in each ECC joint at critical locations. Test observations on the development of cracks and performance are outlined as follows:

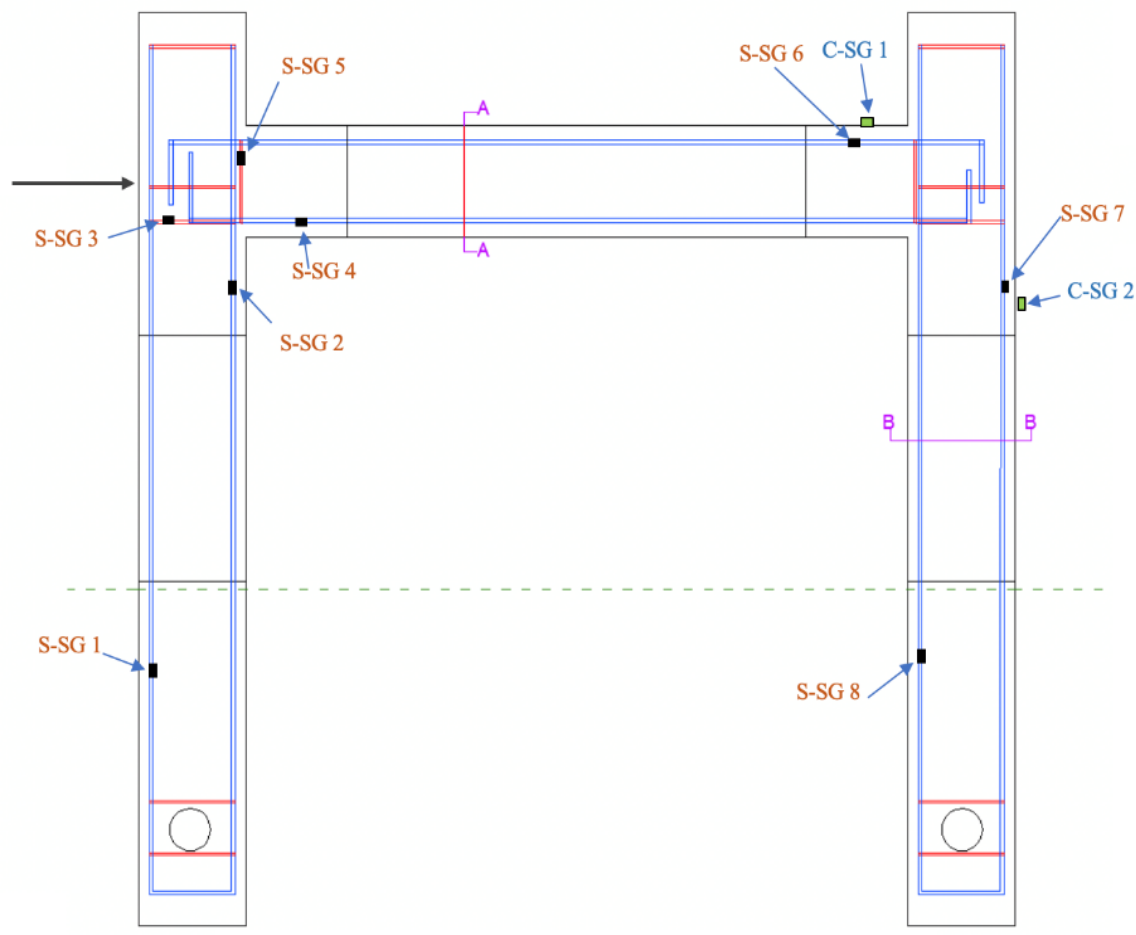

Figure 4.3: ES - Strain gauge locations

- During the initial cycles of the test, interface crack between the joint and column sections appeared as the loading increased.

- Minimal hairline cracks were developed throughout the joints until cycle 20 or so. Beam and column showed no sign of deterioration.

- At approximately cycle 28 , at a load of $+27.59 \mathrm{kN},-24.6 \mathrm{kN}$ a shear crack appeared in the interior column as shown in figure 4.4a. The shear crack migrated from the top of the column from the ECC column/SCC column interface to the bottom of the column. Afterwards, the shear crack penetrated the ECC portion of the column/joint at cycle 36 .

- The crack width between the SCC column and ECC portion of the column significantly differed. The crack within the SCC column was approximately $5 \mathrm{~mm}$ where it was around $2 \mathrm{~mm}$ in the ECC joint. This illustrated the tight crack width properties of ECC.

- Minimal flexure cracks started to appear in the midspan of the beam. 
- At cycle 36, identical shear crack appeared in the outer column, while at this point the crack width of the interior column's shear crack reached approximately $5 \mathrm{~mm}$.

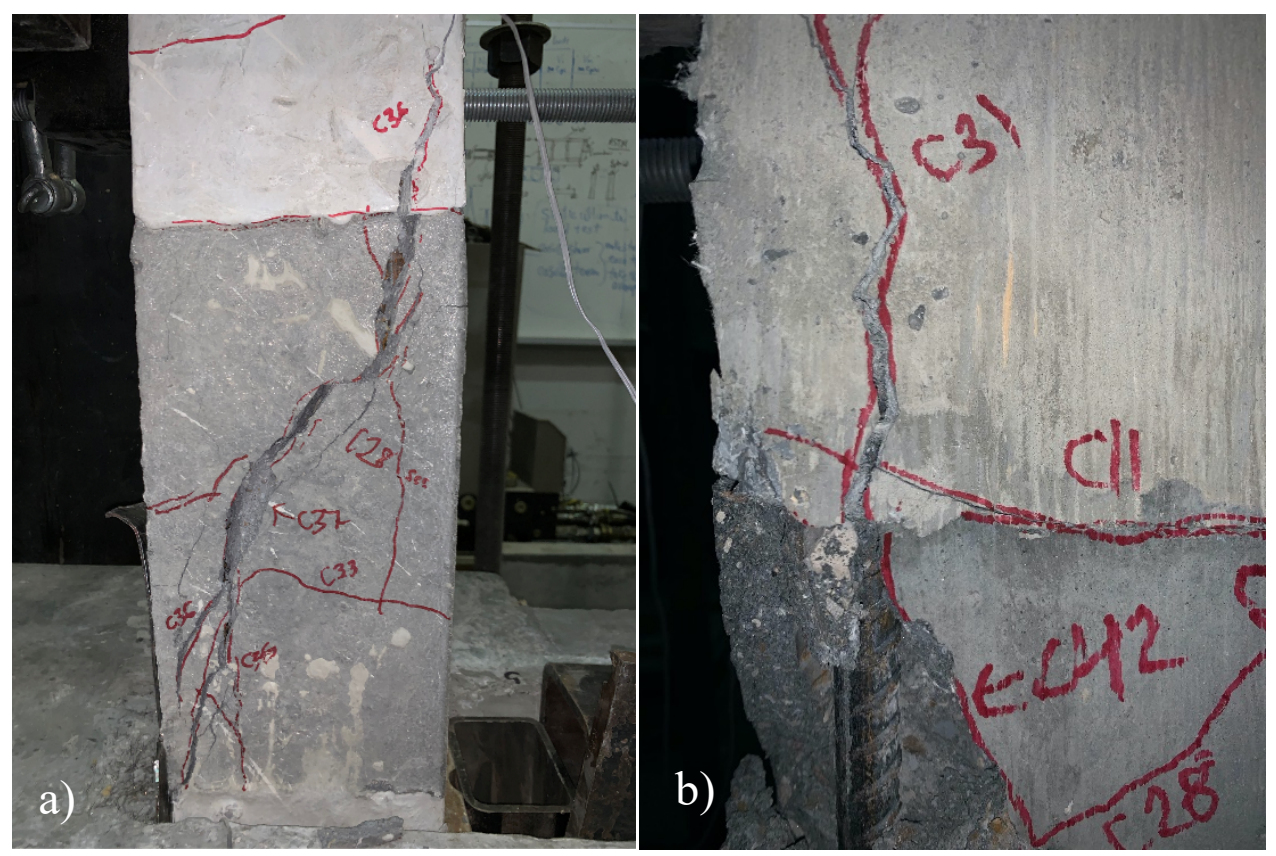

Figure 4.4: ES- a) Shear crack development in the SCC column, b) SCC column \& ECC joint crack width comparison

- Peak load was reached at $+42.898 \mathrm{kN},-39.46 \mathrm{kN}$ at a displacement of $+/-31.37 \mathrm{~mm}$. At this load column crushing and reinforcement exposure occurred.

- The action of pushing and pulling lead to bending of the reinforcement which, resulted in cracking and eventually lead to the crushing/spalling of the concrete. Figure 4.5 illustrates the high durability characteristics of the ECC material when compared to SCC. The ECC joint suffered hairline cracks other than the shear crack that propagated to the joint. Whereas, the SCC column went through complete crushing and spalling of the SCC.

- Figure $4.4 \mathrm{~b}$ shows a closeup of the shear crack that propagated from the column to the joint. The difference in crack width between the two materials was observed and the presence of PVA fiber in the ECC joint material was shown as well. 


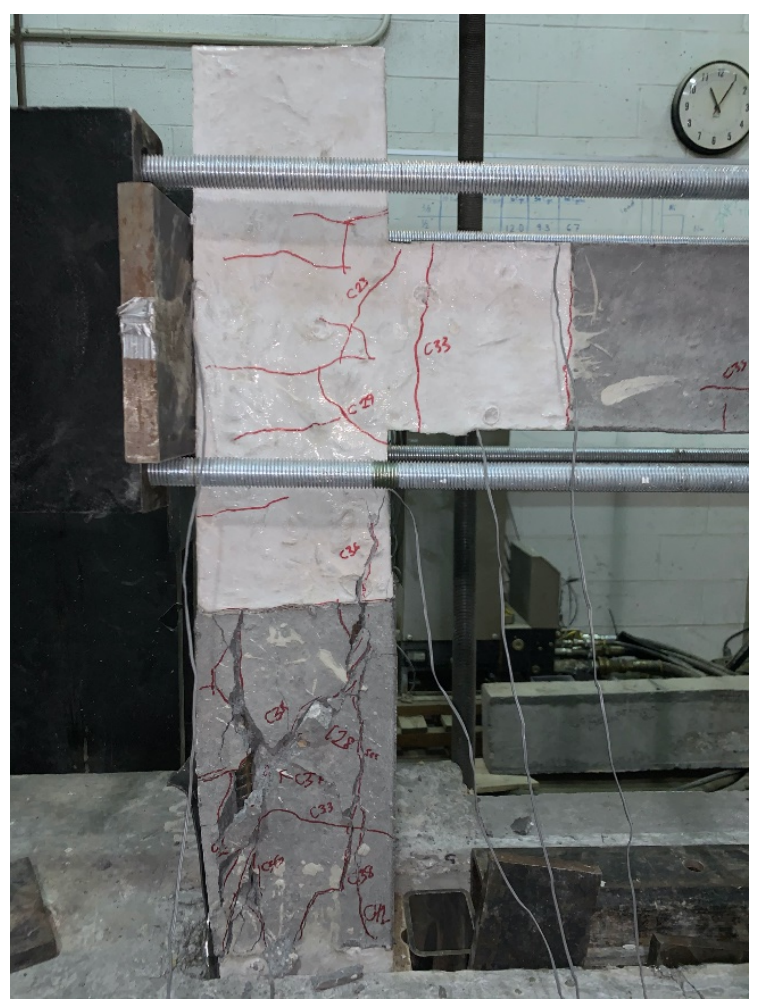

Figure 4.5: ES- shear critical deterioration comparison between SCC column \& ECC joint 


\subsubsection{UHPC Jointed Flexure Critical Frame (UF)}

Test observations for UF, which was a flexure critical UHPC jointed frame specimen are discussed. Figure 4.6 shows the strain gauge locations for reference to describe test observations. Test observations are as follows:

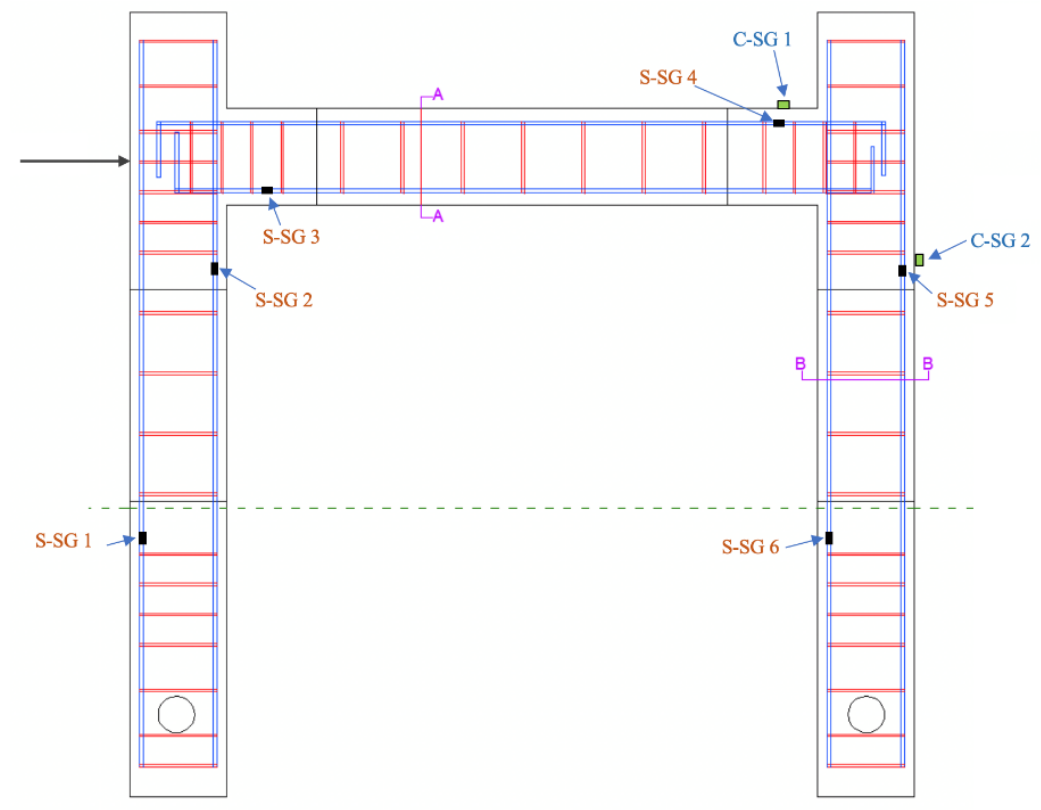

Figure 4.6: UF- Strain gauge locations

- In the initial cycles of this specimen, several hairline cracks appeared in the UHPC joints.

- At cycle 12, transverse cracking in the inner column appeared. Followed by transverse cracking in the inner face of the column in cycle 15. The cracks appeared over the tie reinforcement located in the column sections.

- At approximately cycle 22, transverse cracks appeared in the beam section.

- At cycle 29 , at a force of $+68.41 \mathrm{kN}$ shear cracks developed in both columns that initiated from the column-joint interface and migrated to the middle of the column section as seen in figure 4.7.

- Since approximately cycle 11 , no cracks had formed in the joints, all cracks afterwards occurred in the SCC column sections. No crack at the corner of the joint occurred in this UHPC flexure critical specimen compared to ECC jointed flexure critical frame (EF). 


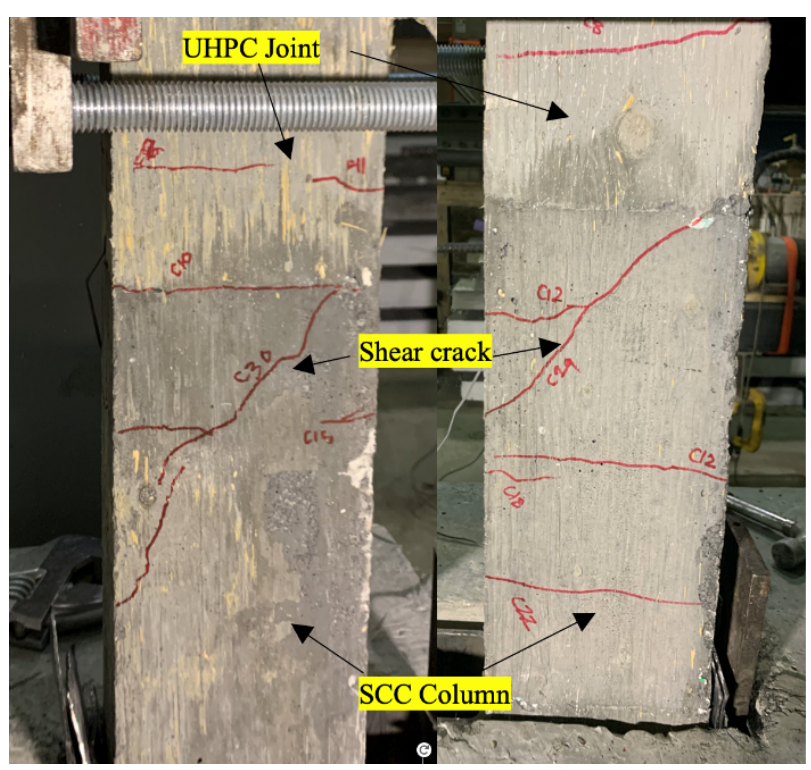

Figure 4.7: UF- Shear crack initiation in SCC columns

- At approximately cycle 36, S-SG 6 resulted in strains greater than $-2000 \mu \varepsilon$, therefore, it appeared that the longitudinal reinforcement yielded in compression at approximately a force of $+94 \mathrm{kN}$.

- At a force of $-69.74 \mathrm{kN}$, another shear crack formed in the hinge and intersected with the initial shear crack that formed as seen in figure 4.8 .

- In the column transverse cracks were hairline cracks, however, the shear cracks were slowly expanding and were at $1.5 \mathrm{~mm}$ thickness.

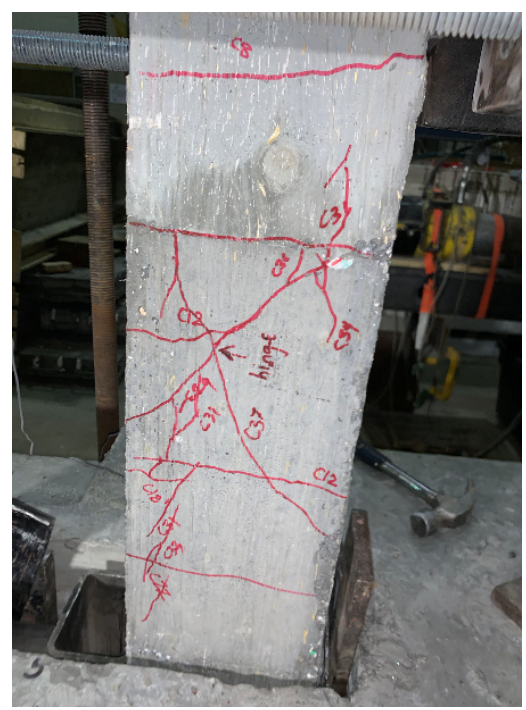

Figure 4.8: UF- Hinge formation in SCC column 
- At the peak load of $+122.06 \mathrm{kN}$ at cycle 40 , the outer UHPC joint and column failed. The inner face of the UHPC joint crushed and then crushing of the column followed immediately after. The concrete crushing resulted in exposing the tie reinforcement in the column, in addition to expanding the shear crack and exposing the longitudinal reinforcement, as well. Figure 4.9 shows the location of the UHPC joint failure where the inner face had crushed, exposing steel fibers. In addition, exposure of the tie reinforcement in the SCC column due to crushing in compression was observed.

- Shortly after, failure of the interior column followed.

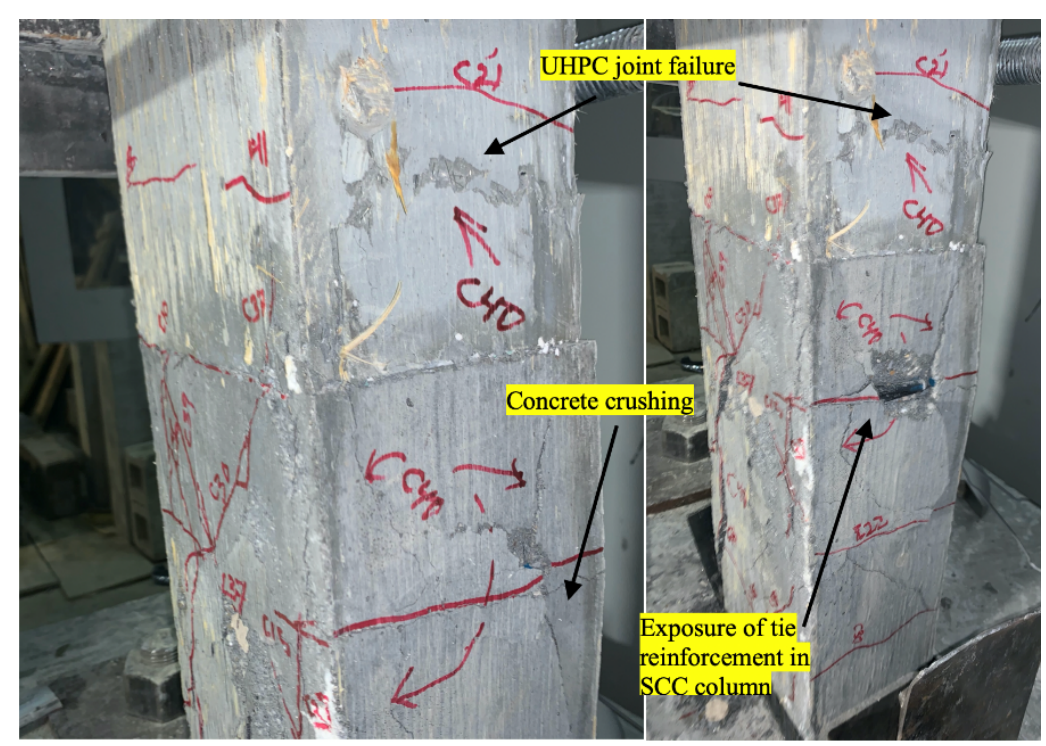

Figure 4.9: UF- UHPC joint and SCC column failure 


\subsubsection{UHPC Jointed Shear Critical Frame (US)}

Test observations for shear critical UHPC jointed frame (US) are discussed. Figure 4.10 presents the strain gauge locations for reference and the test observations are as follows:

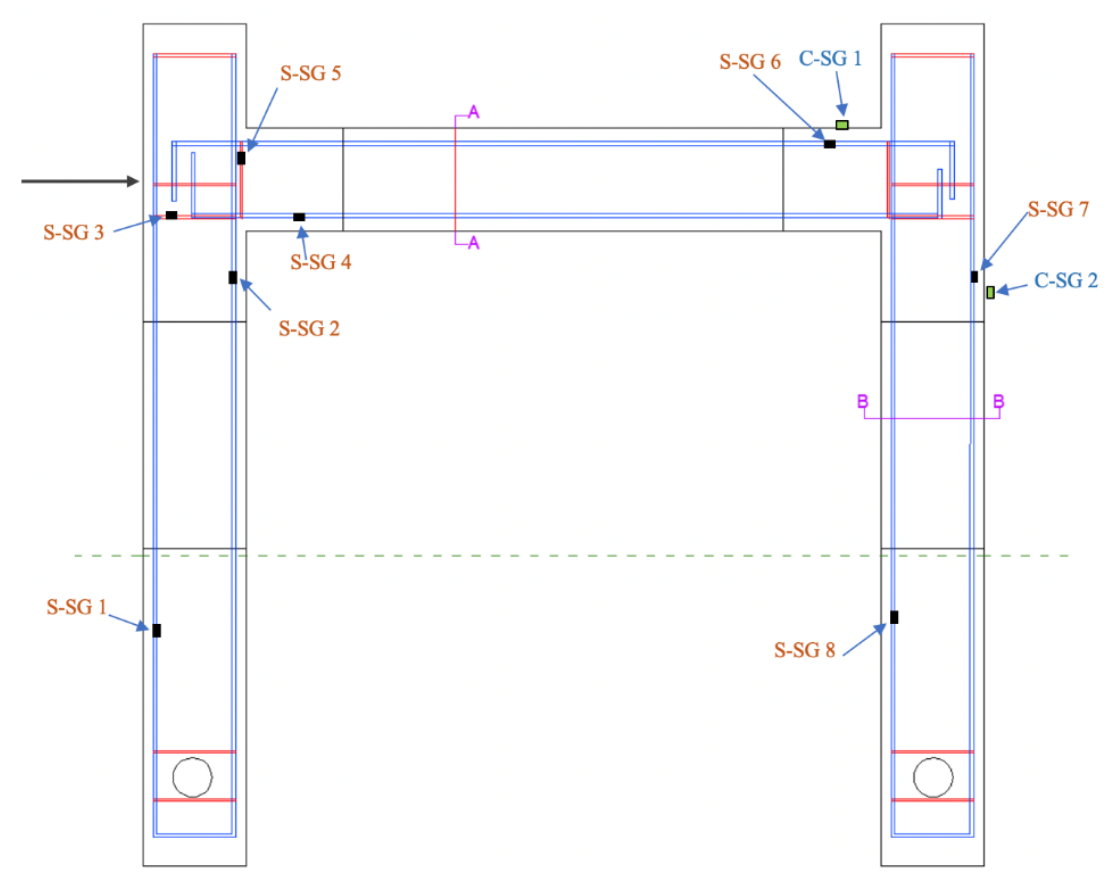

Figure 4.10: US- Strain gauge locations

- Up until cycle 19, hairline cracks appeared in the UHPC joint at loads reaching +16.8 $\mathrm{kN} /-10.8 \mathrm{kN}$

- At cycle 23, first crack in interior column appeared

- At cycle 29, transverse cracks appeared in the interior of the column in the inner face of the column. No cracks were observed in the outer column or beam until this point.

- At cycle 32, interior face of the outer column also developed transverse cracks at loads of $+34 \mathrm{kN} /-40 \mathrm{kN}$

- At cycle 34 , at $-41 \mathrm{kN}$ both columns developed an identical shear crack at the hinge location, which is approximately at the midpoint of the column. At this point, the failure of the specimen was considered through column failure. Several hairline cracks were only observed in the UHPC joints.

- The difference in crack width and crack locations between the UHPC joint and SCC column are illustrated in figure 4.11 . 


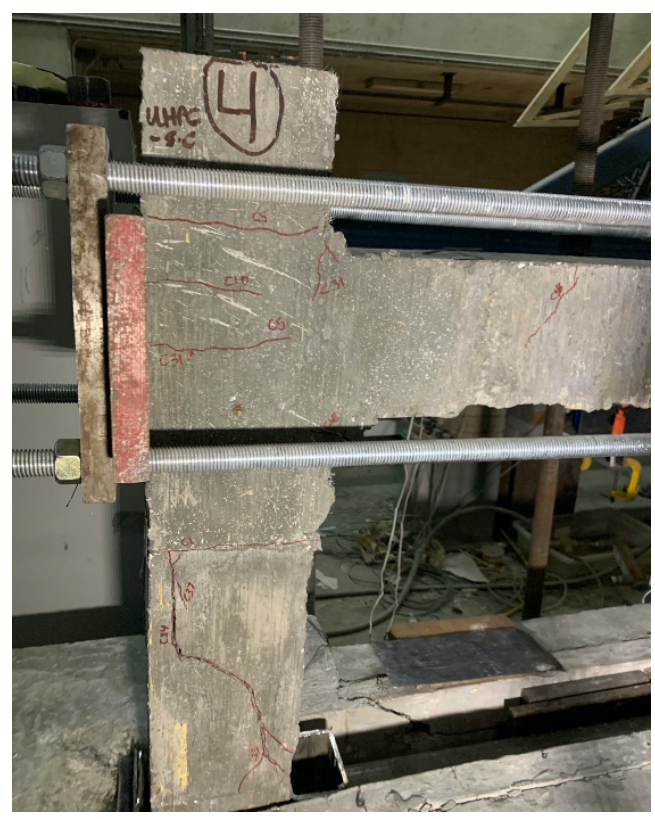

Figure 4.11: US- Shear critical UHPC joint- crack locations

- Figure 4.12 outlines the extent of deterioration that had occurred at the column portion of the SCC when the shear crack had appeared. It can be seen that minimal hairline cracks in the UHPC joint were present. Identical shear cracks at the hinge location in the column and transverse cracks in the column were observed.

- At approximately cycle 37 , at $-54 \mathrm{kN}$, a shear crack appeared in the beam, followed by the shear crack in the column penetrating the UHPC joint. The initial shear crack in the column developed a thicker crack width of approximately $1.5 \mathrm{~mm}$.

- Given that the SCC column had failed, testing still continued to obtain the ultimate load and to be able to continue to observe the performance of the UHPC joints.

- As load continued to increase, at approximately $+65 \mathrm{kN}$, in cycle 39 , further deterioration and crushing of the column occurred, as the crack width increased to $3 \mathrm{~mm}$ and steel fibers in the UHPC joint were now exposed as the crack from the column further migrated into the joint. 


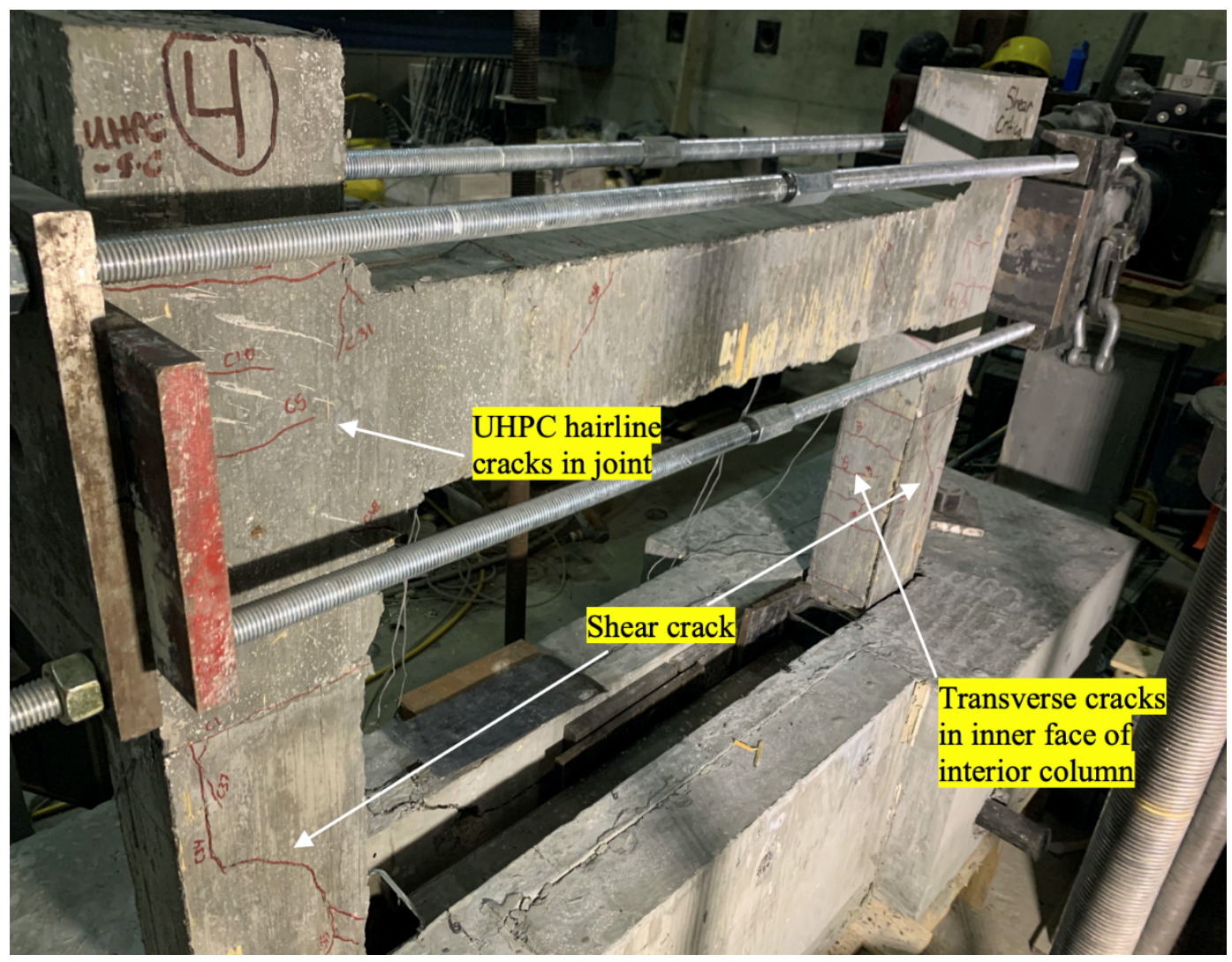

Figure 4.12: US- Shear crack location in columns at failure

- At approximately cycle 42 slippage at the interface of the interior UHPC joint and interior SCC column occurred as seen in figure 4.13. It can also be observed that the longitudinal reinforcement in the column is now exposed.

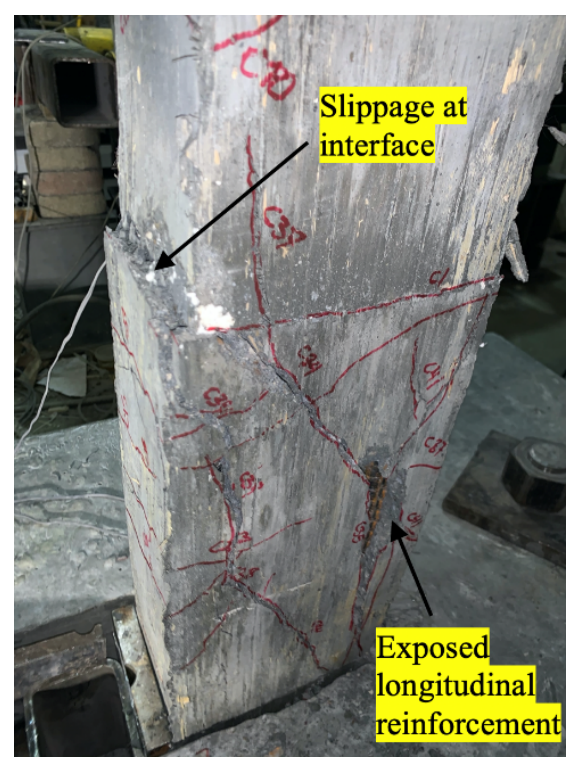

Figure 4.13: US- Slippage between the UHPC joint \& SCC column layers 
- Shortly after, due to concrete crushing the entire outer face of the interior column spalled off (figure 4.14a) fully exposing the longitudinal reinforcement.

- Figure 4.14b illustrates the difference in deterioration between the UHPC joint and SCC column. The high stiffness of UHPC was clearly illustrated.

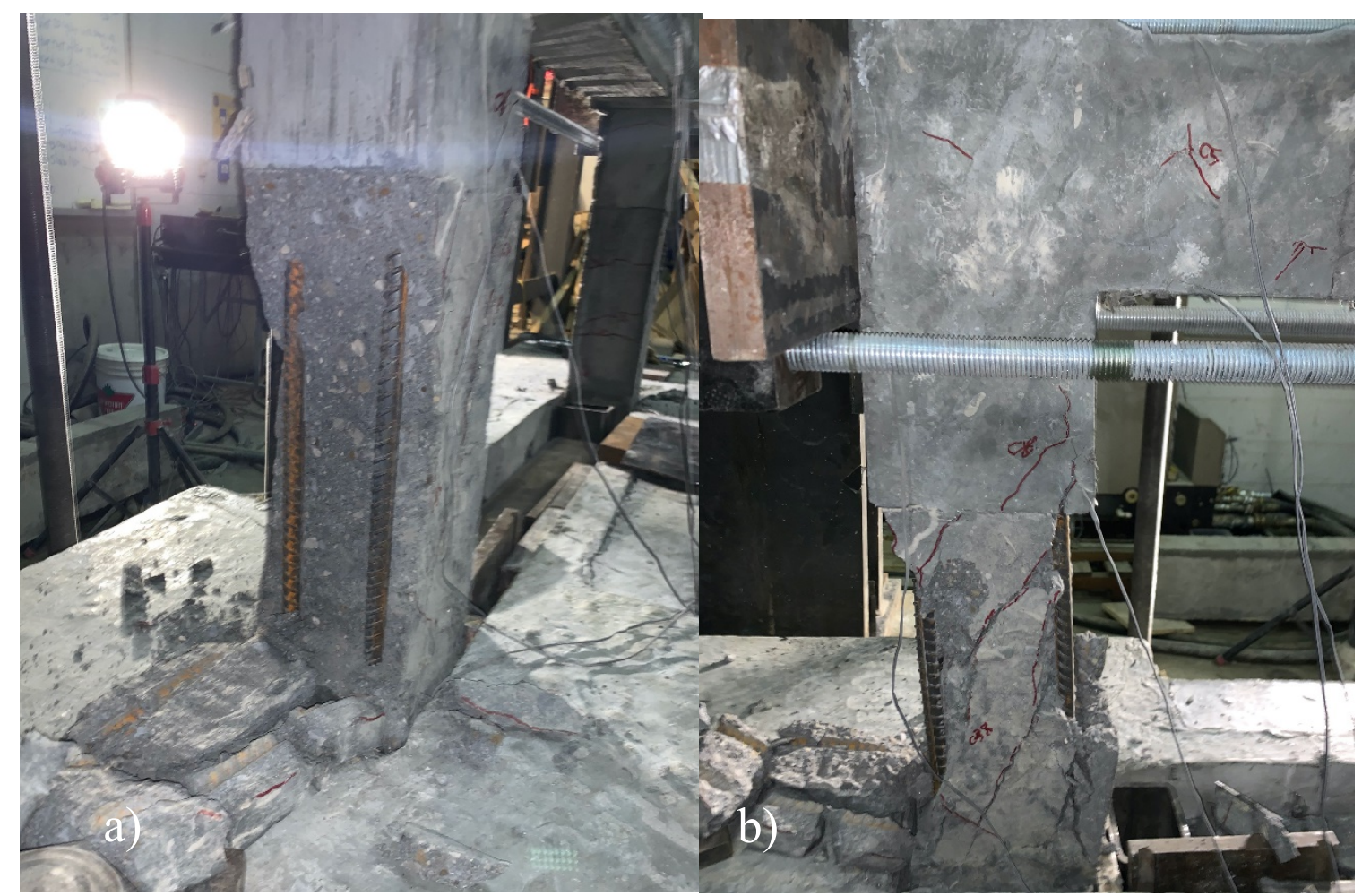

Figure 4.14: US- a) Concrete crushing of interior SCC column, b) UHPC joint \& SCC column deterioration comparison

- The peak load was observed at cycle 43 , at a load of $+67.84 \mathrm{kN}$. At this point the inner face of interior column crushed as well, exposing the longitudinal reinforcement from both sides. The hinge location in the column was measured at $16 \mathrm{~cm}$ from the top of the column, approximately at the midpoint of the column.

- The joint experienced mainly hairline cracks, with the exception of a $1.5 \mathrm{~mm}$ crack exposing the steel fibers, which was due to the bending of the longitudinal reinforcement as seen in figure 4.15. Therefore, the UHPC joint did fail eventually once the rebar managed to push crack the joint and push it out. 


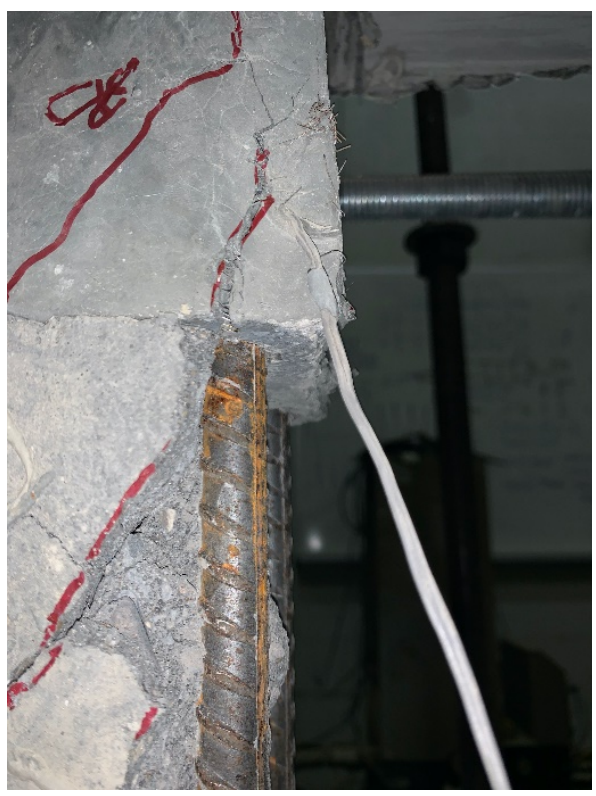

Figure 4.15: US- UHPC joint failure 


\subsection{Crack development and Propagation}

The crack development and propagation are discussed in this section, the average crack with measurements per specimen are illustrated as well. The cracks in the joints of the specimens were only measured and not in the columns or beam sections, since the focus of this research was to analyze the performance of the joint section of the beam-column frame. Crack width measurements will allow for better understanding of the crack width behaviour, maximum crack width and average crack width per specimen per joint of the different materials used (ECC and UHPC). The crack width measurement was measured using a crack scope and hairline cracks were taken to be $0.05 \mathrm{~mm}$ thick. The crack widths of the inner joint and outer joint were measured separately to allow for comparison and analysis on the deterioration occurring at the different joints. The inner joint refers to the joint on the side of the actuator where the load is being applied and the outer joint refers to the joint on the opposite side of the actuator. Note: "1- $3 \mathrm{~mm}$ " crack refers to observing one crack that is $3 \mathrm{~mm}$ wide, and "34- $0.05 \mathrm{~mm}$ ", refers to 34 hairline cracks measured.

\subsubsection{ECC Jointed Flexure Critical Frame (EF)}

Number of cracks and crack width for this frame are described as follows:

- Joint 1 (on side of actuator)

○ $1-3 \mathrm{~mm}$ crack

○ $1-1.5 \mathrm{~mm}$ crack

○ $1-1 \mathrm{~mm}$ crack

○ $34-0.05 \mathrm{~mm}$ (hairline cracks)

- Average Crack width (Joint 1) $=\frac{(1 \times 1 \mathrm{~mm})+(34 \times 0.05 \mathrm{~mm})}{37}=0.194 \mathrm{~mm}$

- Joint 2 (opposite side of actuator) shown in figure 4.16.

- 2 - 2 mm crack

○ $3-1.5 \mathrm{~mm}$ crack

○ $25-0.05 \mathrm{~mm}$ (hairline cracks)

- Average Crack width (Joint 2) $=\frac{(2 \times 2 \mathrm{~mm})+(3 \times 1.5 \mathrm{~mm})+(25 \times 0.05 \mathrm{~mm})}{30}=0.325 \mathrm{~mm}$ 


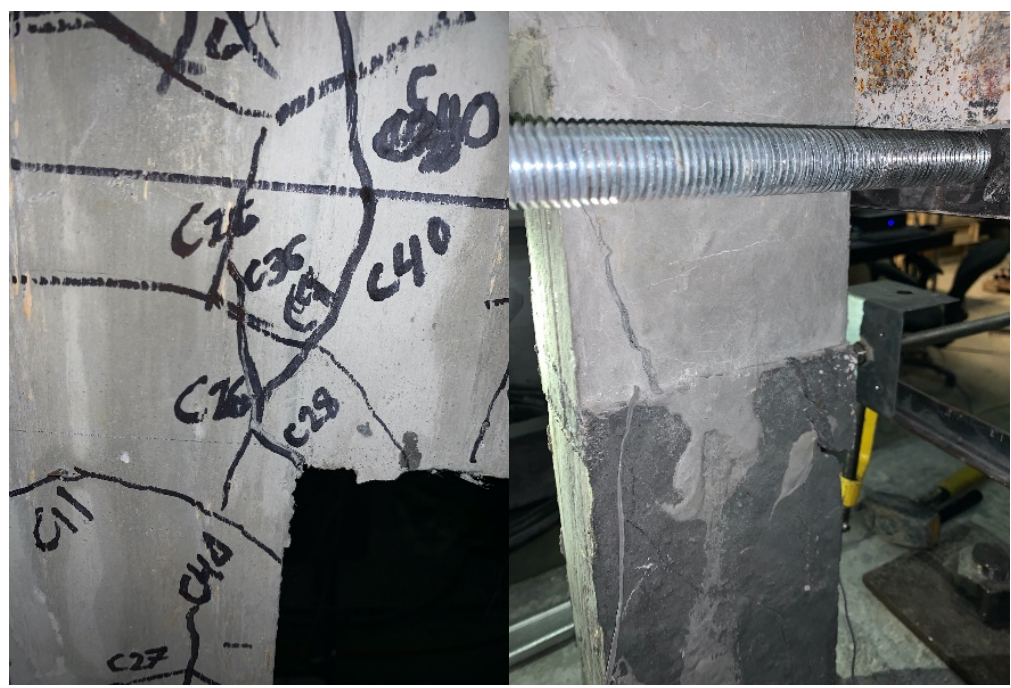

Figure 4.16: EF- Joint 2 crack development

Therefore, the maximum crack width observed in the ECC joint of EF was $3 \mathrm{~mm}$.

\subsubsection{ECC Jointed Shear Critical Frame (ES)}

Number of cracks and crack width for this frame are described as follows:

- Joint 1 (on side of actuator as seen in figure 4.17)

○ 1- $5 \mathrm{~mm}$ crack extended from column up to joint

○ $17-0.05 \mathrm{~mm}$ (hairline cracks)

- Average Crack width (Joint 1) $=\frac{(1 \times 5 \mathrm{~mm})+(17 \times 0.05 \mathrm{~mm})}{18}=0.33 \mathrm{~mm}$

- Joint 2 (opposite side of actuator)

○ 1 - 7 mm crack extended from column up to joint

○ $10-0.05 \mathrm{~mm}$ (hairline cracks)

- Average Crack width (Joint 2$)=\frac{(1 \times 7 \mathrm{~mm})+(10 \times 0.05 \mathrm{~mm})}{11}=0.68 \mathrm{~mm}$

Therefore, for ES, a maximum crack width of $7 \mathrm{~mm}$ was observed, which originated from the top of the SCC portion of the column due to the formation of the shear crack. 


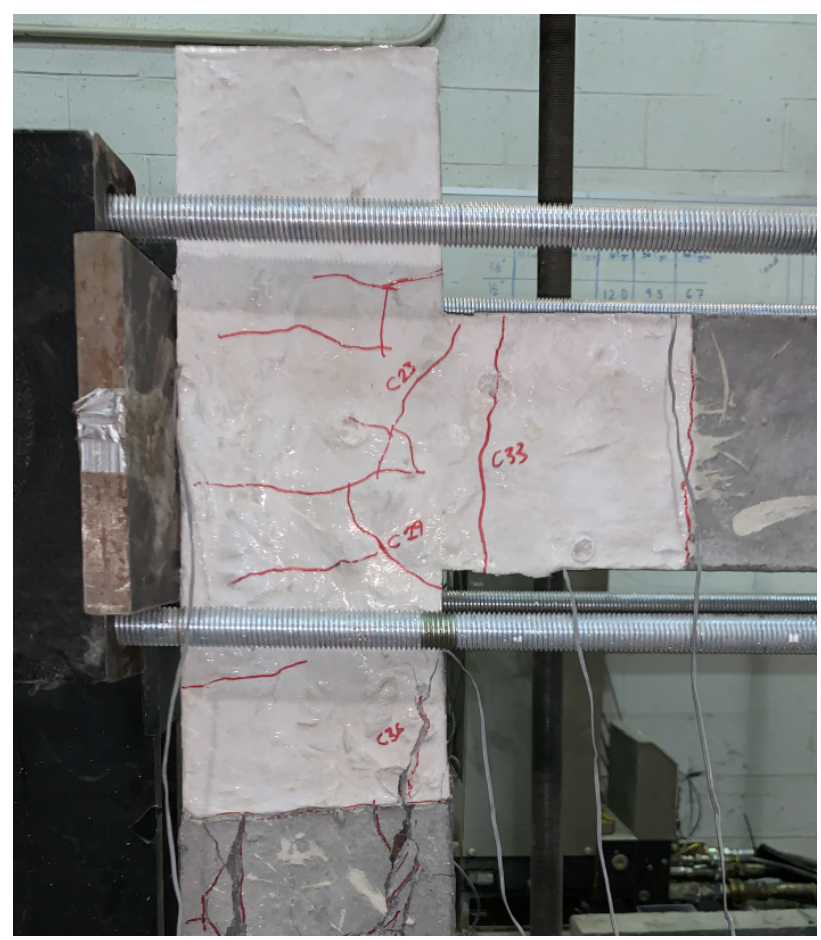

Figure 4.17: ES- Inner joint crack development

\subsubsection{UHPC Jointed Flexure Critical Frame (UF)}

Number of cracks and crack width for this frame are described as follows:

Joint 1 (on side of actuator- Figure 4.18- Right)

○ 9- $0.05 \mathrm{~mm}$ cracks

○ $1-1.5 \mathrm{~mm}$ crack at joint/column.

- Average Crack width (Joint 1) $=\frac{(1 \times 1.5 \mathrm{~mm})+(9 \times 0.05 \mathrm{~mm})}{10}=0.195 \mathrm{~mm}$

- Joint 2 (opposite side of actuator- Figure 4.18- Left)

○ $4-0.05 \mathrm{~mm}$ cracks

- $\quad$ Average Crack width (Joint 2) $=0.05 \mathrm{~mm}$

The maximum crack width observed for this specimen was $1.5 \mathrm{~mm}$ - the smallest crack width observed. This crack formed near the UHPC and SCC column interface, which was a continuation of the shear crack that originated in the SCC portion of the column. 


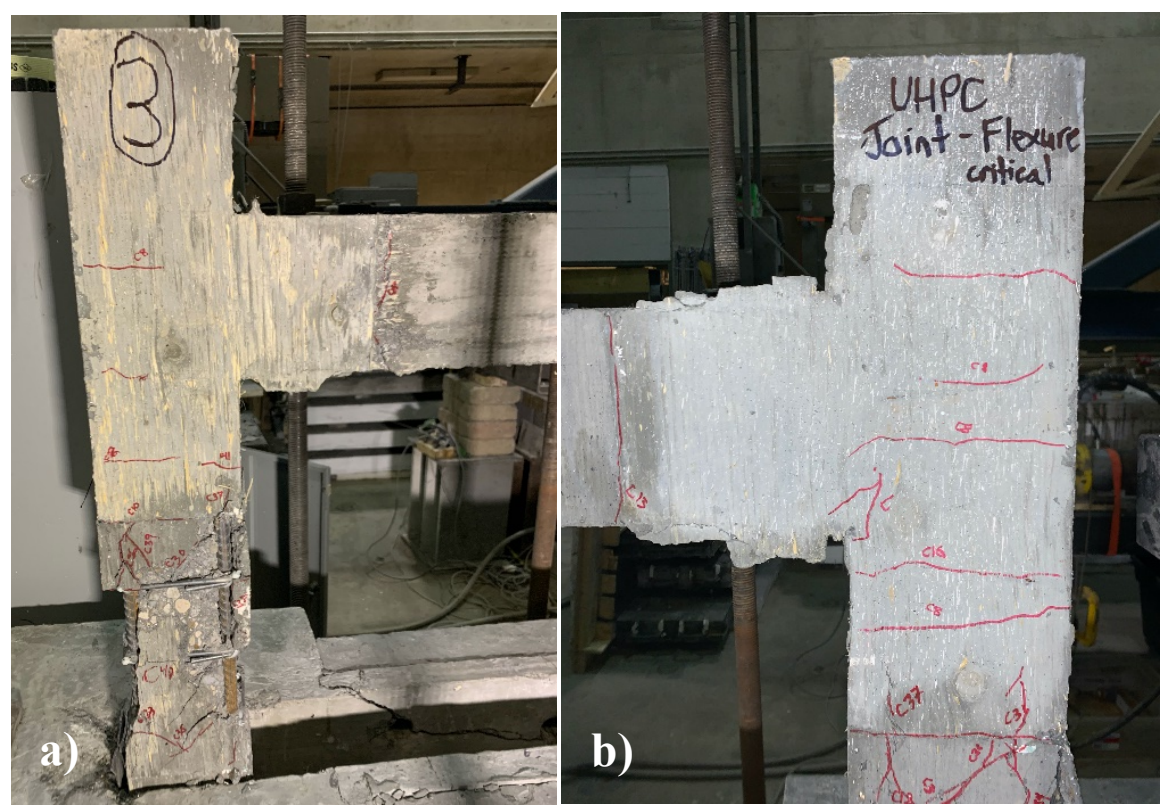

Figure 4.18: UF- a) Outer joint, b) Inner joint's crack development

\subsubsection{UHPC Jointed Shear Critical Frame (US)}

Number of cracks and crack width for this frame are described as follows:

- Joint 1 (on side of actuator)

○ 1 - $1.5 \mathrm{~mm}$ crack extended from column up to joint

○ $9-0.05 \mathrm{~mm}$ (hairline cracks)

- Average Crack width (Joint 1) $=\frac{(1 \times 1.5 \mathrm{~mm})+(9 \times 0.05 \mathrm{~mm})}{10}=0.195 \mathrm{~mm}$

- Joint 2 (opposite side of actuator)

○ $6-0.05 \mathrm{~mm}$ hairline cracks

- Average Crack width (Joint 2) $=\frac{(6 \times 0.05 \mathrm{~mm})}{6}=0.05 \mathrm{~mm}$

The maximum crack width observed for US was $1.5 \mathrm{~mm}$, the same maximum crack width observed in the flexure critical specimen. 4.19 illustrates the crack development in the outer and inner joint. 

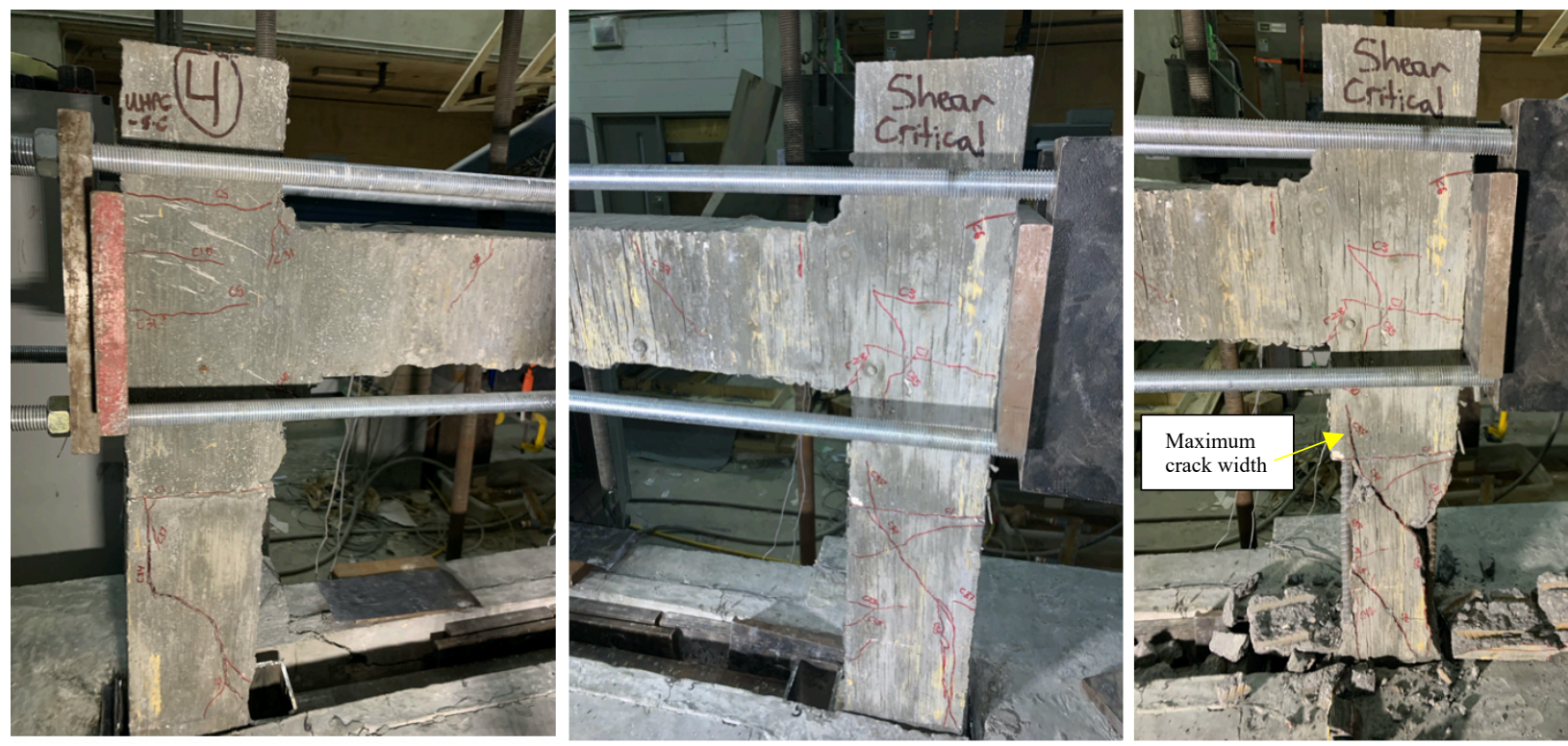

Figure 4.19: US- Crack development

Table 4.1 compares the average crack width per joint for the two flexural critical specimens (EF and UF) and two shear critical specimen (ES and US).

Table 4.1: Average crack width of frame specimens

\begin{tabular}{|l|l|l|}
\hline \multirow{2}{*}{ Flexural Critical Specimens } & \multicolumn{2}{|c|}{ Average Crack width } \\
\cline { 2 - 3 } & EF: ECC Joint & UF: UHPC Joint \\
\hline & Joint $1=0.194 \mathrm{~mm}$ & $\begin{array}{l}\text { Joint } 1=0.195 \mathrm{~mm} \\
\text { Joint } 2=0.05 \mathrm{~mm}\end{array}$ \\
\hline & Joint $2=0.325 \mathrm{~mm}$ & US: UHPC Joint \\
\hline Shear Critical Specimens & ES: ECC joint & $\begin{array}{l}\text { Joint } 1=0.195 \mathrm{~mm} \\
\text { Joint } 2=0.05 \mathrm{~mm}\end{array}$ \\
\hline
\end{tabular}

Note: Joint 1 refers to the inner joint on the side of the actuator where the load is being applied, and Joint 2 refers to the outer joint.

The average crack width observed between the two flexure critical specimens and the shear critical specimens is analyzed. For the flexure critical specimens, the ECC joint had a higher average crack width, which was mainly observed in joint 2. Although ECC has tight crack width properties, in UHPC the use of steel fibers and silica fume resulted in controlling crack propagation and reducing 
the number and size of the cracks present. This was evident for example in the flexure critical specimen, by looking at joint 2, the UHPC had only 4 cracks, whereas the ECC flexure critical specimen had approximately 37 measured cracks. This was also evident in the maximum crack width observed between the two specimens, in which a maximum crack width of $1.5 \mathrm{~mm}$ was observed in the UHPC FC specimen compared to crack width of $7 \mathrm{~mm}$ observed in the ECC specimen. For shear critical specimen, the ECC joint had higher average crack width measured in its joints compared to its flexure critical counterpart. This can be attributed to the lower loadcarrying capacity of the frame due to the lack of shear reinforcement, which controls crack propagation. It was observed that minimal changes in average crack width occurred between the flexure critical and shear critical UHPC specimens. 


\subsection{ECC and UHPC Jointed Flexural Critical Frames Comparison}

This section compares the force vs. displacement response and steel/concrete strain development in flexure critical frames: EF and UF. The hysteretic load-deflection responses for both flexure critical frames are shown in figure 4.20. The cycles shown are the first cycle of each 3 repeated cycles. For example, EF (Fig. 4.20a) had 49 cycles in total, each 3 cycles is when the cycle increases and fatigue loading increases. Looking at the charts, ECC had a peak load of $84.23 \mathrm{kN}$ at cycle 16, whereas UHPC had a peak load of $112.05 \mathrm{kN}$ at cycle 14 (Fig. 4.20b). It is clear that UHPC had a higher capacity than ECC as expected, which portrays the high stiffness and compressive strength properties of UHPC. However, the high ductility properties of ECC can be clearly seen by the high displacement EF managed to achieve. At peak load, the ECC displacement is $31 \mathrm{~mm}$, when compared to $20 \mathrm{~mm}$ displacement for the UHPC joint, which is due to ECC's high strain hardening and tensile capacity properties. The peak load for the ECC joint was achieved during approximately 166 minutes (2.7 hours), however, the UHPC joint achieved peak load at 106 minutes (1.7 hours). This illustrates the high stiffness/low ductility of the UHPC joint compared to the lower stiffness but higher ductility properties of the ECC joint.
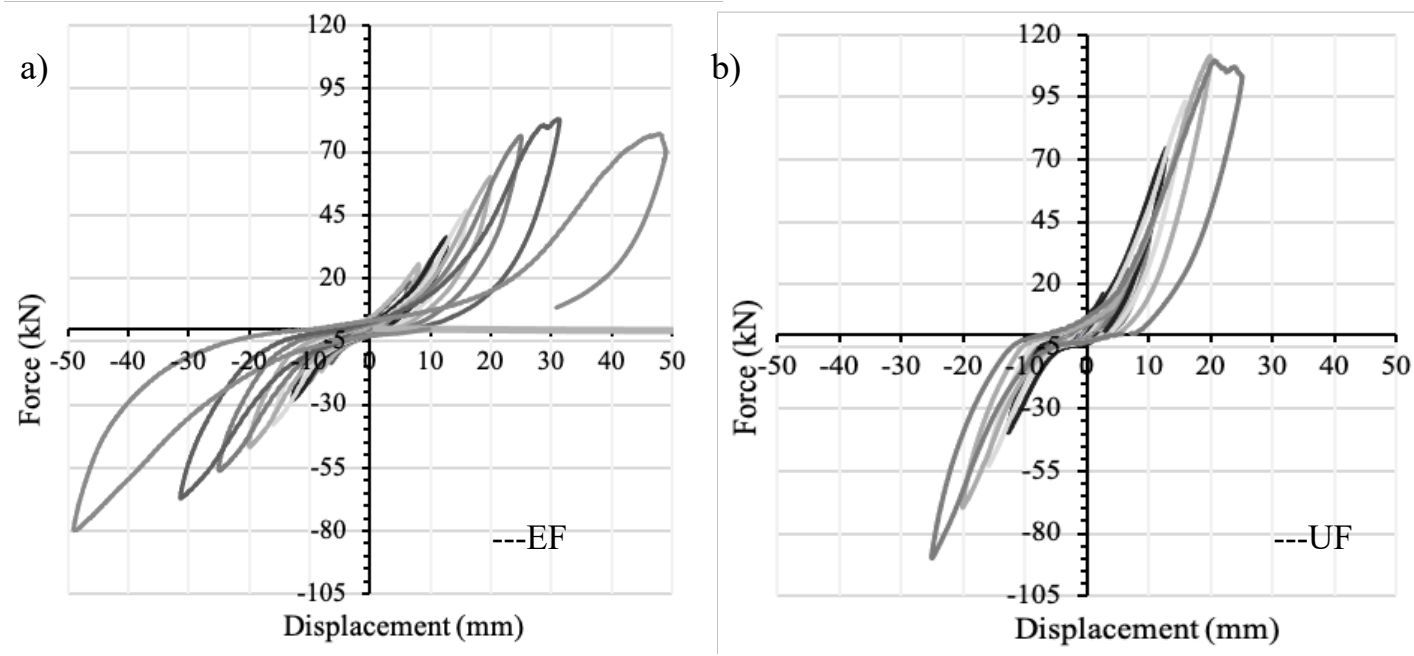

Figure 4.20: Force vs. Displacement curve for a) EF, \& b) UF 


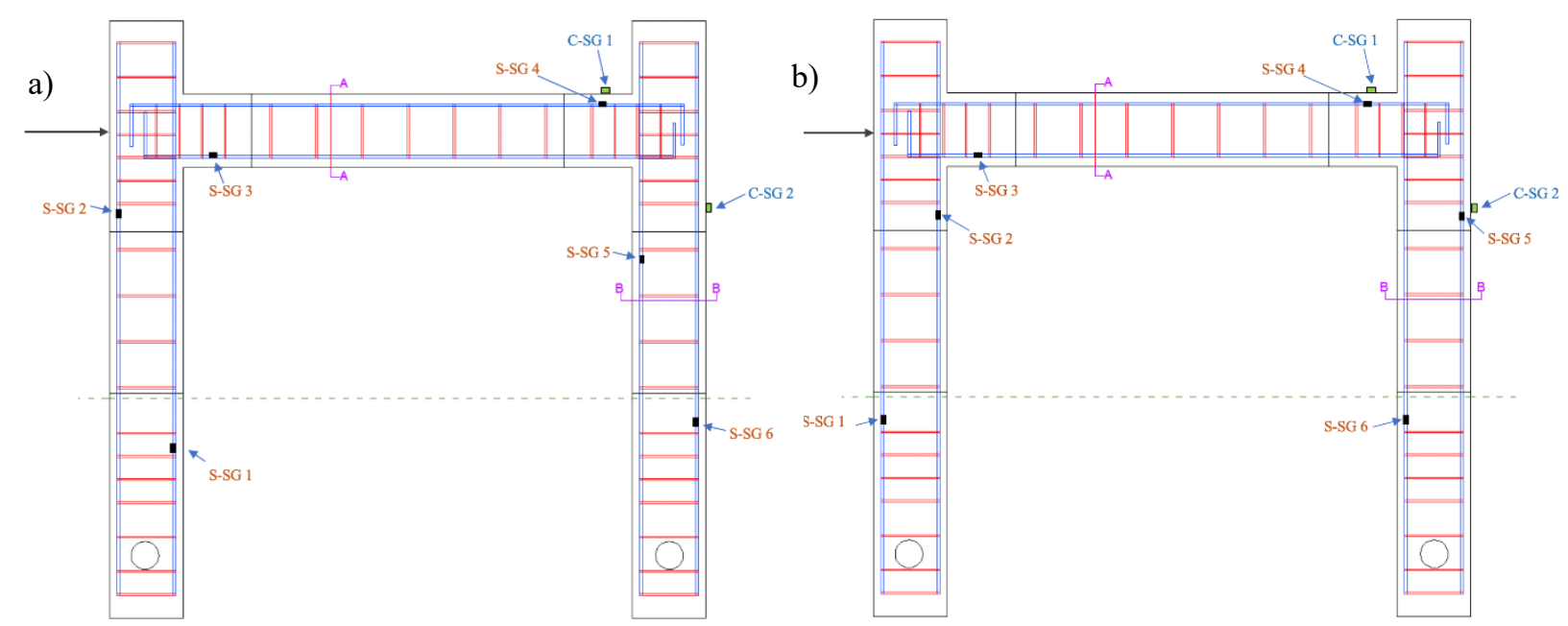

Figure 4.21: Steel and Concrete strain gauge location of a) EF, \& b) UF

Each flexure critical specimen (EF and UF) had two concrete strain gauges and six steel strain gauges for the flexure critical specimen. For the purpose of this analysis, half the frames strain gauges will be analyzed due to symmetry. Please note that concrete strain gauge 1 is noted as $\mathrm{C}$ SG 1, and steel strain gauge 1 is noted as S-SG 1. Figure 4.21 illustrates the steel and concrete strain gauge location of the flexure critical samples for reference in this section. Figure 4.22 shows the force vs. strain data for C-SG 1, which is located on the top of the ECC/UHPC joint, in the joint opposite of the actuator. It can be seen from the figure that EF reached a maximum strain of approximately $3600 \mu \varepsilon$ at peak load (Fig. 4.22a), whereas UF reached approximately $1000 \mu \varepsilon$ at peak load (Fig. 4.22b). This portrays the high tensile capacity and ductility of the ECC concrete as observed previously. In addition, the residual strain in the ECC specimen is higher than the UHPC specimen.
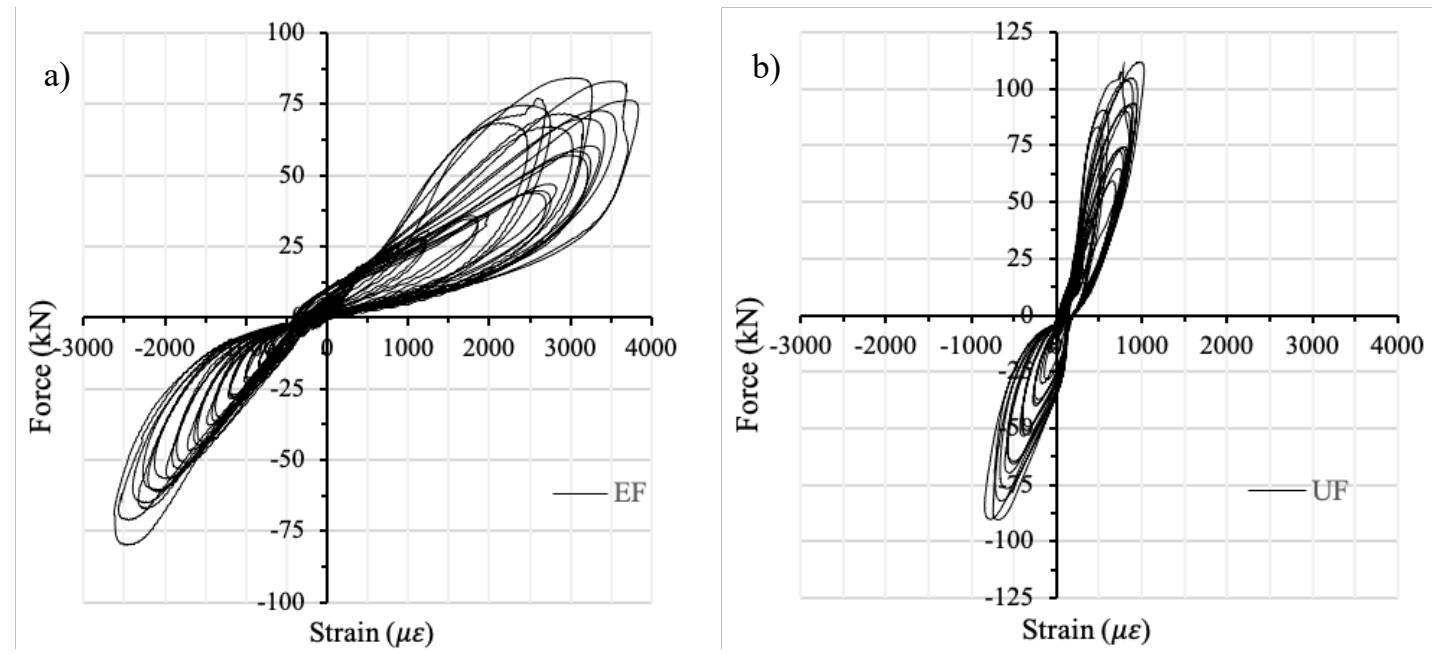

Figure 4.22: Force vs. C-SG 1, a) EF \& b) UF 

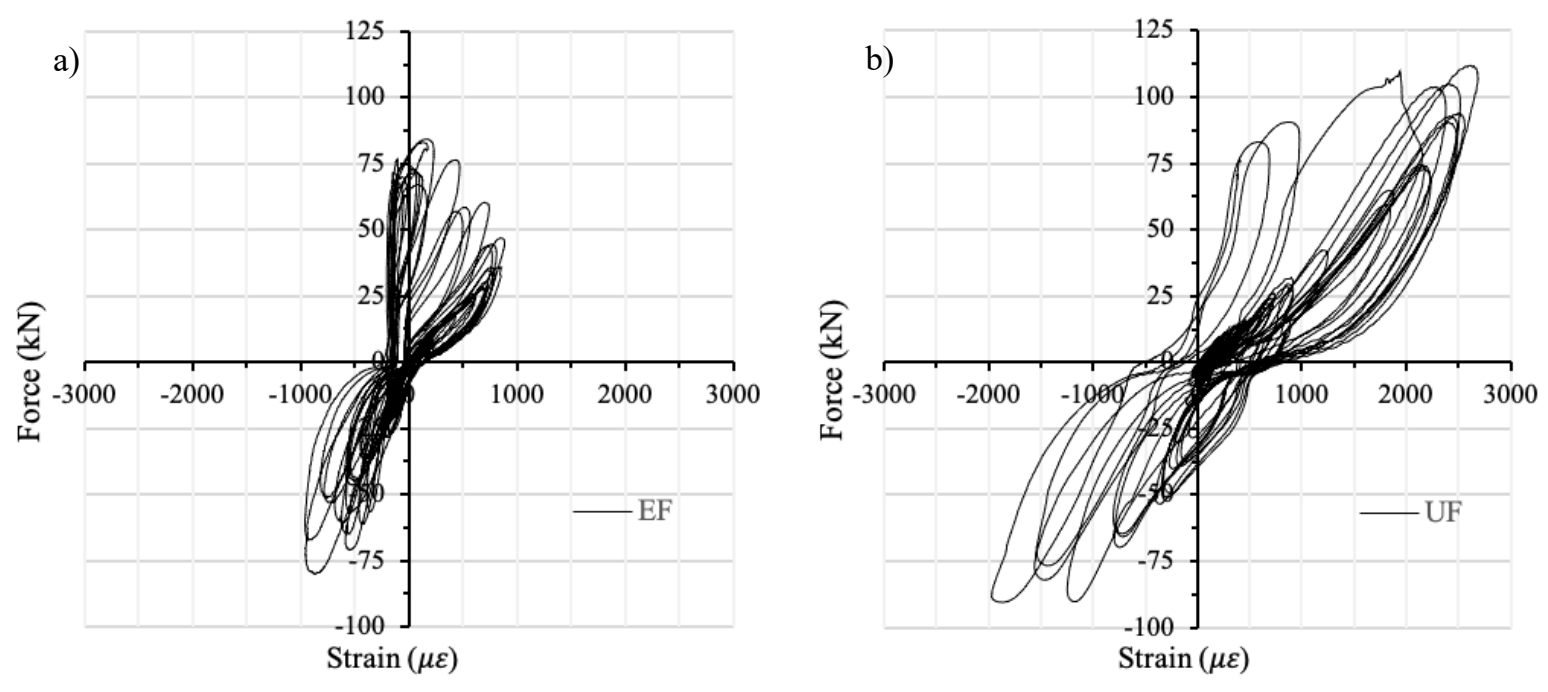

Figure 4.23: Force vs. C-SG 2, a) EF \& b) UF

Figure 4.23 presents the load vs. C-SG 2 data for both flexure critical specimen. C-SG 2 is located in the column portion of the ECC/UHPC joint, it is located on the outside of the joint, on top of the column-joint interface. This strain gauge allows for the adequate analyses on the deterioration occurring in the ECC portion of the column. EF reached a strain of approximately $800 \mu \varepsilon$, in the elastic region of the specimen, afterwards, stiffness degradation occurs, and the specimen reached peak load at $170 \mu \varepsilon$ (Fig. 4.23a). After reaching peak load, the strain reduced from tension to compression due to concrete crushing of the SCC column and spalling of the region. For the UHPC specimen, a high stiffness is observed due to the low stiffness degradation of the hysteretic loop. After peak load it can be seen that a large jump in strain occurs, which is when the UHPC portion of the column and the SCC column ruptured as discussed in the test observations section earlier in the report. The strain reached at peak load for the UHPC joint is at approximately $2700 \mu \varepsilon$ (Fig. $4.23 b)$.

Now looking at steel strain gauges, figure 4.24 shows the force vs. S-SG 1 data for both ECC and UHPC flexure critical joints. S-SG 1 is located in the flexural reinforcement of the joint portion 

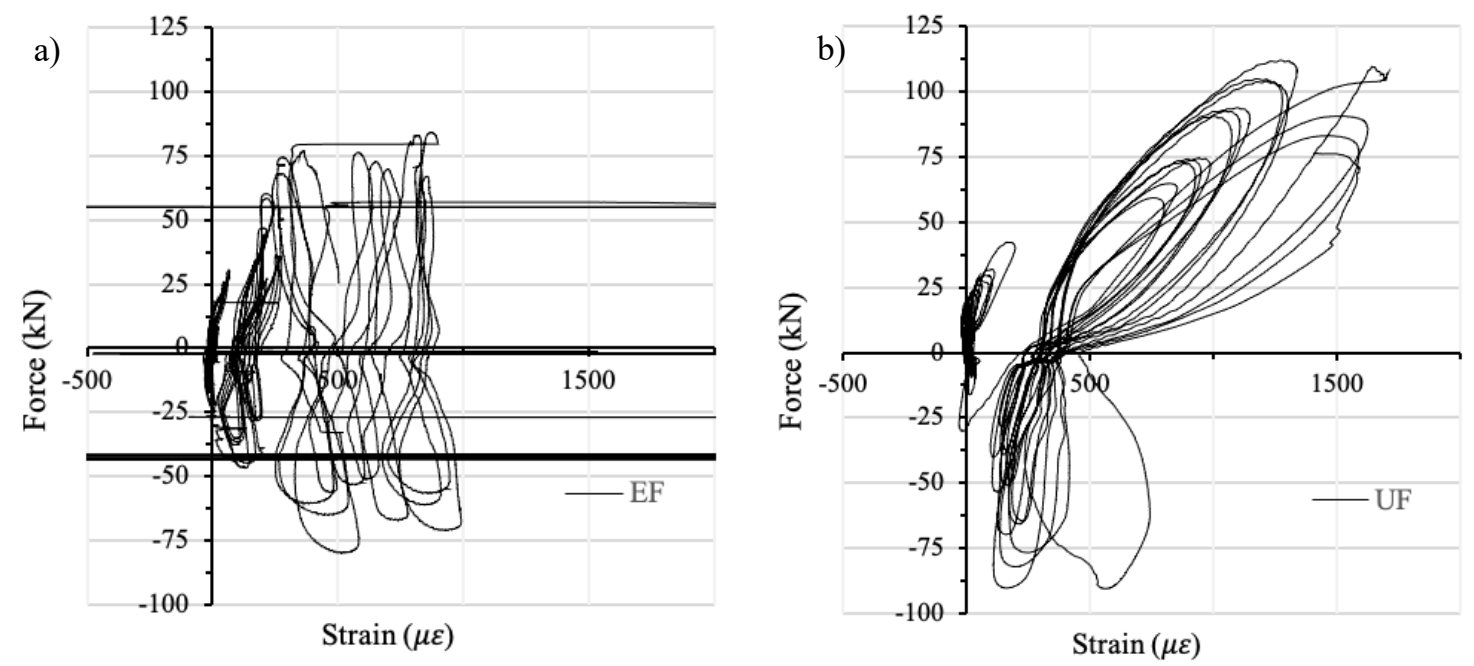

Figure 4.24: Force vs. S-SG 1, a) EF \& b) UF

located in the foundation. Given that the foundation is fixed, tension/compression cycles is just observed throughout the fatigue cycles. Looking at the ECC joint (Fig. 4.24a), the strain kept increasing as the load kept increasing due to the large deformations of the column, that resulted in the bending of the flexural reinforcement, thus increasing the strain. Now looking at the UHPC joint (Fig. 4.24b), residual strain is observed initially and then during pulling action, a strain jump is observed due to crack formation in that area as mentioned in the test observations.

The data for S-SG 4 is provided in figure 4.25, in which this steel strain gauge is located in the top flexural reinforcement of the beam section located in the joint opposite the actuator (point of loading). For the ECC specimen (Fig. 4.25a), the strain gauge started with a low residual strain (+$150 \mu \varepsilon$ ), afterward, as the load kept increasing, after peak load was reached, a permanent strain
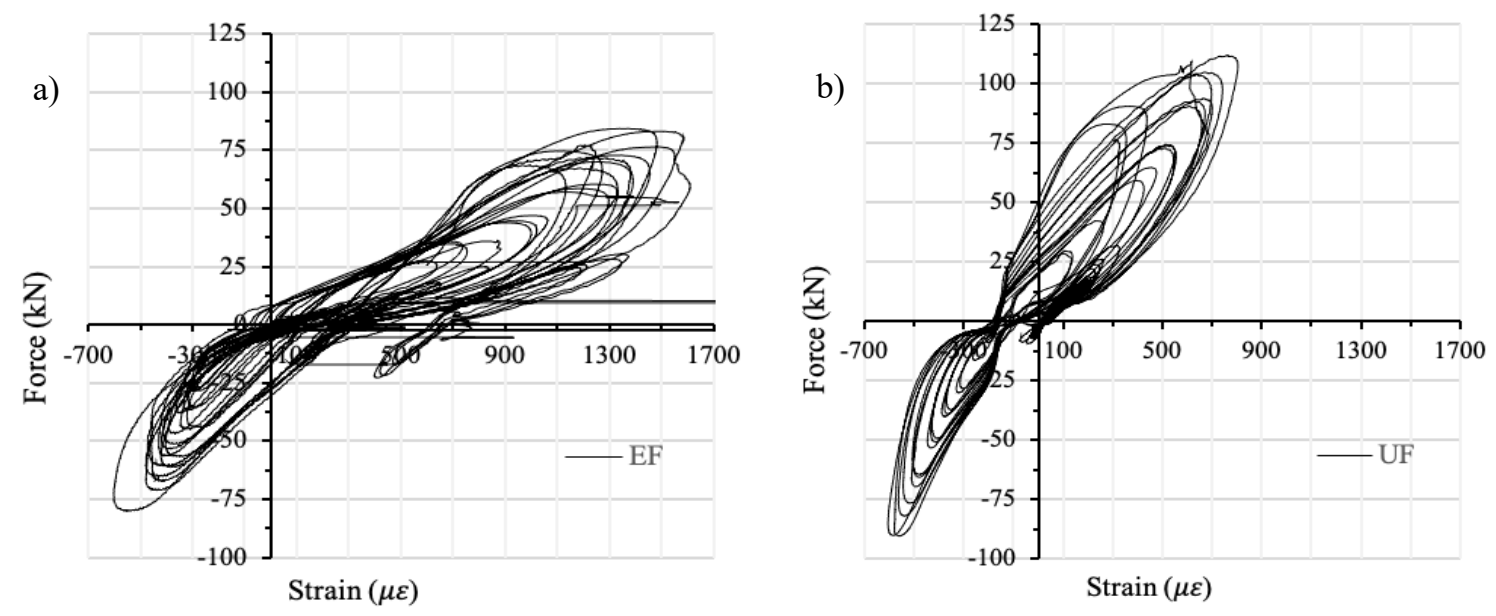

Figure 4.25: Force vs. S-SG 4, a) EF \& b) UF 
deformation is observed since the hysteretic loop reformed around $600 \mu \varepsilon$ with significant stiffness degradation afterwards. This was a result of the large pushing force that resulted in high tensile strain, in which after the peak load damage to the ECC joint had occurred, resulting in the plastic response. Now looking at the UHPC joint (Fig. 4.25b), a similar trend occurred in this strain gauge as well. The loop reformed after peak load was reached and reformed with high stiffness degradation afterwards. The peak load resulted in a strain of $1500 \mu \varepsilon$ in the ECC specimen, when compared to approximately to $800 \mu \varepsilon$ in the UHPC specimen. The smaller strain observed at peak load for the UHPC is related to the high stiffness of the joint, which prevents large deformations
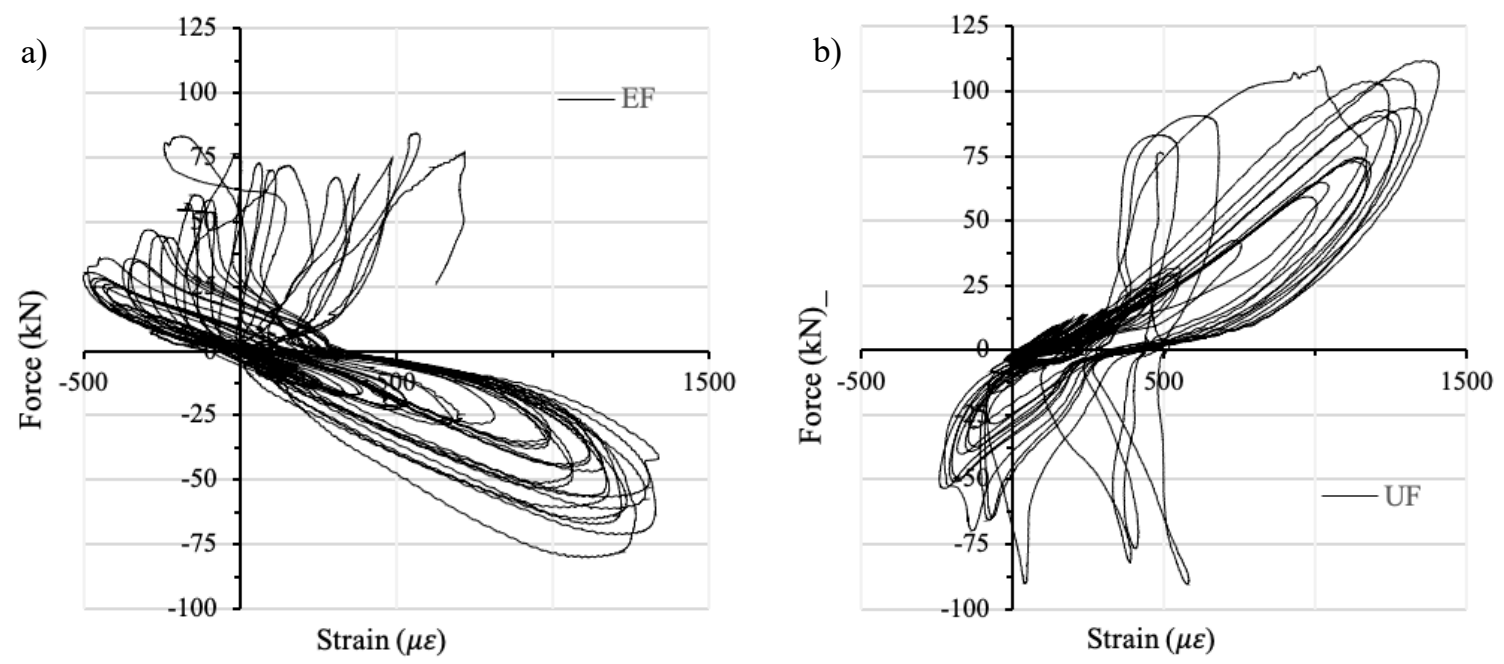

Figure 4.26: Force vs. S-SG 5, a) EF \& b) UF

to occur, unlike ECC. For S-SG 5, which is the strain gauge located in the flexural reinforcement of the joint located opposite of the actuator. Looking at figure 4.26 for the force vs. strain graph of both EF and UF, for the ECC specimen (Fig. 4.26a), the specimen performed well during pulling action, with minimal stiffness degradation, however, looking at the pushing action, as the load kept increasing the strain turned from compression to tension, especially after reaching the peak load at $84 \mathrm{kN}$. This is a result of the outer column's extensive deterioration throughout the test, in which a shear crack that had developed in the SCC column section, migrated into the ECC portion of the column, resulting in the stiffness degradation. For the UHPC strain data (Fig. 4.26b), the change in shape of the loop occurred once the shear crack developed in the column section, which occurred at loads of $+112.06 \mathrm{kN}$ and $-69.74 \mathrm{kN}$. 


\subsection{ECC and UHPC Jointed Shear Critical Frames Comparison}

This section will compare the shear critical frames, ES and US for their force vs. displacement and strain gauge response. The hysteretic load-deflection response for both shear critical frame
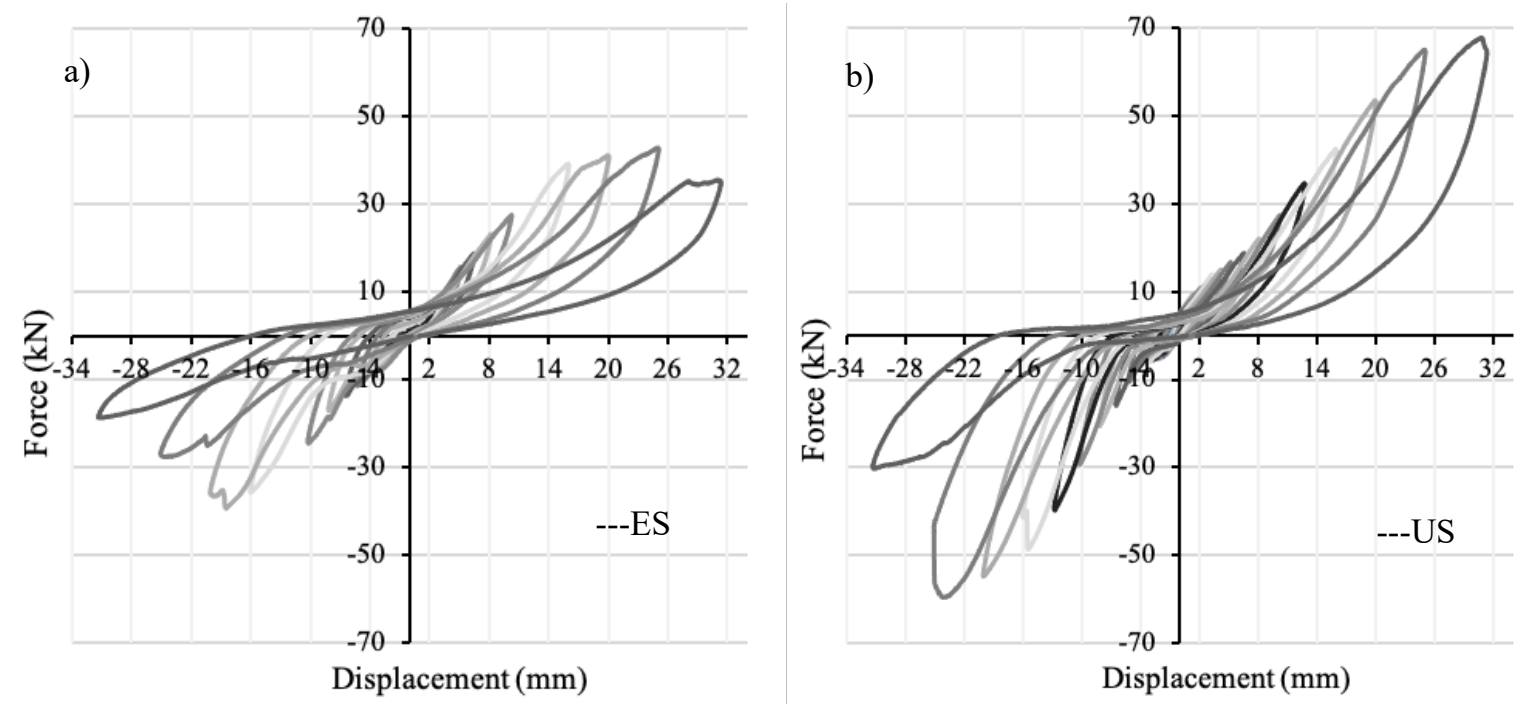

Figure 4.27: Force vs. Displacement curve for a) ES, \& b) US

specimen, ES and US are provided in figure 4.27. Figure 4.27a illustrates the data for the ECC joint specimen and figure $4.27 \mathrm{~b}$ illustrates the data for the UHPC joint. The EF specimen reached a peak load of $+42.898 \mathrm{kN}$ at cycle 14 , whereas the US reached $+67.804 \mathrm{kN}$ at cycle 15 . It can be seen that the ECC specimen exhibited a high initial stiffness with low stiffness degradation initially, until after cycle 11, when stiffness degradation is observed until peak load is hit and significant drop in stiffness is experienced afterwards (Fig. 4.27a). The UHPC also exhibited a high initial stiffness with a steady increase in energy absorption throughout the cycles until peak load (Fig. 4.27b). The ECC specimen reached peak load at a displacement of $25 \mathrm{~mm}$, whereas the UHPC reached peak load at a displacement of $30 \mathrm{~mm}$. The UHPC had higher energy absorption and more ductility than in the ECC specimen, which was the opposite for the flexure critical specimen. The UHPC specimen reached peak load at approximately 133 minutes, whereas the ECC reached peak load at approximately 108 minutes.

Now comparison of the force vs. strain gauge data between the two shear critical specimens, ES and US. The shear critical specimen have two concrete strain gauges, like in the flexure critical specimen. In addition, there are 8 steel-strain gauges embedded into the specimen, there are two more strain gauges than in the flexure critical specimen, in which these strain gauges are placed on the shear stirrup reinforcement of the joint connection. 


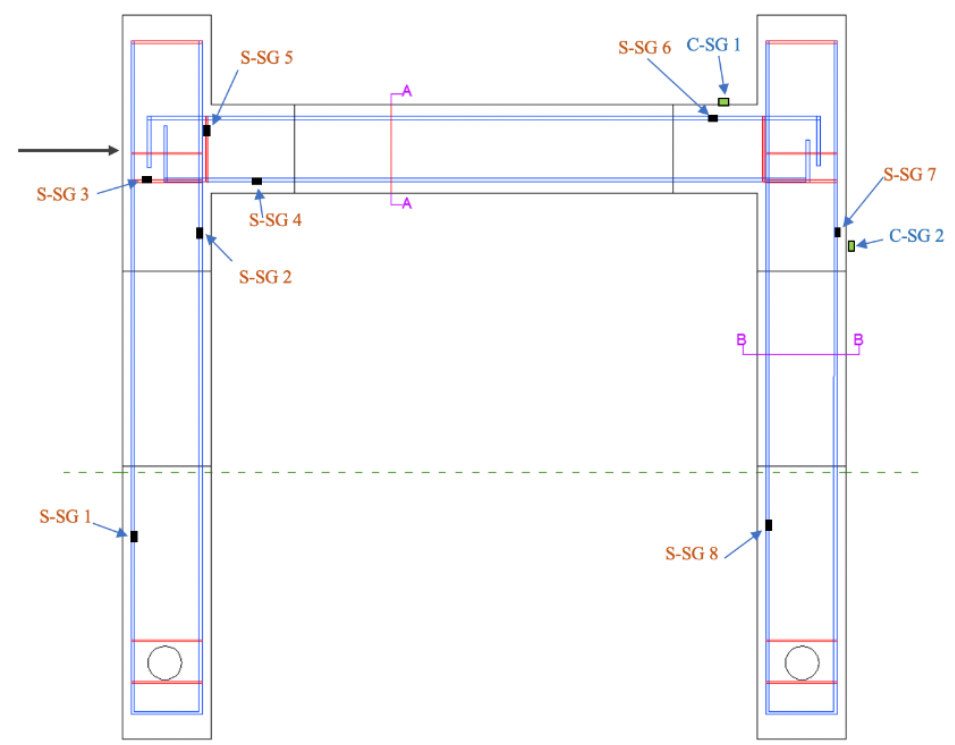

Figure 4.28: Steel and concrete strain gauge location of ES \& US for reference

Figure 4.28 shows the location of the steel and concrete strain gauge location for both shear critical specimens, ES and US. Looking at figure 4.29 for the force vs. C-SG 1 data for ES and US. It can be seen that both specimens have an almost identical hysteretic loop, the residual strain of \pm 200 $\mu \varepsilon$ is observed, in which afterwards, gradual stiffness degradation is observed as the force kept increasing. Both specimens reached peak load at $+1250 \mu \varepsilon$. However, it can be observed that the UHPC specimen had larger capacity (Fig. 4.29b), since higher energy absorption is observed.
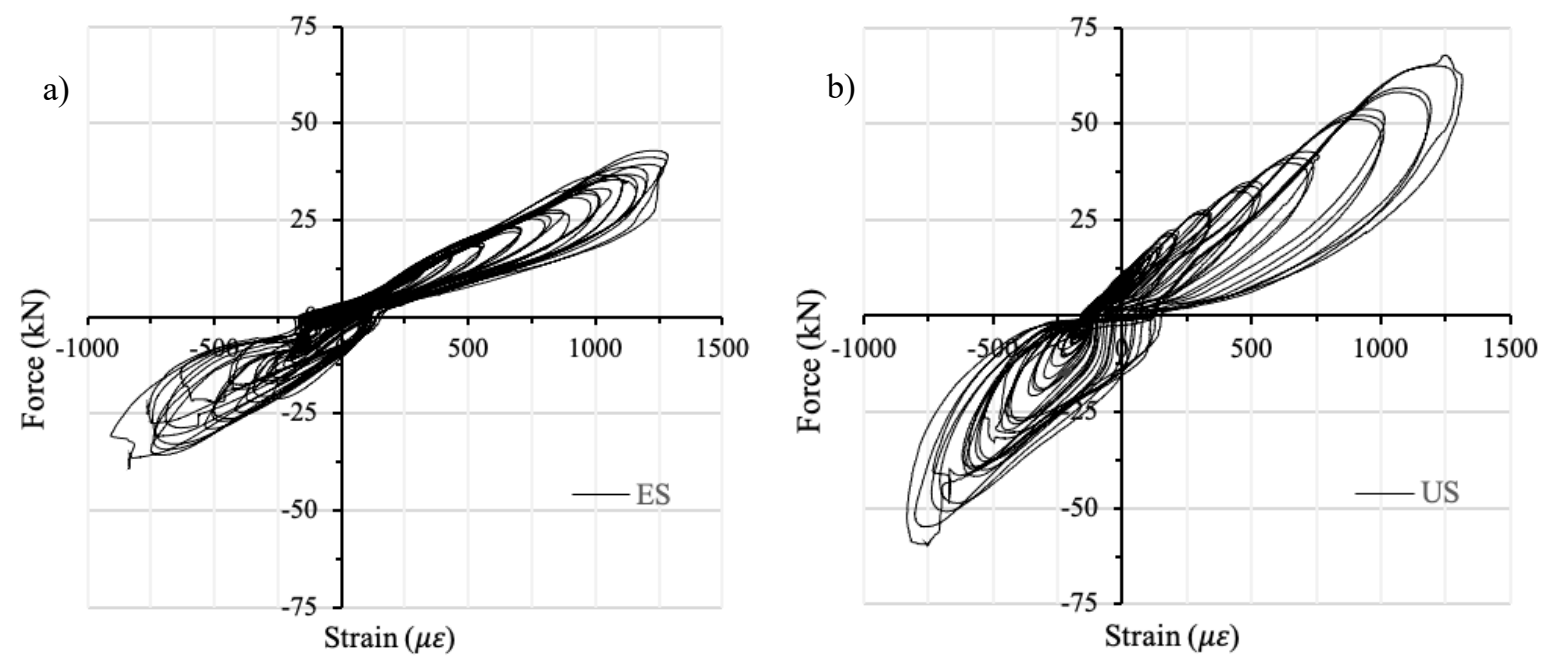

Figure 4.29: Force vs. C-SG 1, a) ES \& b) US 
For the C-SG 2 data, for the ECC specimen the data is illustrated in figure 4.30a. When the strain data left formation of the hysteretic loop and began to turn into compression is when the outer column started to crush and spalling of the concrete was observed at peak load. A similar trend is observed in the UHPC C-SG 2 specimen as well (Fig. 4.30b). At $-41 \mathrm{kN}$, the columns failed as a shear crack had developed in the SCC portion of the column. This led to the shift in the hysteretic loop into experiencing compressive strain, which was also accompanied by stiffness degradation until peak load was reached. In most specimen, the pulling action of the frame by the actuator lead to more damage than pushing.
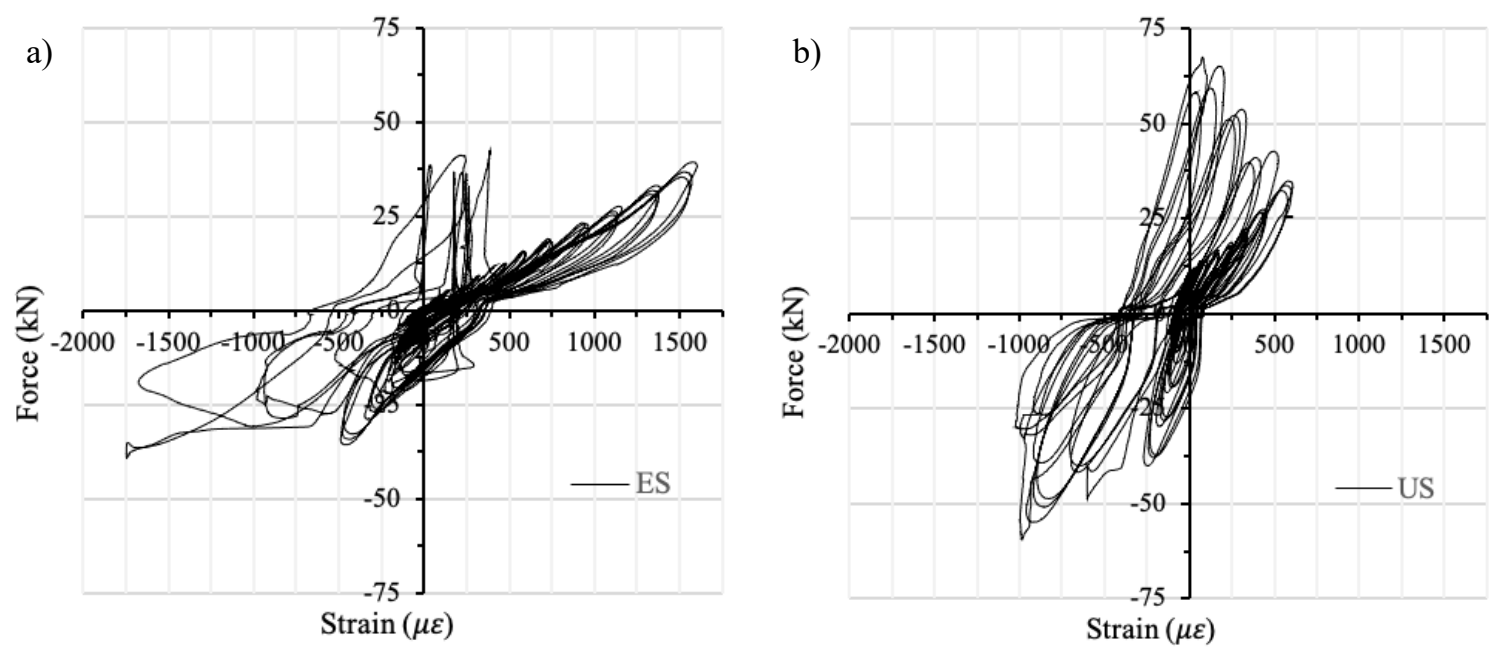

Figure 4.30: Force vs. C-SG 2, a) ES \& b) US

Now analyzing the data for the steel strain gauges, looking at the data for S-SG 1 provided in figure 4.31. Looking at the data for the ECC specimen (Fig. 4.31a), during the test at cycle 28, at a load of $-24.6 \mathrm{kN},+27.59 \mathrm{kN}$ is when a shear crack developed in the interior column of the specimen, which is when the strain jumped from around residual strain $\pm 100 \mu \varepsilon$ to $+400 \mu \varepsilon$, in which afterwards large stiffness degradation is observed until peak load is achieved. For the UHPC data (Fig. 4.31b), a similar trend is also observed in this specimen, however, in this case at a load of $41 \mathrm{kN}$ at cycle 34 , the concrete in the inner column crushed and started to spall, which is where the large stiffness degradation is observed on $+200 \mu \varepsilon$ and onwards. 

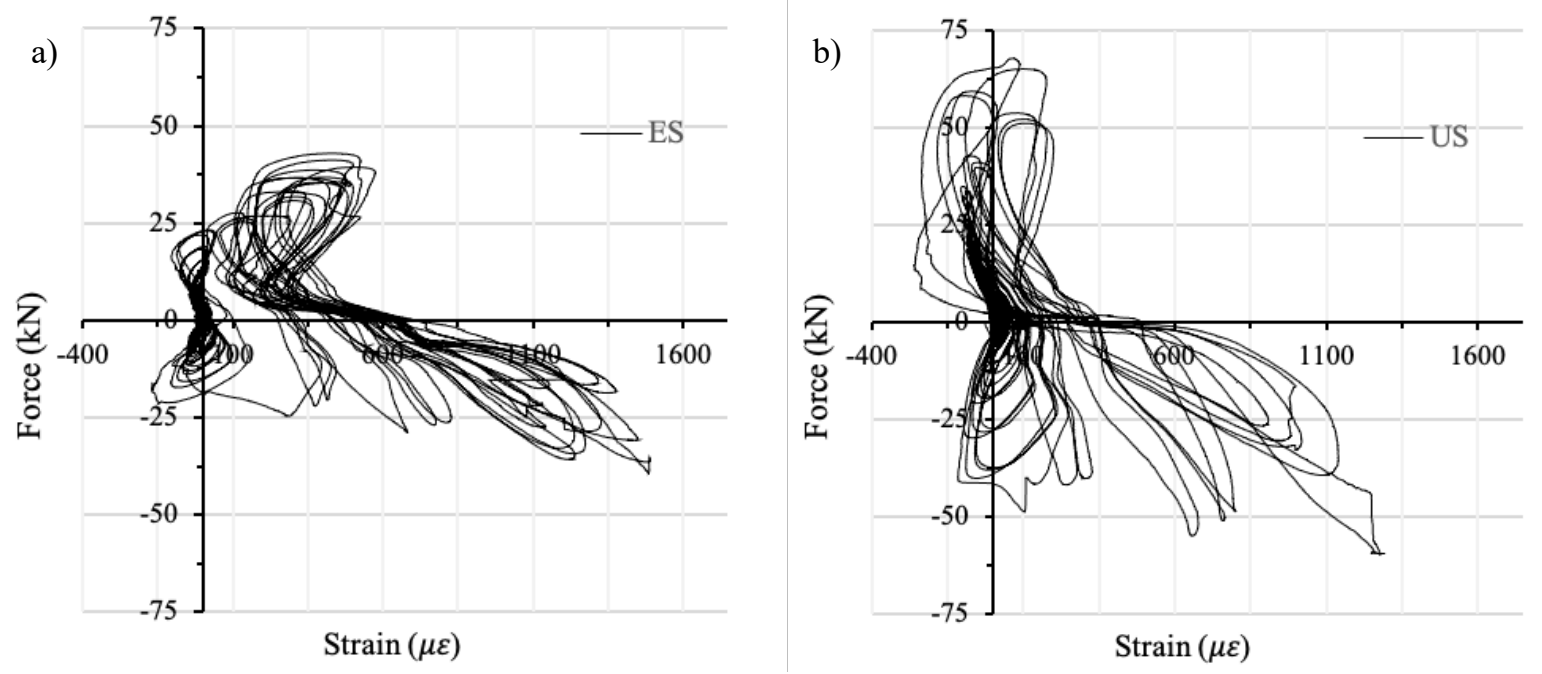

Figure 4.31: Force vs. S-SG 1, a) ES \& b) US

The force vs. S-SG 2 data is provided in figure 4.32. Looking at the data for the ECC specimen (Fig. 4.32a), after the residual strain of $\pm 100 \mu \varepsilon$, the steel experienced tensile strain during both pushing and pulling action, which is attributed to the shear crack development in the SCC column portion, in which that shear crack migrated into the ECC part of the column at cycle 28 at a load of $+27.59 \mathrm{kN},-24.6 \mathrm{kN}$, which is when significant stiffness degradation is observed. The ECC specimen reached peak load at a strain of approximately $+1300 \mu \varepsilon$. Looking at the UHPC specimen (Fig. 4.32b), a similar trend is also observed here, the steel reached a strain of approximately 900 $\mu \varepsilon$ at peak load, which is when the specimen started to turn into compressive strain slightly as the load increased.
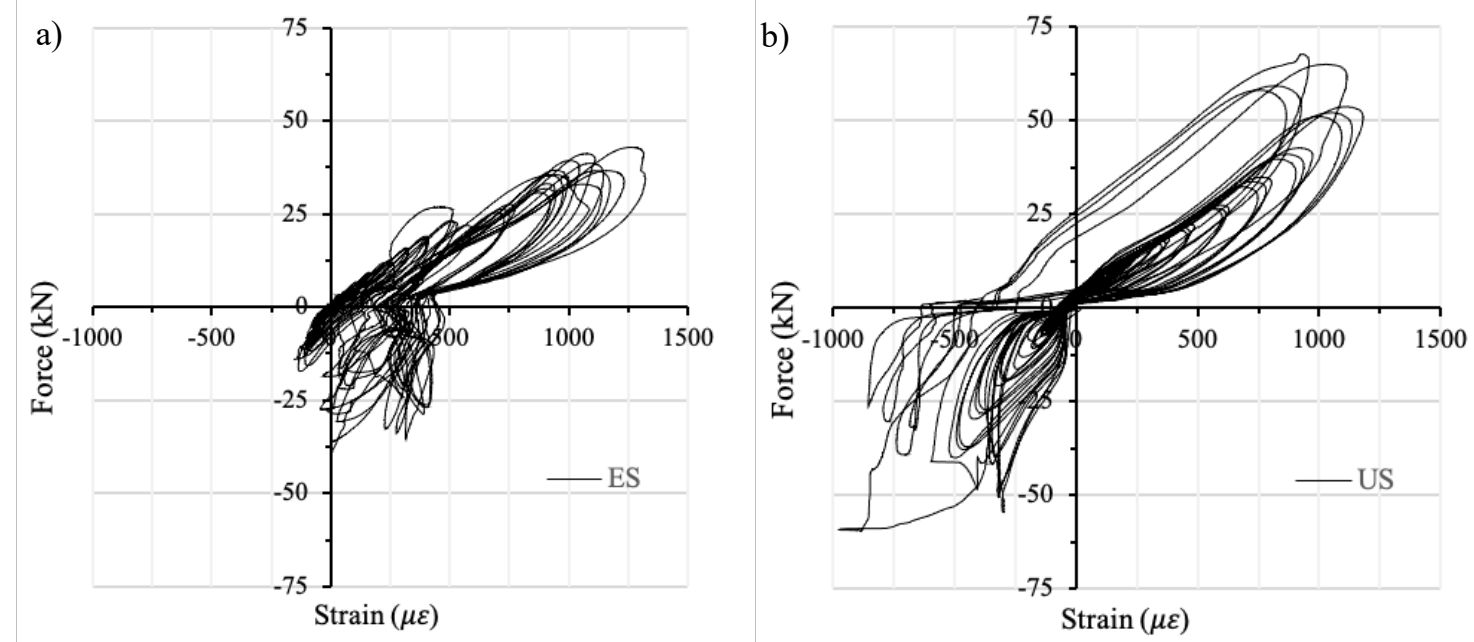

Figure 4.32: Force vs. S-SG 2, a) ES \& b) US 

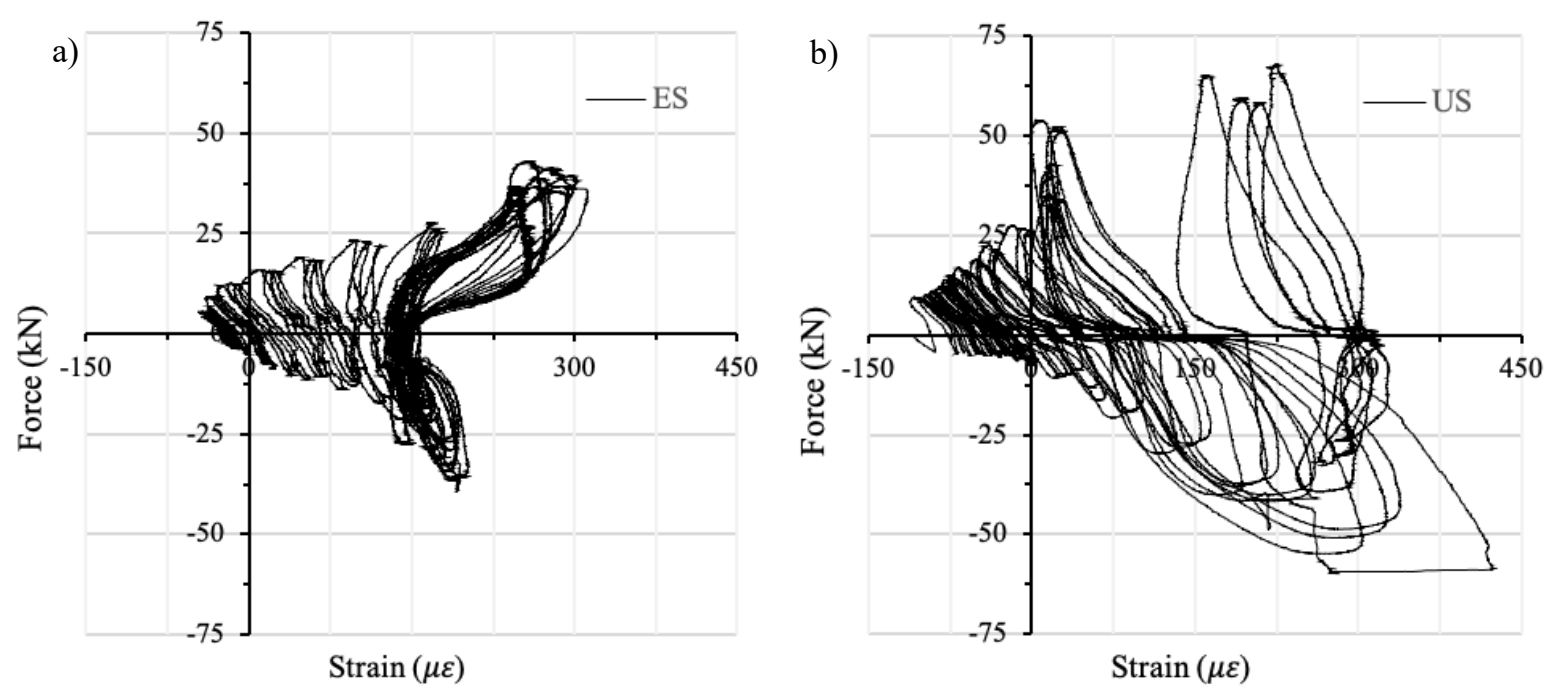

Figure 4.33: Force vs. S-SG 3, a) ES \& b) US

Now for S-SG 3, which was not present in the flexure critical specimen, this strain gauge is located on the horizontal shear stirrup located in the joint reinforcement, the shear stirrup connects the horizontal flexural reinforcement to the vertical flexural reinforcement. The force vs. S-SG 3 data is provided in figure 4.33. Both specimens have shown a very similar trend with an initial high stiffness but afterwards stiffness degradation is observed. For the ECC specimen (Fig. 4.33a), after the shear crack had appeared in the column section, the stiffness degradation is observed after $+150 \mu \varepsilon$, which was experienced at a load of $+27.59 \mathrm{kN},-24.6 \mathrm{kN}$. For the UHPC specimen (Fig. $4.33 \mathrm{~b}$ ), the shear crack appeared at $-41 \mathrm{kN}$, which is where large stiffness degradation is observed in addition to a large jump in tensile strain.

For S-SG 4, located on the horizontal flexural reinforcement of the beam portion in the ECC/UHPC joint. The force vs. S-SG 4 data is provided in figure 4.34, in which it can be seen that both specimens have very similar hysteretic loops. Both specimens approximately reached a strain of $1200 \mu \varepsilon$ at peak load, however, the ECC specimen (Fig. 4.34a) had higher stiffness degradation especially in the compressive strain region. The high stiffness and rigidity of UHPC is illustrated (Fig. 4.34b). 

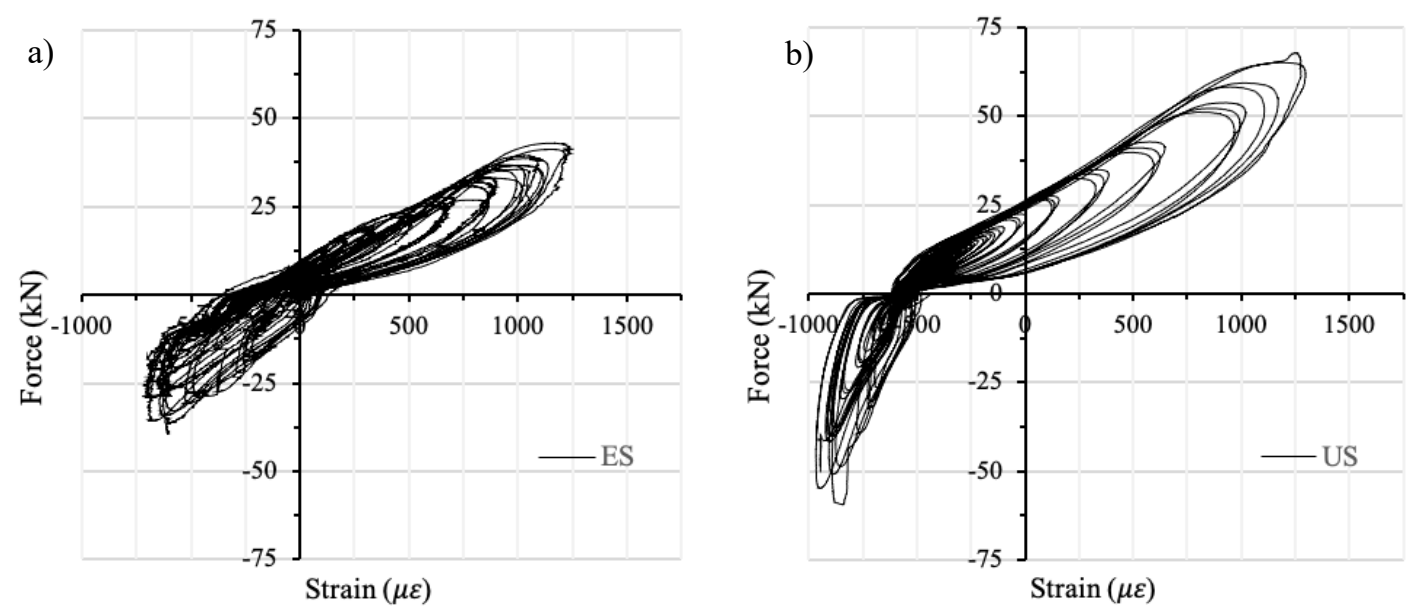

Figure 4.34: Force vs. S-SG 4, a) ES \& b) US

S-SG 5 is also not present in the flexure critical specimen, this strain gauge is located on the vertical stirrup connecting the beam flexural reinforcement to the column's flexural reinforcement. The force vs. S-SG 5 data is provided in figure 4.35, for the ECC specimen (Fig. 4.35a), large increase in strain is observed after the shear crack developed at around $+27 \mathrm{kN}$, reaching a strain of $180 \mu \varepsilon$ approximately at peak load. For the UHPC joint specimen (Fig. 4.35b), lower increase in strain is observed due to the high stiffness of the joint, for this specimen a strain of approximately $95 \mu \varepsilon$ is achieved at peak load. The higher strain observed in the ECC specimen portrays the higher ductility and deformability achieved by the material.
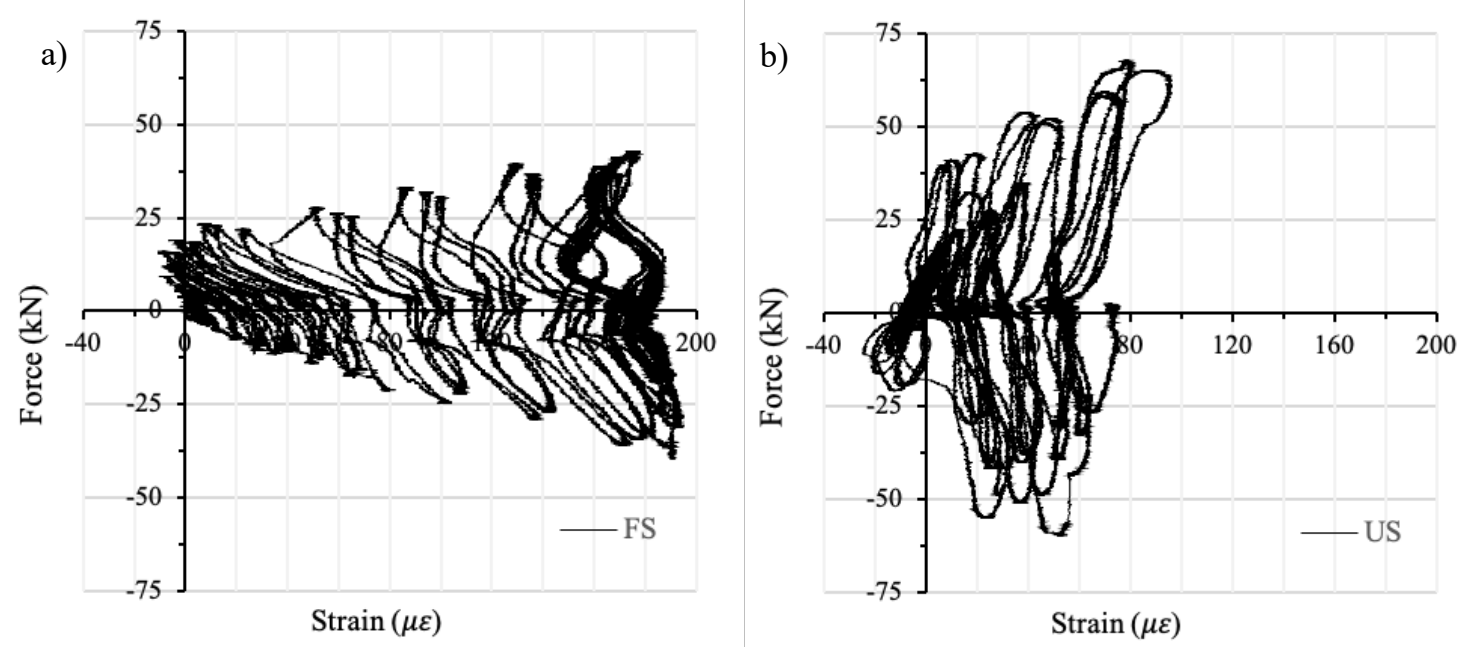

Figure 4.35: Force vs. S-SG 5, a) ES \& b) US 


\subsection{Summary of Strain Development}

Table 4.2 presents a summary of the strain values of each strain gauge discussed at the corresponding max applied load. C-SG refers to concrete strain gauge and S-SG refers to steel strain gauge.

Table 4.2: Strain values at corresponding maximum load for frame specimens

\begin{tabular}{|l|c|c|c|c|}
\hline & \multicolumn{5}{|c|}{ Strain $(\boldsymbol{\mu \varepsilon})$} \\
\hline Strain \# & EF & ES & UF & US \\
\hline C-SG [1] & +3068 & +1222 & +973.46 & +1252 \\
\hline C-SG [2] & +170 & +388 & +2608.87 & +76 \\
\hline S-SG [1] & +872 & +419 & +1269.99 & +65 \\
\hline S-SG [2] & -31 & +1257 & +1358.12 & +933 \\
\hline S-SG [3] & +1772 & +258 & +898.75 & +225 \\
\hline S-SG [4] & +1372 & +1144 & +758.82 & +1251 \\
\hline S-SG [5] & +560 & +75 & +1357.15 & +79 \\
\hline S-SG [6] & +732 & +1161 & +814.44 & +1592 \\
\hline S-SG [7] & N/A & No data & N/A & +1161 \\
\hline S-SG [8] & N/A & +53 & N/A & +46 \\
\hline & \multicolumn{4}{|c|}{ Peak Load } \\
\hline
\end{tabular}

Note: ES: S-SG7-Located in the longitudinal reinforcement in the column was not transferring any current. 


\subsection{Stiffness}

This section involves presenting the initial stiffness of each specimen and illustrating the stiffness degradation as the cycles commence. The stiffness is calculated for each specimen and is presented in the figures 4.36 and 4.37 for comparison between the flexure critical and shear critical frame specimens. The stiffness is calculated for the first cycle of each 3 repeating fatigue cycles.

Table 4.3: Stiffness degradation comparison

\begin{tabular}{|c|c|c|c|}
\hline \multicolumn{4}{|c|}{ Initial Stiffness (K) (kN/mm) } \\
\hline \multicolumn{2}{|c|}{ Flexure critical specimen } & Shear Critical Specimen \\
\hline EF- ECC & UF- UHPC & ES- ECC & US- UHPC \\
\hline $4.72 \mathrm{kN} / \mathrm{mm}$ & $9.44 \mathrm{kN} / \mathrm{mm}$ & $3.45 \mathrm{kN} / \mathrm{mm}$ & $6.85 \mathrm{kN} / \mathrm{mm}$ \\
\hline
\end{tabular}

Table 4.3 summarizes the initial stiffness of each of the four frame specimens. It can be seen that for the flexure critical specimen, the UHPC jointed frame, UF has an initial stiffness of 9.44 $\mathrm{kN} / \mathrm{mm}$, which is approximately double the initial stiffness of the ECC jointed counterpart, EF, achieving $4.72 \mathrm{kN} / \mathrm{mm}$. This clearly illustrates the high stiffness and high concrete compressive strength properties of UHPC, which is attributed to the dense mixture from the use of silica fume and fine aggregates. The difference in stiffness degradation between the two-flexure critical specimen is illustrated in figure 4.36. It can be seen that the UHPC specimen has a higher rate of stiffness degradation per cycle. The ECC specimen managed to withstand more cycles than the UHPC flexure critical specimen. In addition to having a lower rate of stiffness degradation per cycle, ECC jointed frame portrays high ductility when compared to its UHPC counterpart. Looking at the shear critical specimens, the UHPC jointed specimen, US also performed better than its ECC shear critical jointed counterpart, ES, as expected, with a higher stiffness of 6.85 $\mathrm{kN} / \mathrm{mm}$ compared to $3.45 \mathrm{kN} / \mathrm{mm}$. Figure 4.37 , illustrates the large rate of stiffness degradation experienced by the UHPC specimen, which was also seen in the flexure critical specimen. It is also observed that the ECC specimen has a very gradual decline in stiffness degradation throughout the cycles (showing better performance), which is attributed to ECC's ultra-high tensile capacity and high strain hardening characteristics. 


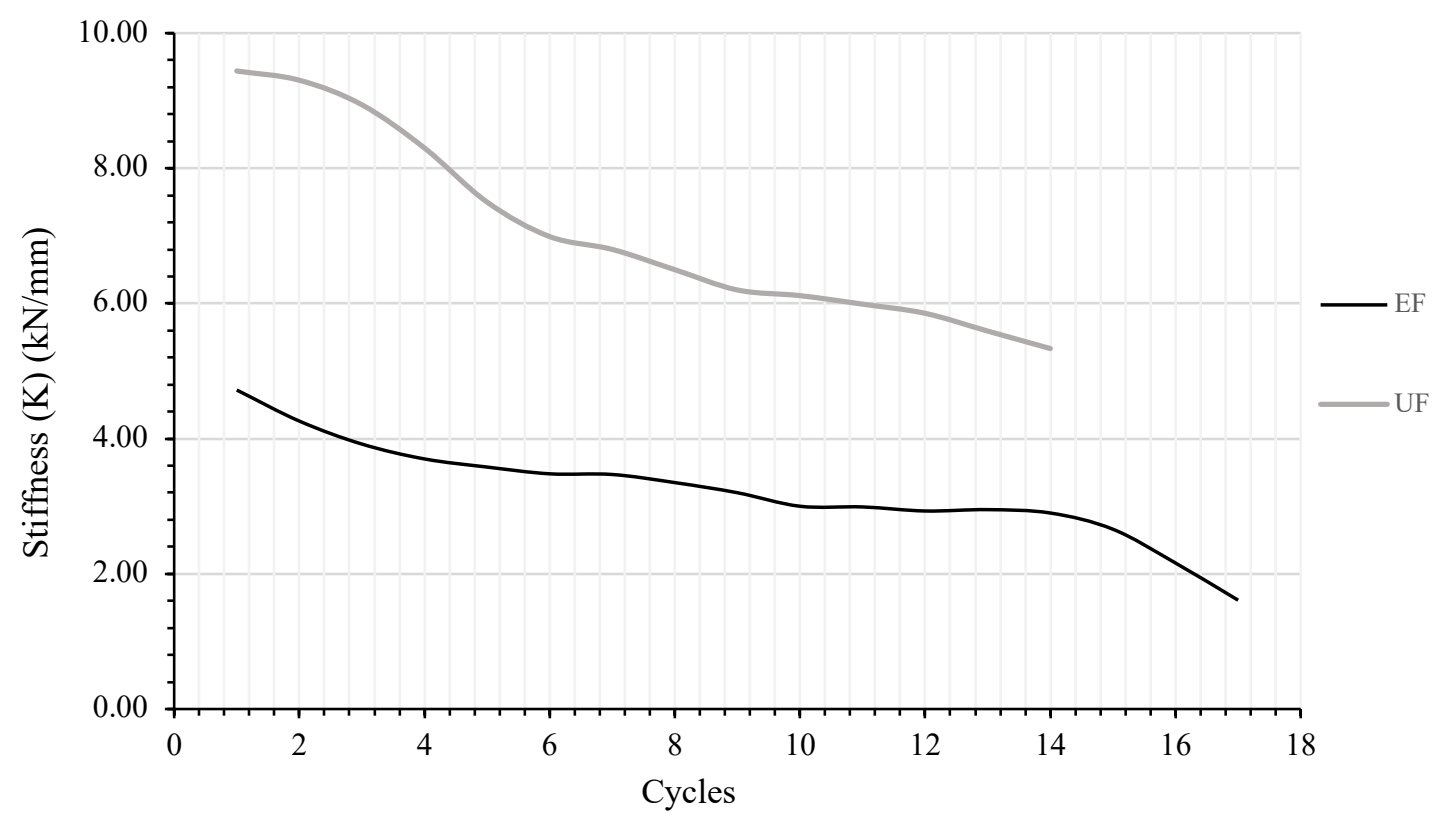

Figure 4.36: Flexure critical specimens, EF \& UF, Stiffness (K) comparison

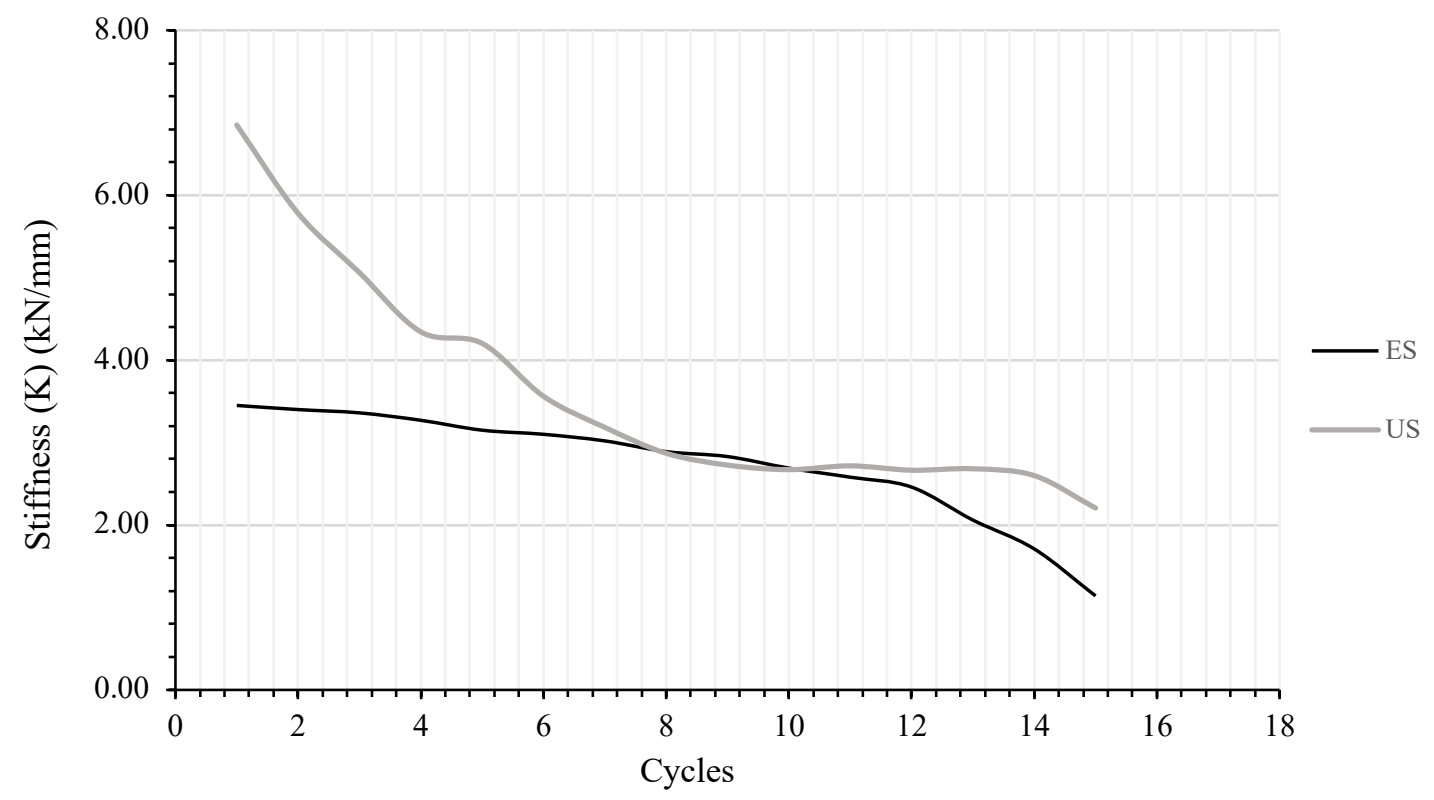

Figure 4.37: Shear critical specimens, ES \& US, Stiffness (K) comparison 


\subsection{Energy Absorption}

The energy absorption of each frame specimen is obtained by calculating the area under the curve for each cycle of the force vs. displacement graphs provided earlier in figures 4.20 and 4.27. Matlab software was used to obtain the energy absorption values of each cycle, by inserting the appropriate data of each cycle and using the "trapz $(\mathrm{x}, \mathrm{y})$ " function in the software. The data of each cycle of each specimen had to be isolated to be able to obtain the required values.

\subsubsection{Flexure critical specimens (EF and UF) comparison}

Energy absorption capacities of EF and UF are described and compared. The peak energy absorption values to be analyzed are considered at the peak load of the specimen. For some specimen, energy absorption kept increasing even after peak load was reached, but with significant reduction in stiffness. Figure 4.38 shows the energy absorption of the flexure critical specimen, EF and UF. Both ECC and UHPC specimens had similar trends of energy absorption, until approximately cycle 10, where UF had large jumps in energy absorbing, but EF exceeded the UF specimen due to its high ductility. The energy absorption of the ECC flexure critical specimen at peak load at cycle 16 is 1246.70 Joules, whereas for the UHPC a value of 601.83 Joules at peak load at cycle 13. Figure 4.39 compares the energy absorption of the flexure critical and shear critical ECC frame specimens, EF and ES. A very similar trend is observed initially, which after cycle 14, the flexure critical continues to resist load and absorb energy as expected. The energy absorption of the ECC shear critical specimen at peak load at cycle 14 is 517.06 Joules, which is almost as half as the flexure critical ECC frame specimen, which is due to the more brittle failure that is expected with shear critical frames. 


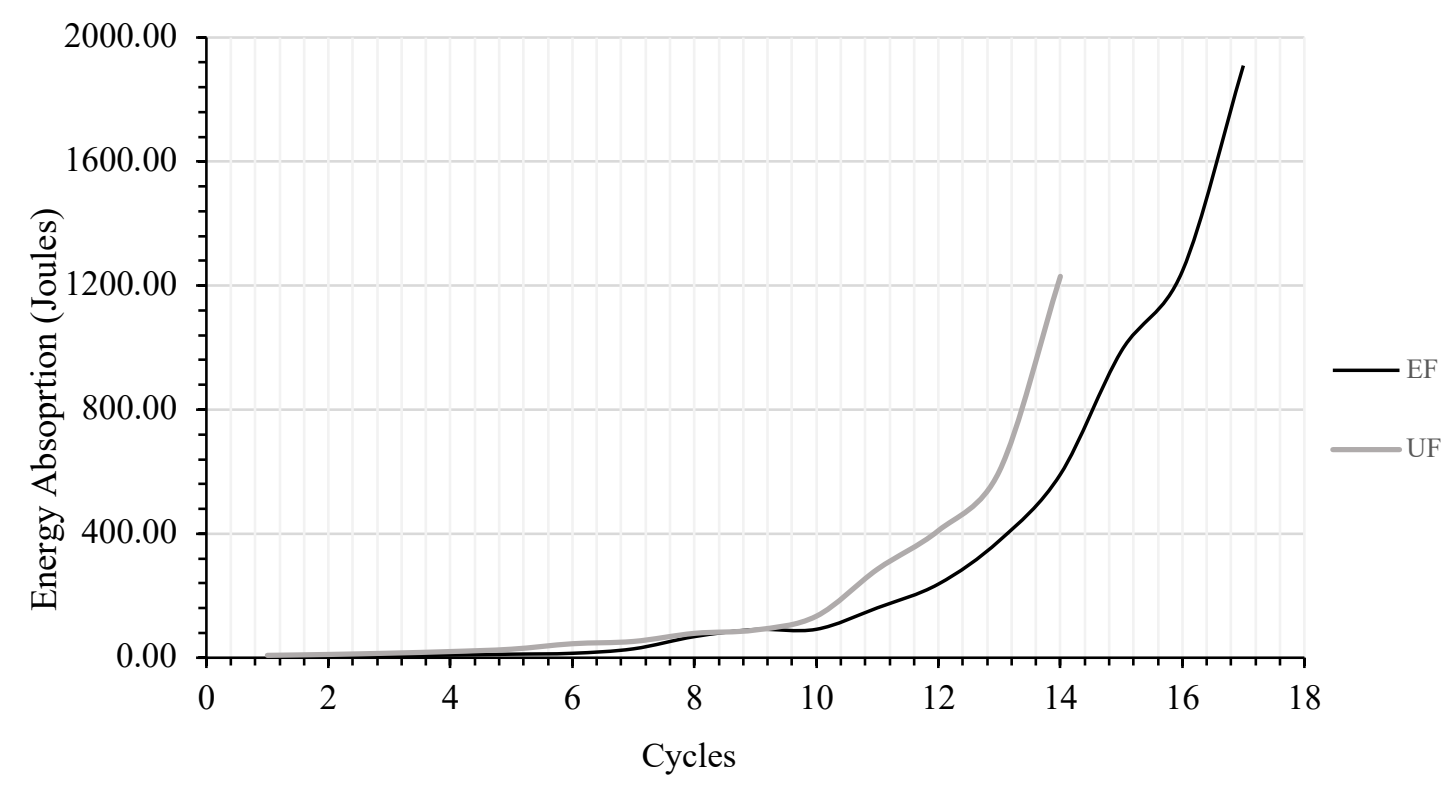

Figure 4.38: Energy Absorption comparison for flexure critical specimens, EF \& UF

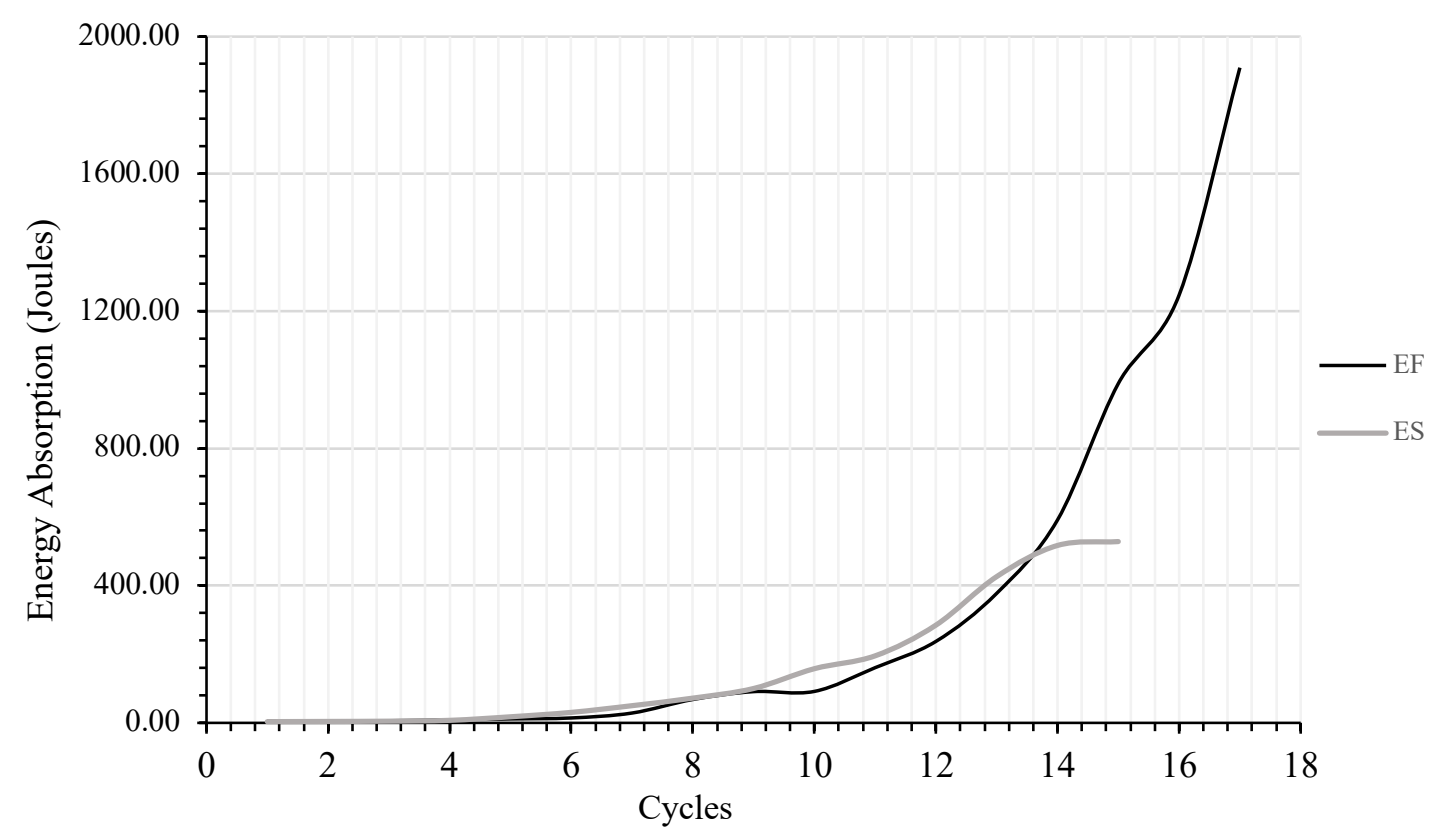

Figure 4.39: Energy Absorption comparison for both ECC joint specimens, EF \& ES 


\subsubsection{Shear critical specimens (ES and US) comparison}

Figure 4.40 shows the energy absorption of both ECC and UHPC shear critical frame specimens: ES and US. It can be seen that the UHPC shear critical specimen outperforms the ECC frame specimen, although the opposite was the case in the flexure critical specimen. It is clear that the presence of shear reinforcement is vital for the ductile performance of ECC. The energy absorption for the shear critical ECC specimen at peak load at cycle 14 is 517.06 Joules, whereas the UHPC reached an energy absorption value of 816.19 Joules at peak load at cycle 15. Figure 4.41 also compares the energy absorption performance of the UHPC frame UF and US. The flexure critical specimen outperforms the shear critical specimen as expected. At approximately cycle 10 as well, the energy absorption of the two specimen starts to differ, as observed in the ECC specimen. With the increasing number of cycles, the presence of shear reinforcement is vital for enhancing performance and durability of the frame specimen.

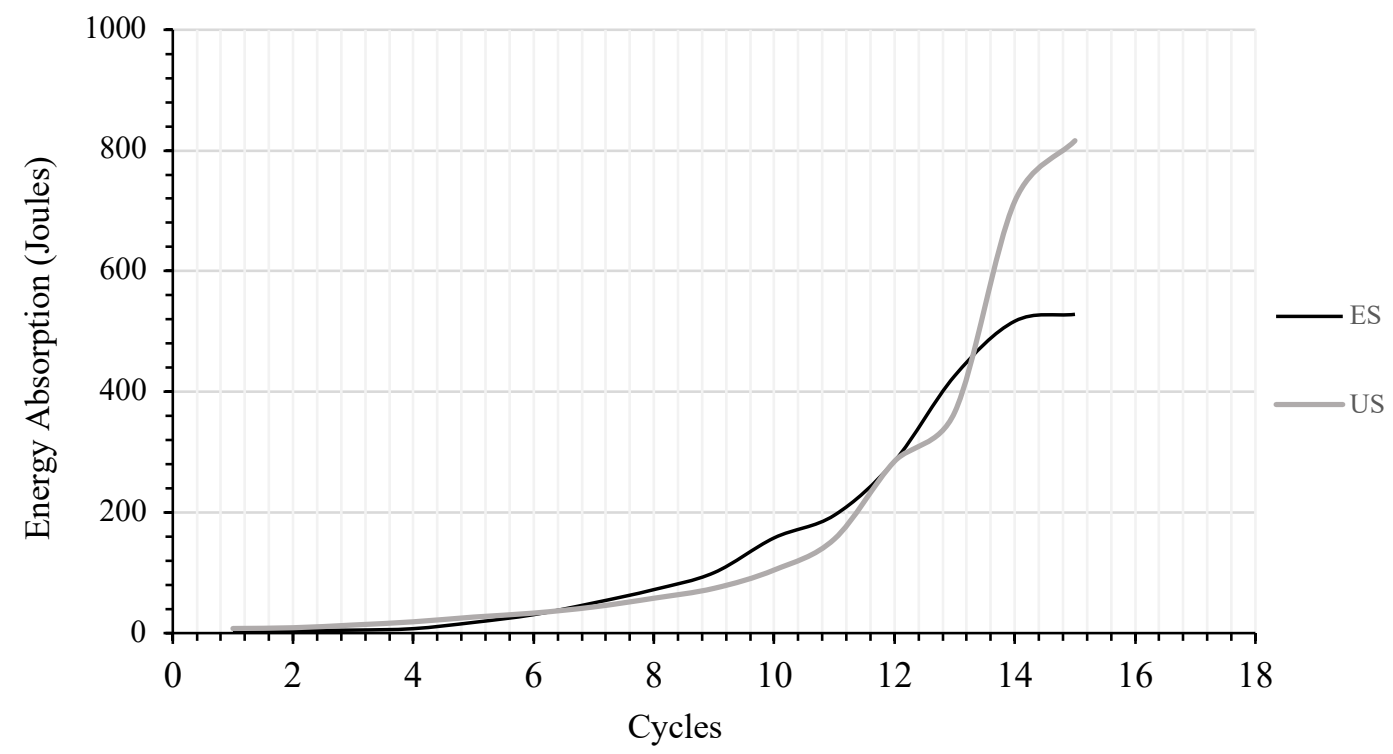

Figure 4.40: Energy absorption comparison of shear critical specimen's ES \& US 


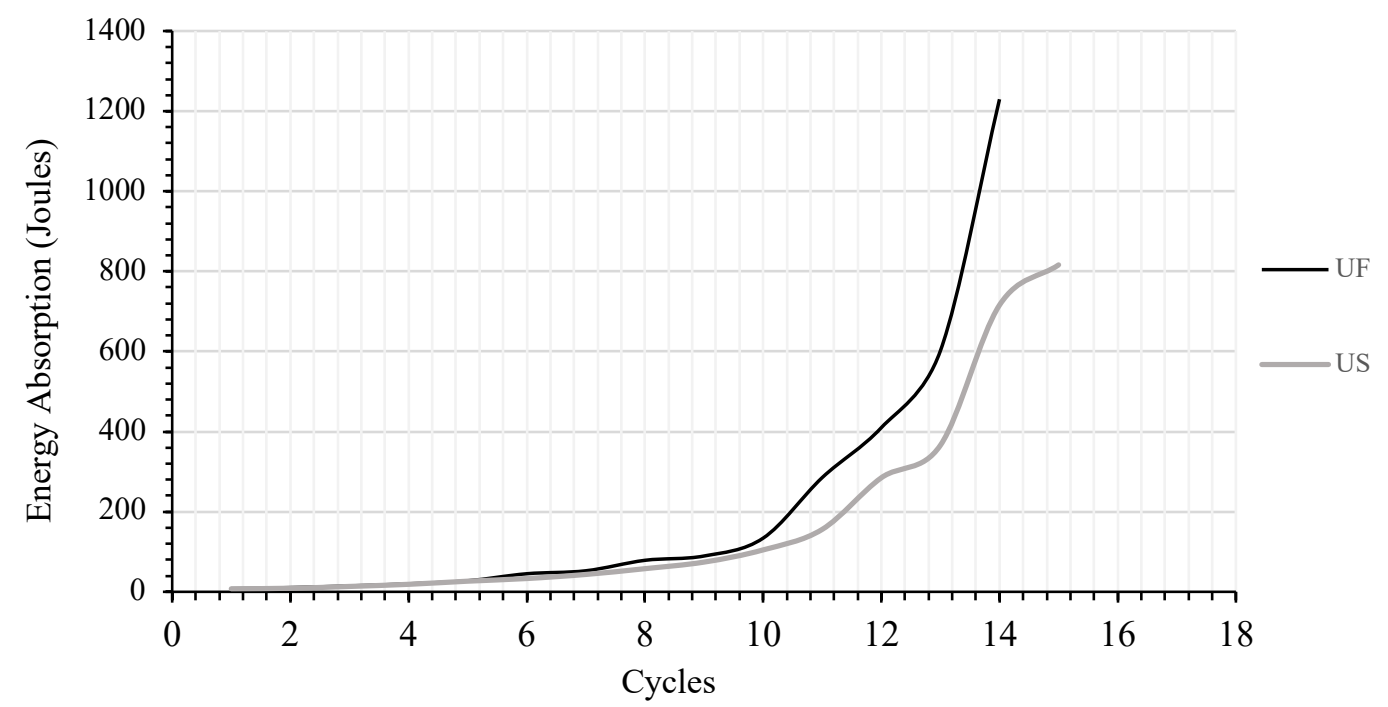

Figure 4.41: Energy absorption comparison of UHPC joints, UF \& US

Table 4.4 summarizes the peak energy absorption values at peak load of each specimen. It can be observed that the ECC joint outperforms the UHPC joint in the flexure critical case. The flexure critical case is of more importance than the shear critical since that is the condition used in the design of structural elements, since we want to avoid the occurrence of brittle failure that occurs in shear critical specimen. ECC outperforms UHPC mainly because of its ability to sustain large deformations due to its high tensile capacity and strain hardening characteristics. Table 4.4 also summarizes the results for the initial stiffness and peak load (strength) achieved by each of the frame specimens.

Table 4.4: Energy Absorption, Initial stiffness and peak load (strength) of frame specimens

\begin{tabular}{|l|c|c|c|c|}
\hline & \multicolumn{2}{|c|}{ Flexure critical specimen } & \multicolumn{2}{c|}{ Shear Critical Specimen } \\
\hline & EF- ECC & UF- UHPC & ES- ECC & US- UHPC \\
\hline $\begin{array}{l}\text { Peak Energy Absorption at } \\
\text { Ultimate load (Joules) }\end{array}$ & 1246.70 Joules & 601.83 Joules & 517.06 Joules & 816.19 Joules \\
\hline $\begin{array}{l}\text { Initial Stiffness (K) } \\
(\mathbf{k N} / \mathbf{m m})\end{array}$ & $4.72 \mathrm{kN} / \mathrm{mm}$ & $9.44 \mathrm{kN} / \mathrm{mm}$ & $3.45 \mathrm{kN} / \mathrm{mm}$ & $6.85 \mathrm{kN} / \mathrm{mm}$ \\
\hline Peak Load (kN) & & & & \\
\hline
\end{tabular}




\subsection{Experimental and Theoretical based Results and Discussion}

This section presents and analyzes the experimental and theoretical shear and flexural capacities of beam and column elements of the frames. Table 4.5 and 4.6 present the results for theoretical s and experimental member capacities. The theoretical member capacities are based on existing code provisions and design formulations. The results obtained for the flexural and shear capacities are summarized in these tables, in which the detailed calculations can be found in appendix A, sections A.1 to A.3.

Table 4.5: Experimental and theoretical shear member capacity results comparison

\begin{tabular}{|l|c|c|c|c|}
\hline & \multicolumn{3}{|c|}{ Theoretical Capacities } & \multicolumn{2}{c|}{ Experimental Capacities } \\
\hline & $\begin{array}{c}\text { Beam Shear capacity } \\
(\mathrm{kN})\end{array}$ & $\begin{array}{c}\text { Column Shear capacity } \\
(\mathrm{kN})\end{array}$ & $\begin{array}{c}\text { Beam Shear } \\
\text { capacity }(\mathrm{kN})\end{array}$ & $\begin{array}{c}\text { Column Shear } \\
\text { capacity }(\mathrm{kN})\end{array}$ \\
\hline & \multicolumn{4}{|c|}{ Flexure Critical Specimens } \\
\hline EF- ECC Joint & 41.5 & 42.1 & 25.1 & 42.1 \\
\hline UF- UHPC joint & 41.5 & 42.1 & 33.39 & 56.03 \\
\hline ES- ECC joint & 13.9 & \multicolumn{5}{|c|}{ Shear Critical Specimens } \\
\hline US- UHPC joint & 13.9 & 14.1 & 12.78 & 21.45 \\
\hline
\end{tabular}

The joint shear strength of the ECC/UHPC jointed frames were calculated based on ACI 352R-02 and the procedure was outlined earlier in Chapter 2. It is observed that the code based joint strength for both flexure critical and shear critical ECC specimen (EF and ES), is $167.1 \mathrm{kN}$, whereas for the UHPC jointed one, the joint strength is $203.9 \mathrm{kN}$. The joint shear strength is the same for both flexure critical specimen and shear critical specimen since the same amount of minimum shear reinforcement is provided in the joint section. Since both ECC and UHPC joint shear strengths exceed the amount of shear applied, this justifies no joint failure of the frames and, why failure was only observed in the members not in the joints. It should be noted that the joint shear strength of the UHPC joint is greater than the ECC joint due to the higher tensile strength and higher strain at ultimate stress.

The experimental capacities of the beam and column sections were calculated by using the Portal Method, by obtaining the reactions and member capacities from the shear force diagram as seen in appendix A, section A.3. Looking at the code-based capacities, it can be seen that both flexure 
critical specimen have the same beam shear capacity and column shear capacity, and the same occurs in the shear critical specimen. The shear capacities identified are of the SCC material, since the SCC shear capacity will govern over the ECC and UHPC, due to its smaller capacity. However, through tests, it is clear that that is not the case and that the ECC and UHPC have higher shear capacity than the SCC portion of the same members, since mainly shear failure in the SCC portion of the beam or column members was observed, and not in the ECC/UHPC portion of the members, validating that they do indeed have higher shear capacities. Therefore, it is observed that these equations cannot be used in calculating the shear capacity of the ECC or UHPC portion of the beam and column, since it is only adequate for the SCC portion of the beam/column member. The values presented in the table 4.5 represent mainly the shear capacity of the SCC portion of the beam/column and neglecting the higher capacity of the ECC and UHPC portion of the beam and column. Therefore, special equations need to be introduced or the introduction of some sort of coefficient that can relate the code-based capacity to the experimental should be utilized in further research.

Looking at the experimental capacities of column, the beam shear capacities of the flexure critical specimen resulted in a shear capacity of $25.1 \mathrm{kN}$ for EF and $33.39 \mathrm{kN}$ for UF. According to the code-based capacities calculated for the beam sections, the applied shear is smaller than the theoretical capacity of the beam members, which justifies not having shear failure in the beam members of the flexure critical specimen. Looking at the beam shear capacities of the shear critical specimen, ES had an experimental capacity of $12.78 \mathrm{kN}$, whereas US had an experimental capacity of $20.20 \mathrm{kN}$. Given that the code-based capacity calculated is around $13.9 \mathrm{kN}$, this justifies not experiencing any shear failure in the beam in ES. Since US's experimental shear capacity is greater than the code-based capacity, this validates the shear cracks observed in the beam section of that specimen, which was outlined in the test observations of US.

Looking at the column shear capacities, the experimental column shear capacity for UF section is $56.03 \mathrm{kN}$, whereas the EF had a column shear capacity of $42.1 \mathrm{kN}$. Comparing to the code-based capacities of the flexure critical specimen, both specimens have an applied load that is around or exceeds the code-based capacity of $42.1 \mathrm{kN}$, which justifies the shear failure and significant damage observed in the column sections of those flexure critical specimen. For the shear critical 
specimens, experimental shear capacity of $21.45 \mathrm{kN}$ is achieved by ES and $33.90 \mathrm{kN}$ by US - both are higher than the code-based shear capacity of $14.1 \mathrm{kN}$. This also clearly validates the shear failure observed in both these specimens and the extend of the damage observed such as the spalling and crushing mainly in the SCC portion of the columns.

Table 4.6: Experimental and theoretical flexural member capacity results comparison

\begin{tabular}{|c|c|c|c|c|c|}
\hline & & \multicolumn{2}{|c|}{ Theoretical capacities } & \multicolumn{2}{|c|}{ Experimental capacities } \\
\hline & & $\begin{array}{l}\text { Beam Flexural } \\
\text { capacity }(\mathrm{kNm})\end{array}$ & $\begin{array}{c}\text { Column } \\
\text { Flexural } \\
\text { Capacity }(\mathrm{kNm})\end{array}$ & $\begin{array}{l}\text { Beam Flexural } \\
\text { capacity }(\mathrm{kNm})\end{array}$ & $\begin{array}{c}\text { Column } \\
\text { Flexural } \\
\text { Capacity }(\mathrm{kNm})\end{array}$ \\
\hline & & \multicolumn{4}{|c|}{ Flexure Critical specimen } \\
\hline \multirow[t]{2}{*}{ EF- ECC Joint } & $\begin{array}{l}\text { SCC portion of } \\
\text { member }\end{array}$ & 10.67 & 17.72 & 6.39 & 2.31 \\
\hline & $\begin{array}{l}\text { ECC portion of } \\
\text { member }\end{array}$ & 7.88 & 10.51 & 10.40 & 9.04 \\
\hline \multirow{3}{*}{$\begin{array}{l}\text { UF- UHPC } \\
\text { joint }\end{array}$} & $\begin{array}{l}\text { SCC portion of } \\
\text { member }\end{array}$ & 10.67 & 17.72 & 8.52 & 3.08 \\
\hline & $\begin{array}{l}\text { UHPC portion of } \\
\text { member }\end{array}$ & 15.32 & 26.01 & 13.86 & 12.05 \\
\hline & & \multicolumn{4}{|c|}{ Shear Critical specimen } \\
\hline \multirow[t]{2}{*}{ ES- ECC joint } & $\begin{array}{l}\text { SCC portion of } \\
\text { member }\end{array}$ & 10.67 & 17.72 & 3.26 & 1.18 \\
\hline & $\begin{array}{l}\text { ECC portion of } \\
\text { member }\end{array}$ & 7.88 & 10.51 & 5.31 & 4.61 \\
\hline \multirow{2}{*}{$\begin{array}{l}\text { US- UHPC } \\
\text { joint }\end{array}$} & $\begin{array}{l}\text { SCC portion of } \\
\text { member }\end{array}$ & 10.67 & 17.72 & 5.15 & 1.86 \\
\hline & $\begin{array}{l}\text { UHPC portion of } \\
\text { member }\end{array}$ & 15.32 & 26.01 & 8.38 & 7.29 \\
\hline
\end{tabular}

Table 4.6 above outlines the code based and experimental flexural capacities of the beam and column members. For each member, the amount of flexure in each material is identified, such as in the SCC portion of the beam and the ECC portion of the beam. Figure 4.42 illustrates the location where the flexural capacities are obtained in both beam and column members. In most cases it can be seen that the code-based flexural capacities are greater than the experimental 
capacities for both beam and column sections achieved during testing. This justifies having shear failure in all specimen, and not flexure failure as discussed above. Only one specimen exceeds the theoretical capacity, which is flexure critical EF. A moment of $10.40 \mathrm{kNm}$ is applied onto the ECC portion of the beam, in which the code outlines a capacity of $7.88 \mathrm{kNm}$. This is evident by minor flexure cracks that were observed during testing. However, other than this specimen, all other members are below the theoretical code-based capacity, thus not having flexure failure is justified. Looking into the flexural capacity of the ECC and UHPC material portion of the beam/column members. It is clear that the UHPC has the highest flexure capacity as observed in both theoretical capacities and experimental capacities. The calculation for the code-based flexural capacity of the ECC portion of the beam seems to underestimate the flexural capacity of the beam. Since It outlines that the flexural capacity of the ECC portion of the beam is lower than the SCC portion of the beam, which is not the case.

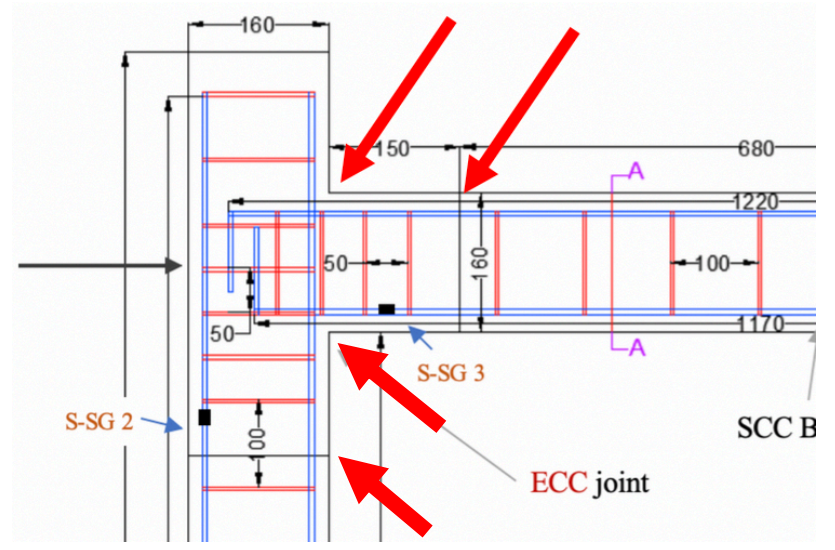

Figure 4.42: Location of calculating experimental \& theoretical flexure capacities

\subsection{Chapter Review}

This chapter presented the results obtained from the cyclic load testing of the four frame specimens, which included the test observations on the failure modes of the frames and crack development with and propagation observed in the joint section of the frame. Afterwards, the flexure critical frames and shear critical frames were analyzed separately by comparing their hysteretic load-deflection response and force vs. strain gauge response. Doing so helped understand the behaviour and performance of the frames. The initial stiffness and stiffness degradation of each of the specimens was analyzed, in addition to comparing the energy absorption of each frame. Lastly, the experimental and code-based member flexural and shear capacities were compared and analyzed. 


\section{Chapter 5 - Conclusion and Future Recommendations}

The use of high performance concretes (HPCs) such as self-consolidating concrete (SCC), engineered cementitious composite (ECC) and ultra-high performance concrete (UHPC) allows for utilizing their many benefits that range from high strength, ductility and durability in various structural applications. This project involved researching the structural behavior of beam-column frames with HPC joints under cyclic loading. The performance of the ECC/UHPC jointed SCC shear and flexure critical frames were investigated experimentally and theoretically using Code based/other existing design procedures. One ECC jointed flexure critical (EF) and one ECC jointed shear critical (ES) frames were tested. The other two frames consisted of UHPC joints with one being flexure critical (UF) and one being shear critical (US). The purpose of introducing these new HPCs is to provide alternatives to existing conventional concrete materials to develop building frames with enhanced strength, ductility, energy absorbing capacity and durability. Such HPC building frames with enhanced seismic resistance is vital for structures in earthquake prone areas. The structural behavior of the frames was tested under lateral cyclic loading to failure and their performance is analyzed based on hysteretic load-deformation response, rebar/concrete strain development, energy absorption, crack width propagation, stiffness degradation and failure modes. In addition, theoretical capacity of frame members that involved using code-based and other existing design formulations were compared to their experimental capacity. Section 5.1 will outline conclusions drawn from this research, with section 5.2 defining future recommendations.

\subsection{Conclusion}

The following conclusions have been drawn from this study:

- After testing, crack propagation and average crack width were measured in the joint material. It was observed that lower number of cracks and smaller average crack width were observed in the UHPC jointed specimens compared to their ECC counterparts. For example, comparing frames ES and US, the average crack width in the ECC joint was 0.33 $\mathrm{mm}$ compared to $0.195 \mathrm{~mm}$ in the UHPC joint. This was mainly attributed to the presence of steel fiber and silica fume in UHPC, which results in reducing the number and size of cracks in addition to delaying crack propagation. 
- High stiffness is observed in the UHPC jointed specimens as expected compared to its ECC counterparts. Peak load of $112.054 \mathrm{kN}$ was reached in the UF specimen compared to 84.23 $\mathrm{kN}$ of its ECC counterpart, EF.

- During cyclic loading, the ECC jointed frame specimens portrayed higher deformability properties since higher displacement were achieved by the frames. This can be attributed to the high strain hardening and tensile capacity properties of ECC. At peak load, the ECC jointed specimen EF achieved a displacement of $31 \mathrm{~mm}$ compared to $20 \mathrm{~mm}$ displacement of its UHPC counterpart UF.

- In addition to higher deformability, high ductility is also observed in ECC specimens as confirmed from the development of significantly higher tensile strains in ECC compared to UHPC specimen.

- The initial stiffness and stiffness degradation of the frames were calculated and analyzed. It was observed that the UHPC jointed frame UF exhibited higher initial stiffness of 9.44 $\mathrm{kN} / \mathrm{mm}$ when compared to $4.72 \mathrm{kN} / \mathrm{mm}$ of its ECC counterpart EF. Although the ECC joints had a lower initial stiffness compared to their UHPC counterparts, the very low stiffness degradation throughout the duration of cyclic loading is a clear indication of ECC's high ductility. The UHPC joints reached ultimate load at lower fatigue cycles in addition to a higher rate of stiffness degradation observed at each cycle compared to their ECC counterparts.

- Analysis of energy absorption capacity revealed that in the flexure critical specimen, EF performed better and achieved a higher energy absorption of 1246.70 Joules compared to its UHPC counterpart UF achieving 601.83 Joules. ECC's high ductility, high tensile capacity and strain hardening properties and micro-cracking capability allowed the frame to sustain large deformations with minimal damage.

- Experimental and theoretical member capacities were compared and analyzed. It was observed that UHPC had a higher joint shear strength of $203.9 \mathrm{kN}$, when compared to 167.1 $\mathrm{kN}$ of its ECC counterpart. However, both materials exceeded the amount of shear applied, thus not experiencing joint failure during testing was validated.

- Shear capacities of the members were analyzed, in which for the beam members, the experimental shear capacity was lower than the code-based shear capacities, justifying not getting any shear failure in the beams. 
- For the shear capacities of the SCC portion of the column, the experimental shear capacities met or exceeded the code-based capacities, validating the shear failure observed in the SCC portion of the column sections of the frames. However, the shear capacity of the ECC/UHPC portion of the column and beam members significantly exceeded the codebased capacities, thus indicating the need for modification of existing equations and procedures.

- For flexure critical frames both beam and column sections code-based flexural capacities were greater than the applied experimental capacities, thus justifying not observing flexure failure in the members.

- After considering all the factors that include; performance, crack width formation, stiffness, and energy absorption, ECC appears to be the more appropriate joint material to be used in such frames. Considering seismic regions, high seismic resistance of frames is necessary. Despite high stiffness and crack width properties of UHPC jointed frames, the ECC jointed frames with high energy absorption, high ductility, micro-cracking characteristics, high durability and lower cost will be the better choice for construction of building frames especially in seismic regions.

\subsection{Future Recommendations}

The following recommendations are suggested for future research studies:

- It is suggested that numerical and finite element (FEM) modeling should be conducted on the beam-column frames researched in this report.

- Investigations on interior joints utilizing SCC, ECC and UHPC material composition under monotonic/cyclic loading.

- Investigation on multi-storey frames consisting of SCC beam-column sections and ECC/UHPC joints. 


\section{Appendix A- Capacity Calculations}

Appendix A provides the detailed calculations for the theoretical member shear and flexural capacities. The procedure and equations used for the calculations is explained in section 2.5: Design of High-Performance concrete beam-column members found earlier in the report.

\section{A.1 Code-based Shear Capacity:}

The code-based shear capacity is calculated in this section for both beam-column members, including joint strength.

\section{A.1.1 SCC Beam Shear Capacity}

The shear resistance of the SCC beam member is calculated by equation 2.1. First the concrete shear resistance is calculated using equation 2.2. The SCC material consists of a compressive strength of $f_{c}^{\prime}=49.57 \mathrm{MPa}$, the $6 \mathrm{~mm}$ shear stirrup has a yield stress of $f_{y}=429 \mathrm{MPa}, \beta=0.21$ (Clause 11.3.6.2), $\lambda=1.0$, for normal density concrete. The effective shear depth is taken as the maximum of $0.9 d=0.9 \times 134 \mathrm{~mm}=120.6 \mathrm{~mm}$ and $0.72 \mathrm{~h}=0.72 \times 160 \mathrm{~mm}=115.2 \mathrm{~mm}$, therefore, $d_{v}=120.6 \mathrm{~mm} . d=160 \mathrm{~mm}-15 \mathrm{~mm}-6 \mathrm{~mm}-10 / 2 \mathrm{~mm}=134 \mathrm{~mm}$

$V_{c}=\varphi_{c} \lambda \beta \sqrt{f_{c}^{\prime}} b_{w} d_{v}=0.65 \times 1.0 \times 0.21 \times \sqrt{49.57 \mathrm{MPa}} \times 120 \mathrm{~mm} \times 120.6 \mathrm{~mm}=13.9 \mathrm{kN}$

The steel shear contribution is calculated using equation $2.3, A_{v}=56.5 \mathrm{~mm}^{2}$ (6 mm stirrups), $\theta=42^{\circ}$ (clause 11.3.6.2), and stirrup spacing of $100 \mathrm{~mm}$.

$V_{s}=\left(\varphi_{s} A_{v} f_{y} d_{v} \cot (\theta)\right) / s$

$V_{s}=\frac{\left(0.85 \times 56.5 \mathrm{~mm}^{2} \times 429 \mathrm{MPa} \times 120.6 \mathrm{~mm} \times \cot (42)\right)}{100 \mathrm{~mm}}=27.6 \mathrm{kN}$

The shear resistance is calculated using equation 2.1, in which the shear resistance of the prestressing steel is taken as zero.

$V_{r}=V_{c}+V_{s}+V_{p}=13.9 k N+27.6 k N+0 k N=\mathbf{4 1 . 5} \boldsymbol{k N}$ 
The maximum shear resistance is to be checked to make sure it satisfies the limit, $V_{r} \leq V_{r, \max }$, using equation 2.4

$V_{r, \max }=0.25 \varphi_{c} f_{c}^{\prime} b_{w} d_{v}=0.25 \times 0.65 \times 49.57 \mathrm{MPa} \times 120 \mathrm{~mm} \times 120.6 \mathrm{~mm}=116.6 \mathrm{kN}$

Therefore, the shear resistance satisfies the specified limit specified by the CSA A2.3-14, clause 11.3.3. The shear capacity of the SCC beam section is $41.5 \mathrm{kN}$.

\section{A.1.2 SCC Column Shear Capacity}

The same procedure is used to calculate the column shear capacity of the SCC member. Since the flexural reinforcement is different in the column sections (15M instead of $10 \mathrm{M})$, the cover of the member changed from $15 \mathrm{~mm}$ to $10.5 \mathrm{~mm}$. $d=160 \mathrm{~mm}-24 \mathrm{~mm}=136 \mathrm{~mm}$. Therefore, the effective shear depth taken as the maximum of $0.9 d=0.9 \times 136 \mathrm{~mm}=122.4 \mathrm{~mm}$ and $0.72 \mathrm{~h}=0.72 \times$ $160 \mathrm{~mm}=115.2 \mathrm{~mm}$, therefore, $d_{v}=122.4 \mathrm{~mm}$. Cover $=24 \mathrm{~mm}-(15 \mathrm{~mm} / 2)-6 \mathrm{~mm}=10.5 \mathrm{~mm}$.

$V_{c}=\varphi_{c} \lambda \beta \sqrt{f_{c}^{\prime}} b_{w} d_{v}=0.65 \times 1.0 \times 0.21 \times \sqrt{49.57 \mathrm{MPa}} \times 120 \mathrm{~mm} \times 122.4 \mathrm{~mm}=14.1 \mathrm{kN}$

$V_{s}=\frac{\left(0.85 \times 56.5 \mathrm{~mm}^{2} \times 429 \mathrm{MPa} \times 122.4 \mathrm{~mm} \times \cot (42)\right)}{100 \mathrm{~mm}}=28.0 \mathrm{kN}$

$V_{r}=V_{c}+V_{s}+V_{p}=14.1 k N+28.0 k N+0 k N=42.1 \mathbf{k N}$

$V_{r, \max }=0.25 \varphi_{c} f_{c}^{\prime} b_{w} d_{v}=0.25 \times 0.65 \times 49.57 \mathrm{MPa} \times 120 \mathrm{~mm} \times 122.4 \mathrm{~mm}=118.3 \mathrm{kN}$

Therefore. $V_{r}=42.1 k N \leq V_{r, \max }=118.3 \mathrm{kN}$

Therefore, the shear capacity of the SCC column is $42.1 \mathrm{kN}$. 


\section{A.1.3 ECC \& UHPC Joint Shear Strength \\ ECC Joint Strength:}

The joint shear strength is calculated using equation 2.5, in which, $\gamma=12$, which is a constant that depends on the beam-column connection, $f_{c}^{\prime}=76.37 \mathrm{MPa}, h_{c}=160 \mathrm{~mm}, b_{j}$ is the effective joint width, calculated using equation 2.6:

$b_{j} \ll\left\langle\frac{120 \mathrm{~mm}+120 \mathrm{~mm}}{2}=120 \mathrm{~mm},\right| 120 \mathrm{~mm}+\frac{0.5 \times 160 \mathrm{~mm}}{2}=160 \mathrm{~mm}$, and $|120 \mathrm{~mm}\rangle$

Therefore, $b_{j}=120 \mathrm{~mm}$

$V_{n}=0.083 \gamma \sqrt{f_{c}^{\prime}} b_{j} h_{c}=0.083 \times 12 \times \sqrt{76.37 M P a} \times 120 \mathrm{~mm} \times 160 \mathrm{~mm}=\mathbf{1 6 7 . 1} \mathbf{~ k N}$

Therefore, the ECC joint shear strength is $167.1 \mathrm{kN}$. This joint shear strength applies to both EF and UF, both flexure critical and shear critical specimen, since in both joints the minimum shear reinforcement in the joint is provided.

\section{UHPC Joint Strength:}

The joint shear strength for the UHPC specimens UF and US, is calculated using the same procedure. The compressive strength of the material changes, in which UHPC has a concrete compressive strength of $f_{c}^{\prime}=113.66 \mathrm{MPa}$

$V_{n}=0.083 \gamma \sqrt{f_{c}^{\prime}} b_{j} h_{c}=0.083 \times 12 \times \sqrt{113.66 \mathrm{MPa}} \times 120 \mathrm{~mm} \times 160 \mathrm{~mm}=\mathbf{2 0 3 . 9} \mathbf{~ k N}$

Therefore, the UHPC joint shear strength is $203.9 \mathrm{kN}$. 


\section{A.2 Code-based Flexural Capacity:}

The code-based flexural capacity is calculated in this section.

\section{A.2.1 SCC Beam flexural capacity}

The flexural capacity of the SCC portion of the beam is calculated using equation 2.7. The flexural reinforcement in the beam consists of $10 \mathrm{M}$ bars, in which, $A_{s}=200 \mathrm{~mm}^{2}$, the yielding stress of the flexural bar is $f_{y}=527 \mathrm{MPa}, \varphi_{s}=0.85, d=160 \mathrm{~mm}-26 \mathrm{~mm}=134 \mathrm{~mm}$. The depth of equivalent rectangular stress block, $a$, is calculated using equation 2.8, $\alpha_{1}=0.85-$ $(0.0015(40.57 M P a))=0.78>0.67$.

$a=\frac{\varphi_{s} A_{s} f_{y}}{\alpha_{1} \varphi_{c} f_{c}^{\prime} b}=\frac{0.85 \times 200 \mathrm{~mm}^{2} \times 527 \mathrm{MPa}}{0.78 \times 0.65 \times 49.57 \mathrm{MPa} \times 120 \mathrm{~mm}}=29.7 \mathrm{~mm}$

$M_{r}=\varphi_{s} A_{s} f_{y}\left(d-\frac{a}{2}\right)=0.85 \times 200 \mathrm{~mm}^{2} \times 527 \mathrm{MPa} \times\left(134 \mathrm{~mm}-\frac{29.7 \mathrm{~mm}}{2}\right)=\mathbf{1 0 . 6 7} \mathbf{k N m}$

Therefore, the flexural capacity of the SCC portion of the beam is $10.67 \mathrm{kNm}$.

\section{A.2.2 SCC Column flexural capacity}

For the column flexural capacity of the SCC portion of the member, the column consists of $15 \mathrm{M}$ bars, instead of $10 \mathrm{M}$ as in the beam section. The yielding stress of the flexural reinforcement is $478 \mathrm{MPa}, d=136 \mathrm{~mm}, A_{s}=400 \mathrm{~mm}^{2}$, therefore,

$$
\begin{aligned}
& a=\frac{\varphi_{s} A_{s} f_{y}}{\alpha_{1} \varphi_{c} f_{c}^{\prime} b}=\frac{0.85 \times 400 \mathrm{~mm}^{2} \times 478 \mathrm{MPa}}{0.78 \times 0.65 \times 49.57 \mathrm{MPa} \times 120 \mathrm{~mm}}=53.9 \mathrm{~mm} \\
& M_{r}=\varphi_{s} A_{s} f_{y}\left(d-\frac{a}{2}\right)=0.85 \times 400 \mathrm{~mm}^{2} \times 478 \mathrm{MPa} \times\left(136 \mathrm{~mm}-\frac{53.9 \mathrm{~mm}}{2}\right)=\mathbf{1 7 . 7 2} \mathbf{~ N m}
\end{aligned}
$$

Therefore, the flexural capacity of the SCC portion of the column is $17.72 \mathrm{kNm}$. 


\section{A.2.3 ECC Beam flexural capacity}

The flexural capacity of the ECC portion of the beam is calculated using equation 2.9 (Yeganeh, 2015).

$M_{r}=\left[T_{\text {steel }} d+T_{E C C-1}\left(\frac{\left(1-n_{\varepsilon}\right) d+c}{2}+n_{\varepsilon} d\right)+T_{E C C-2}\left(\frac{2}{3}\right) n_{\varepsilon} d+C_{E C C}\left(\frac{2}{3}\right)\left(t_{s}-d-c\right)\right]\left(\frac{1}{1000}\right)$

In which, the force in the steel, $T_{\text {steel }}$, is calculated using equation 2.10 .

$T_{\text {steel }}=0.4 f_{y} A_{s}=0.4 \times 527 \mathrm{MPa} \times 200 \mathrm{~mm}^{2}=42.16 \mathrm{kN}$

The tensile force of the ECC material, is calculated by $T_{E C C-1}$ and $T_{E C C-2}$, using equations 2.11 and 2.12. In which, $f_{t}=3.45 \mathrm{MPa}$ is the tensile stress of the ECC, $c=26 \mathrm{~mm}, b=120 \mathrm{~mm}, n_{\varepsilon}$ is the modular ratio, calculated using equation $2.12, \varepsilon_{y-\text { steel }}=0.00231$ from table 3.4. $d$, is the distance from the neutral axis to the center of the tensile flexural reinforcement, which will be calculated using equilibrium of the forces.

$n_{\varepsilon}=\frac{\varepsilon_{y-E C C}}{0.4 \varepsilon_{y-s t e e l}}=\frac{0.0002}{0.4 \times 0.00231}=0.216$

$T_{E C C-1}=f_{t}\left[\left(1-n_{\varepsilon}\right) d+c\right] b=3.45 \mathrm{~N} / \mathrm{mm}^{2} \times[(1-0.216) \times d+26 \mathrm{~mm}] \times 120 \mathrm{~mm}=$

$T_{E C C-1}=324.6 \mathrm{~N} / \mathrm{mm}(d)+10764 \mathrm{~N}$

$T_{E C C-2}=0.5 f_{t} n_{\varepsilon} d b=0.5 \times 3.45 \mathrm{MPa} \times 0.216 \times d \times 120 \mathrm{~mm}=44.71 \mathrm{~N} / \mathrm{mm}(\mathrm{d})$

The concrete compressive contribution, $C_{E C C}$, is calculated using equation 2.13 , in which, $t_{s}$ is the depth of the section $=160 \mathrm{~mm}$

$C_{E C C}=0.5 f_{t}\left(\frac{1}{n_{\varepsilon} d}\right)\left(t_{s}-d-c\right)^{2} b$

$C_{E C C}=0.5 \times 3.45 \mathrm{MPa} \times\left(\frac{1}{0.216 \times d}\right)(160 \mathrm{~mm}-\mathrm{d}-26 \mathrm{~mm})^{2} \times 120 \mathrm{~mm}$ 
Therefore, through equilibrium, $T_{\text {steel }}+T_{E C C-1}+T_{E C C-2}=C_{E C C}$

Solving this equation, results in $d=63.1 \mathrm{~mm}$

Therefore, knowing $d$, the forces can be calculated:

- $T_{\text {steel }}=42.16 \mathrm{kN}$

- $T_{E C C-1}=31.25 \mathrm{kN}$

- $T_{E C C-2}=2.82 \mathrm{kN}$

- $C_{E C C}=76.35 \mathrm{kN}$

Finally, the flexural capacity can be calculated using equation 2.9

$M_{r}=\left[T_{\text {steel }} d+T_{E C C-1}\left(\frac{\left(1-n_{\varepsilon}\right) d+c}{2}+n_{\varepsilon} d\right)+T_{E C C-2}\left(\frac{2}{3}\right) n_{\varepsilon} d+C_{E C C}\left(\frac{2}{3}\right)\left(t_{s}-d-c\right)\right]\left(\frac{1}{1000}\right)$

$M_{r}=\left[(42.16 \mathrm{kN} \times 62.64 \mathrm{~mm})+\left(31.25 \mathrm{kN} \times\left(\frac{(1-0.216) 63.1 \mathrm{~mm}+26 \mathrm{~mm}}{2}+0.216 \times 63.1 \mathrm{~mm}\right)+(2.82 \mathrm{kN} \times\right.\right.$ $\left.\left.\left(\frac{2}{3}\right) \times 0.216 \times 63.1 \mathrm{~mm}\right)+76.35 \mathrm{kN} \times\left(\frac{2}{3}\right)(160 \mathrm{~mm}-63.1 \mathrm{~mm}-26 \mathrm{~mm})\right] \times\left(\frac{1}{1000}\right)=7.88 \mathrm{kNm}$

Therefore, the flexural capacity of the ECC portion of the beam, $M_{r}=7.88 \mathrm{kNm}$.

\section{A.2.4 ECC Column flexural capacity}

The flexural capacity of the ECC portion of the column is calculated using equation 2.9 (Yeganeh, 2015).

$M_{r}=\left[T_{\text {steel }} d+T_{E C C-1}\left(\frac{\left(1-n_{\varepsilon}\right) d+c}{2}+n_{\varepsilon} d\right)+T_{E C C-2}\left(\frac{2}{3}\right) n_{\varepsilon} d+C_{E C C}\left(\frac{2}{3}\right)\left(t_{s}-d-c\right)\right]\left(\frac{1}{1000}\right)$

$T_{\text {steel }}=0.4 f_{y} A_{s}=0.4 \times 428 \mathrm{MPa} \times 400 \mathrm{~mm}^{2}=68.5 \mathrm{kN}$ 
The tensile force of the ECC material, is calculated by $T_{E C C-1}$ and $T_{E C C-2}$, using equations 2.11 and 2.12. In which, $f_{t}=3.45 \mathrm{MPa}$ is the tensile stress of the ECC, $c=24 \mathrm{~mm}, b=120 \mathrm{~mm}, n_{\varepsilon}$ is the modular ratio, calculated using equation $2.14, \varepsilon_{y-\text { steel }}=0.002240$ from table 3.4 . $d$, is the distance from the neutral axis to the center of the tensile flexural reinforcement, which will be calculated using equilibrium of the forces.

$$
\begin{aligned}
& n_{\varepsilon}=\frac{\varepsilon_{y-E C C}}{0.4 \varepsilon_{y-\text { steel }}}=\frac{0.0002}{0.4 \times 0.002240}=0.223 \\
& T_{E C C-1}=f_{t}\left[\left(1-n_{\varepsilon}\right) d+c\right] b=3.45 \mathrm{~N} / \mathrm{mm}^{2} \times[(1-0.223) \times d+24 \mathrm{~mm}] \times 120 \mathrm{~mm}= \\
& T_{E C C-1}=321.7 \mathrm{~N} / \mathrm{mm}(d)+9936 \mathrm{~N} \\
& T_{E C C-2}=0.5 f_{t} n_{\varepsilon} d b=0.5 \times 3.45 \mathrm{MPa} \times 0.223 \times d \times 120 \mathrm{~mm}=46.16 \mathrm{~N} / \mathrm{mm}(d)
\end{aligned}
$$

The concrete compressive contribution, $C_{E C C}$, is calculated using equation 2.13 , in which, $t_{s}$ is the depth of the section $=160 \mathrm{~mm}$

$$
\begin{aligned}
& C_{E C C}=0.5 f_{t}\left(\frac{1}{n_{\varepsilon} d}\right)\left(t_{s}-d-c\right)^{2} b \\
& C_{E C C}=0.5 \times 3.45 \mathrm{MPa} \times\left(\frac{1}{0.223 \times d}\right)(160 \mathrm{~mm}-d-24 \mathrm{~mm})^{2} \times 120 \mathrm{~mm}
\end{aligned}
$$

Therefore, through equilibrium, $T_{\text {steel }}+T_{E C C-1}+T_{E C C-2}=C_{E C C}$

Solving this equation, results in $d=57.47 \mathrm{~mm}$

Therefore, knowing $d$, the forces can be calculated:

- $T_{\text {steel }}=68.5 \mathrm{kN}$

- $T_{E C C-1}=28.4 \mathrm{kN}$

- $T_{E C C-2}=2.65 \mathrm{kN}$ 
- $C_{E C C}=99.6 \mathrm{kN}$

Finally, the flexural capacity can be calculated using equation 2.9

$M_{r}=\left[T_{\text {steel }} d+T_{E C C-1}\left(\frac{\left(1-n_{\varepsilon}\right) d+c}{2}+n_{\varepsilon} d\right)+T_{E C C-2}\left(\frac{2}{3}\right) n_{\varepsilon} d+C_{E C C}\left(\frac{2}{3}\right)\left(t_{s}-d-c\right)\right]\left(\frac{1}{1000}\right)$

$M_{r}=\left[(68.5 \mathrm{kN} \times 57.47 \mathrm{~mm})+\left(28.4 \mathrm{kN} \times\left(\frac{(1-0.223) 57.47 \mathrm{~mm}+24 \mathrm{~mm}}{2}+0.223 \times 57.47 \mathrm{~mm}\right)+(2.65 \mathrm{kN} \times\right.\right.$ $\left.\left.\left(\frac{2}{3}\right) \times 0.223 \times 57.47 \mathrm{~mm}\right)+99.6 \mathrm{kN} \times\left(\frac{2}{3}\right)(160 \mathrm{~mm}-57.47 \mathrm{~mm}-24 \mathrm{~mm})\right] \times\left(\frac{1}{1000}\right)=\mathbf{1 0 . 5 1} \mathbf{~ N m}$

Therefore, the flexural capacity of the ECC portion of the column, $M_{r}=10.51 \mathrm{kNm}$. 


\section{A.2.5 UHPC Beam flexural capacity}

To calculate the flexural capacity of the UHPC portion of the beam for UF and US, equation 2.15 is used (Yeganeh, 2015). The equivalent rectangular stress block, a, is calculated using equation 2.16. In which, $A_{s}=200 \mathrm{~mm}^{2}, f_{y}=527 \mathrm{MPa}, \mathrm{b}=120 \mathrm{~mm}, \mathrm{~h}=160 \mathrm{~mm}, \lambda=0.86$ for $f_{c}^{\prime} \geq 55 \mathrm{MPa}$, $f_{c f}^{\prime}=113.7 \mathrm{MPa}$ (compressive strength of the fibrous concrete), and $\sigma_{t}$, the ultimate tensile strength of fibrous concrete, using equation 2.17 .

To calculate $\sigma_{t}$, the following fiber properties of the UHPC material is used as specified in (Yeganeh, 2015). In which, $\eta_{o}=0.41$ (orientation factor), $\eta_{b}=0.5$ (round fibers), $\eta_{l}=0.86$ (length efficiency factor), $V_{f}=0.021 \%$ (volume fraction of steel fiber), $l_{f}=14 \mathrm{~mm}$ (length of fiber), $d_{f}=0.4 \mathrm{~mm}$ (diameter of fibers), and $\tau_{f}=0.66 \sqrt{f_{c}^{\prime}}=0.66 \times \sqrt{113.7 M P a}$. Therefore: $\sigma_{t}=2 \eta_{o} \eta_{b} \eta_{l} V_{f} \tau_{f}\left(\frac{l_{f}}{d_{f}}\right)$

$\sigma_{t}=2 \times 0.41 \times 0.5 \times 0.86 \times 0.021 \times(0.66 \times \sqrt{113.7 M P a}) \times\left(\frac{14 \mathrm{~mm}}{0.4 \mathrm{~mm}}\right)=1.82 \mathrm{MPa}$

Therefore, the equivalent rectangular stress block:

$$
\begin{aligned}
& a=\frac{\left(A_{s} f_{y}+\sigma_{t} b h\right)}{\lambda f_{c f}^{\prime} b+\sigma_{t} b} \\
& a=\frac{\left(\left(200 \mathrm{~mm}^{2} \times 527 M P a\right)+(1.82 \mathrm{MPa} \times 120 \mathrm{~mm} \times 160 \mathrm{~mm})\right)}{(0.86 \times 113.7 M P a \times 120 \mathrm{~mm})+(1.82 \mathrm{MPa} \times 120 \mathrm{~mm})}=11.74 \mathrm{~mm}
\end{aligned}
$$

Therefore, the moment capacity of the UHPC portion of the beam is:

$$
\begin{aligned}
& M_{n}=A_{s} f_{y}\left(d-\frac{a}{2}\right)+\sigma_{t} b(h-c)(h+c-a) / 2 \\
& \begin{aligned}
M_{n}=\left[200 \mathrm{~mm}^{2}\right. & \left.\times 527 \mathrm{MPa}\left(134 \mathrm{~mm}-\frac{11.74 \mathrm{~mm}}{2}\right)\right] \\
+ & {[1.82 \mathrm{MPa} \times 120 \mathrm{~mm} \times(160 \mathrm{~mm}-90 \mathrm{~mm}) \times(160 \mathrm{~mm}+90 \mathrm{~mm}} \\
& -11.74 \mathrm{~mm}) / 2]=13.5 \mathrm{kNm}+1.82 \mathrm{kNm}=\mathbf{1 5 . 3 2} \mathbf{k N m}
\end{aligned}
\end{aligned}
$$


Therefore, the flexural capacity of the UHPC portion of the beam is $15.32 \mathrm{kNm}$.

\section{A.2.6 UHPC Column flexural capacity}

To calculate the flexural capacity of the UHPC portion of the column in specimens UF \& US. The equivalent rectangular stress block, a, is calculated using equation 2.16. In which, $A_{s}=400 \mathrm{~mm}^{2}$, $f_{y}=478 \mathrm{MPa}, b=120 \mathrm{~mm}, d=136 \mathrm{~mm}, h=160 \mathrm{~mm}, \lambda=0.86$ for $f_{c}^{\prime} \geq 55 \mathrm{MPa}, f_{c f}^{\prime}=$ 113.7 $\mathrm{MPa}$ (compressive strength of the fibrous concrete), and $\sigma_{t}$, the ultimate tensile strength of fibrous concrete $=1.82 \mathrm{MPa}$ (Calculated above).

Therefore, the equivalent rectangular stress block:

$$
a=\frac{\left(\left(400 \mathrm{~mm}^{2} \times 478 M P a\right)+(1.82 \mathrm{MPa} \times 120 \mathrm{~mm} \times 160 \mathrm{~mm})\right)}{(0.86 \times 113.7 \mathrm{MPa} \times 120 \mathrm{~mm})+(1.82 \mathrm{MPa} \times 120 \mathrm{~mm})}=18.92 \mathrm{~mm}
$$

Therefore, the moment capacity of the UHPC portion of the beam is:

$$
\begin{aligned}
M_{n}=\left[400 \mathrm{~mm}^{2}\right. & \left.\times 478 \mathrm{MPa}\left(136 \mathrm{~mm}-\frac{18.92 \mathrm{~mm}}{2}\right)\right] \\
+ & {[1.82 \mathrm{MPa} \times 120 \mathrm{~mm} \times(160 \mathrm{~mm}-90 \mathrm{~mm}) \times(160 \mathrm{~mm}+90 \mathrm{~mm}} \\
- & 11.74 \mathrm{~mm}) / 2]=24.19 \mathrm{kNm}+1.82 \mathrm{kNm}=\mathbf{2 6 . 0 1 ~} \mathbf{k N m}
\end{aligned}
$$

Therefore, the flexural capacity of the UHPC portion of the beam is $26.01 \mathrm{kNm}$. 


\section{A.3 Experimental Flexural \& Shear Capacity:}

The experimental flexural and shear capacity are obtained using the Portal Method. The Portal Method is an approximate analysis that assumes inflection points at the mid-points of the frames members, therefore, internal hinges are placed in the center of the member frames to achieve a statically determinate frame (Kassimali, 2011). This allows for the calculation of the frame reactions. The shear force diagram (SFD) is drawn to obtain the column and beam shear capacity, which is constant along both different type of materials. The bending moment diagram is also drawn to obtain the flexural capacity of the beam and column members at critical sections. For ECC/UHPC, the flexural capacity is obtained at the corner of the joint-column/beam section, and for the SCC portion of the beam/column, it is obtained at the interface between the ECC and SCC material or UHPC and SCC material.

\section{EF: ECC joint- Flexure critical frame}

For EF, which is the flexure critical frame consisting of an ECC joint. The peak load achieved by this specimen is $84.2 \mathrm{kN}$, in which the reactions obtained are presented in the figure A-1. The shear force diagram and bending moment diagram are presented in figure A-2. From the shear force diagram below:

- Column shear capacity $=42.1 \mathrm{kN}$

- Beam Shear capacity $=25.1 \mathrm{kN}$

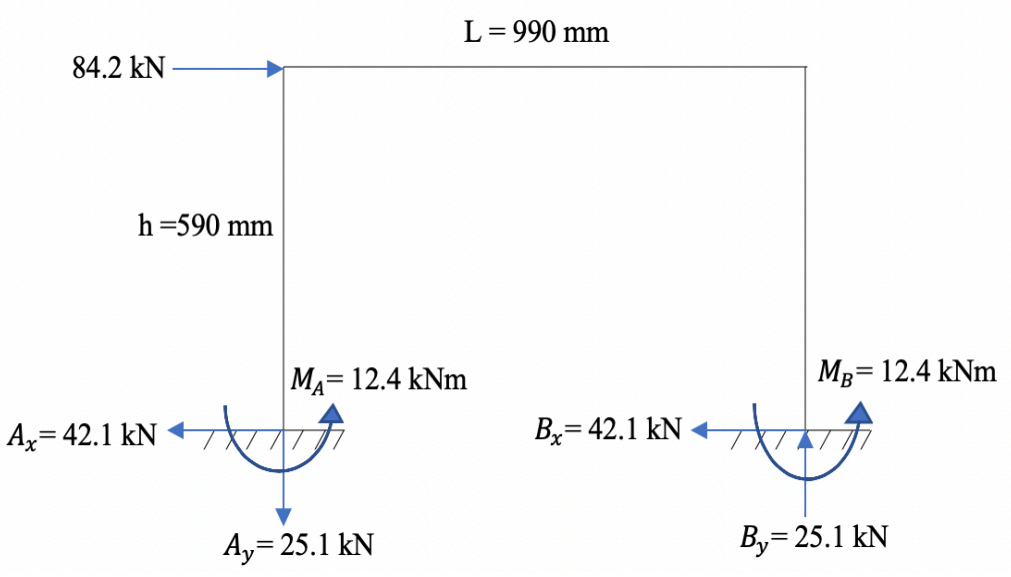

Figure A- 1: EF Reactions 
From the bending moment diagram, it can be seen:

- Column Flexural capacity:

○ ECC portion: $9.04 \mathrm{kNm}$,

○ SCC portion: $2.31 \mathrm{kNm}$.

- Beam Flexural capacity:

○ ECC portion: $10.40 \mathrm{kNm}$,

○ SCC portion: $6.39 \mathrm{kNm}$.

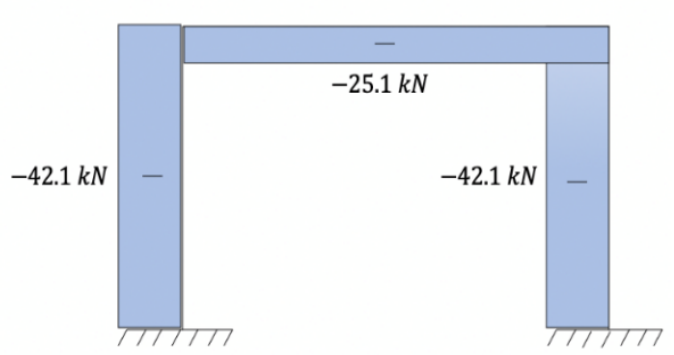

SFD

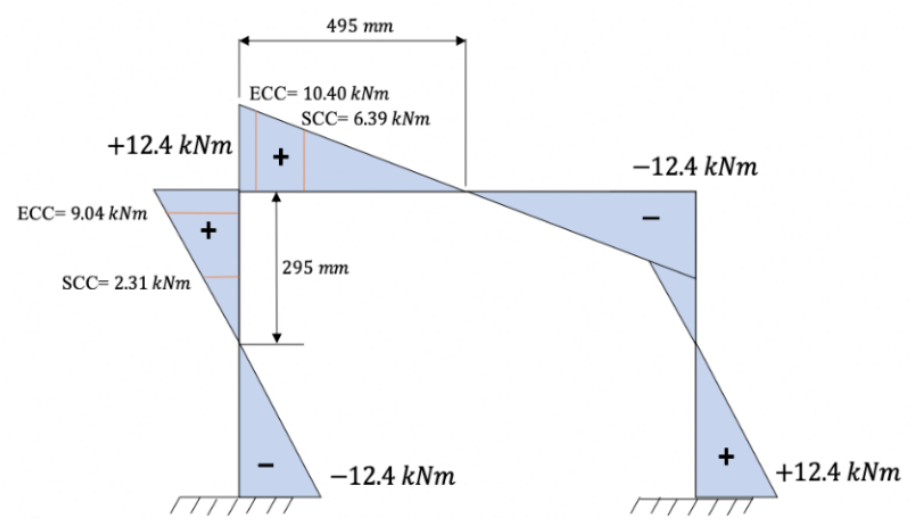

BMD

Figure A- 2: EF SFD \& BMD 


\section{ES: ECC joint- Shear critical frame}

For ES, which is the shear critical frame consisting of an ECC joint. The peak load achieved by this specimen is $42.9 \mathrm{kN}$, in which the reactions obtained are presented in the figure A-3. The SFD and $\mathrm{BMD}$ are presented in figure $\mathrm{A}-4$, from the shear force diagram below:

- Column shear capacity $=21.45 \mathrm{kN}$

- Beam Shear capacity $=12.78 \mathrm{kN}$

From the bending moment diagram, it can be seen:

- Column Flexural capacity:

○ ECC portion: $4.61 \mathrm{kNm}$,

○ SCC portion: $1.18 \mathrm{kNm}$.

- Beam Flexural capacity:

○ ECC portion: $5.31 \mathrm{kNm}$,

○ SCC portion: $3.26 \mathrm{kNm}$

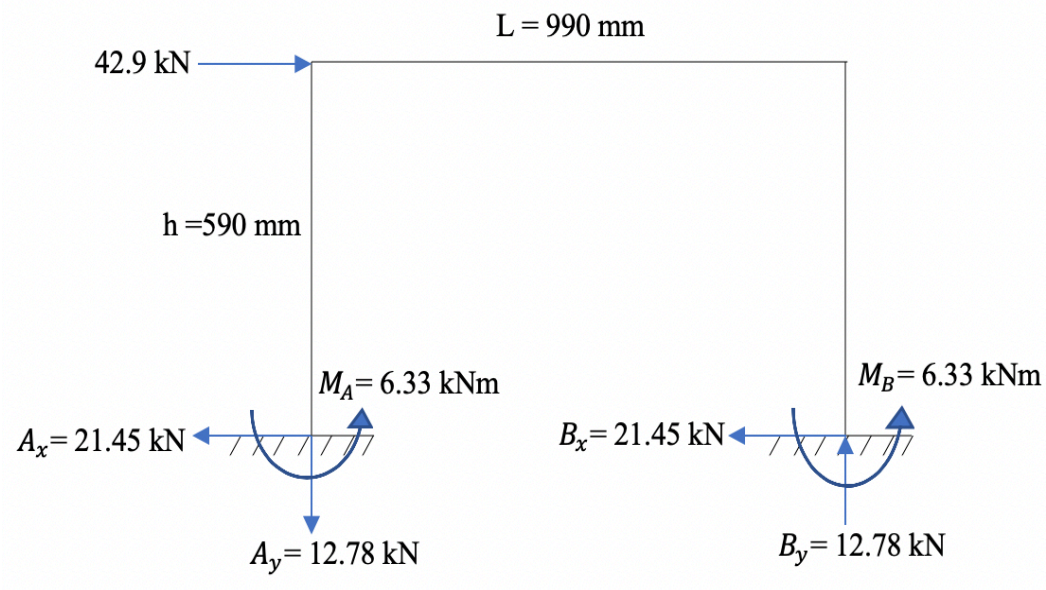

Figure A- 3: ES Reactions 

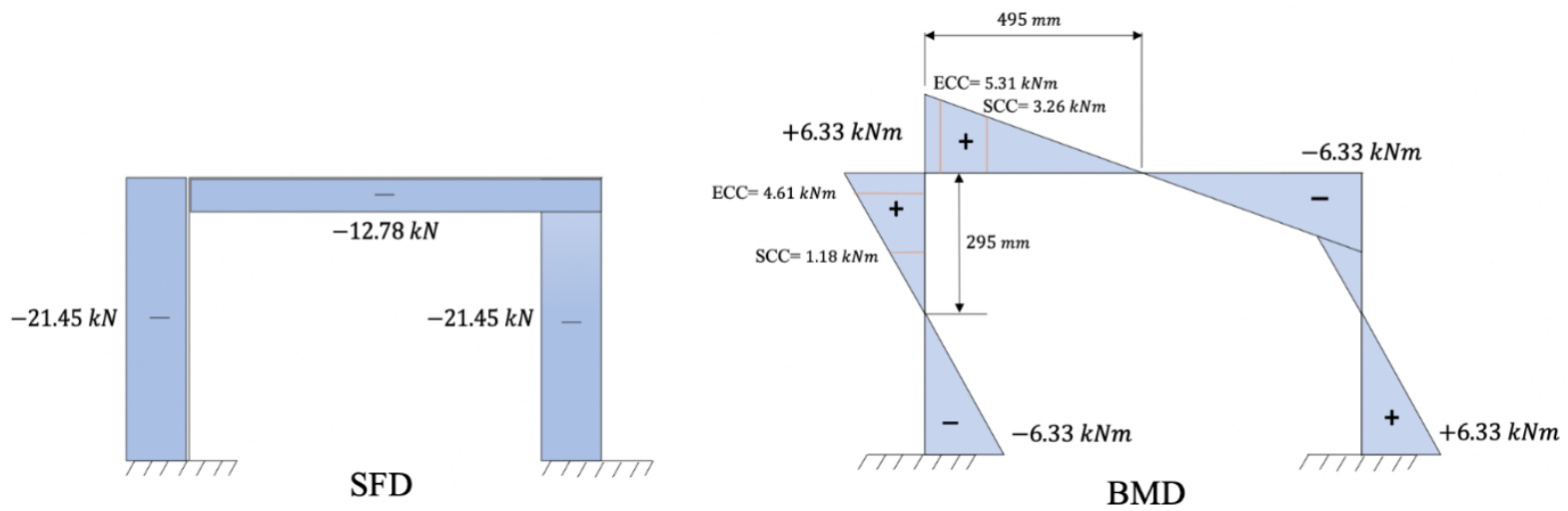

Figure A- 4: ES SFD \& BMD 


\section{UF: UHPC joint- Flexure critical frame}

1. For UF, which is the flexure critical frame consisting of an UHPC joint. The peak load achieved by this specimen is $112.05 \mathrm{kN}$, in which the reactions obtained are presented in figure A-5. The SFD and BMD are presented in figure A-6, from the shear force diagram below:

- Column shear capacity $=56.03 \mathrm{kN}$

- $\quad$ Beam Shear capacity $=33.39 \mathrm{kN}$

From the bending moment diagram, it can be seen:

- Column Flexural capacity:

○ UHPC portion: $12.05 \mathrm{kNm}$,

○ SCC portion: $3.08 \mathrm{kNm}$.

- Beam Flexural capacity:

○ UHPC portion: $13.86 \mathrm{kNm}$,

○ SCC portion: $8.52 \mathrm{kNm}$

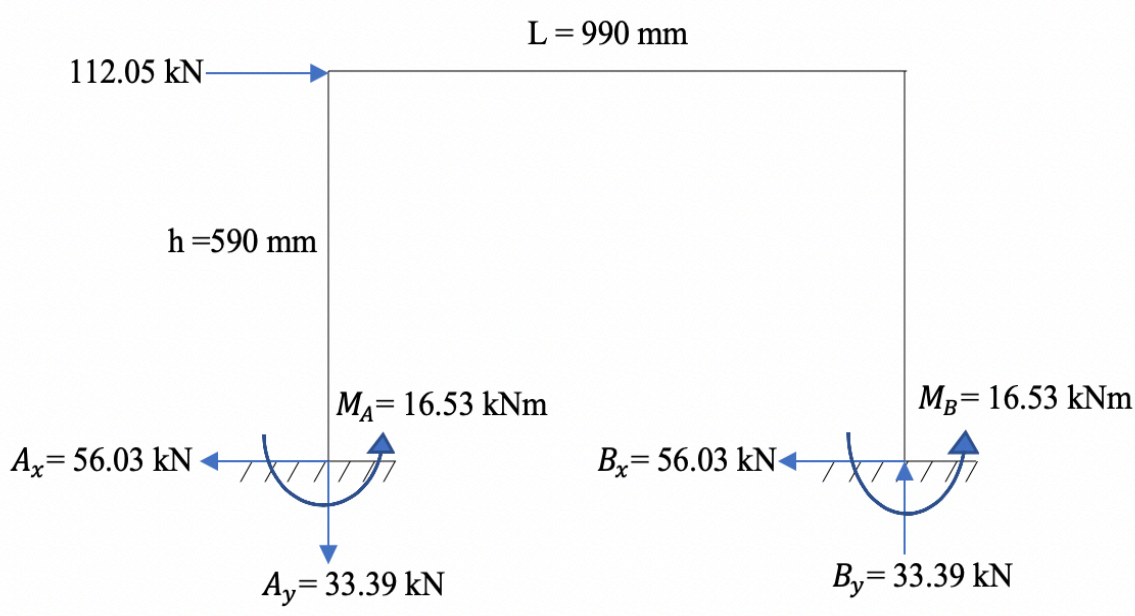

Figure A- 5: UF Reactions 


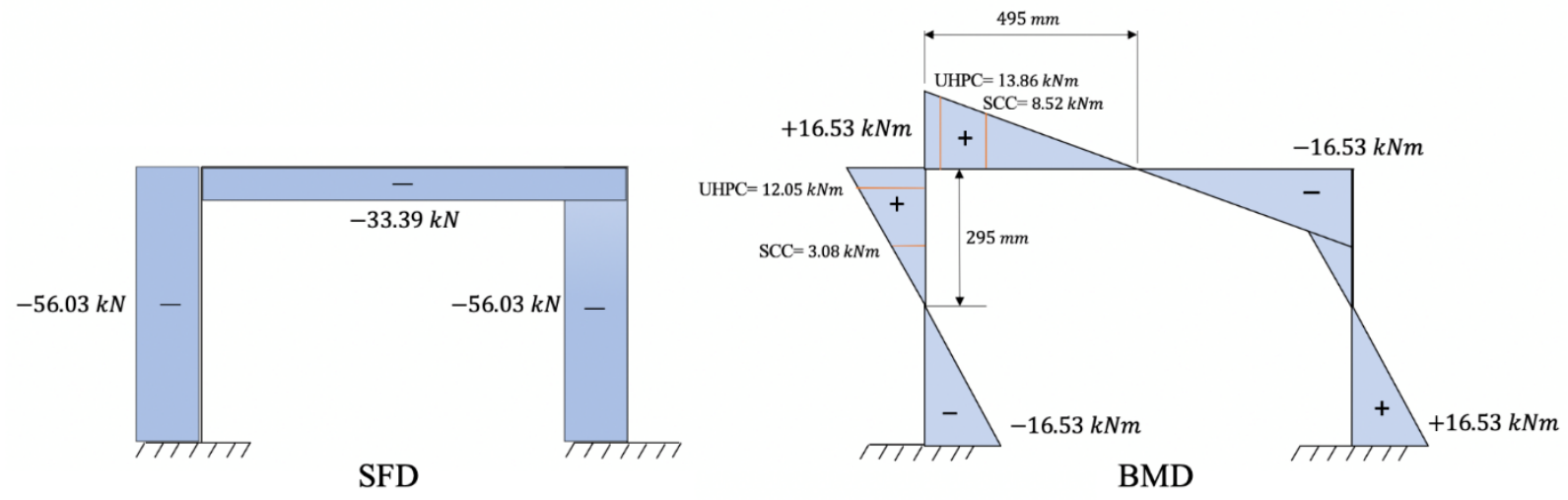

Figure A- 6: UF SFD \& BMD 


\section{US: UHPC joint- Shear critical frame}

For US, which is the shear critical frame consisting of an UHPC joint. The peak load achieved by this specimen is $67.80 \mathrm{kN}$, in which the reactions obtained are presented in figure A-7. The SFD \& BMD for US is presented in figure A-8, from the shear force diagram below:

- Column shear capacity $=33.9 \mathrm{kN}$

- Beam Shear capacity $=20.20 \mathrm{kN}$

From the bending moment diagram, it can be seen:

- Column Flexural capacity:

○ UHPC portion: $7.29 \mathrm{kNm}$,

○ SCC portion: $1.86 \mathrm{kNm}$.

- Beam Flexural capacity:

○ UHPC portion: $8.38 \mathrm{kNm}$

○ SCC portion: $5.15 \mathrm{kNm}$

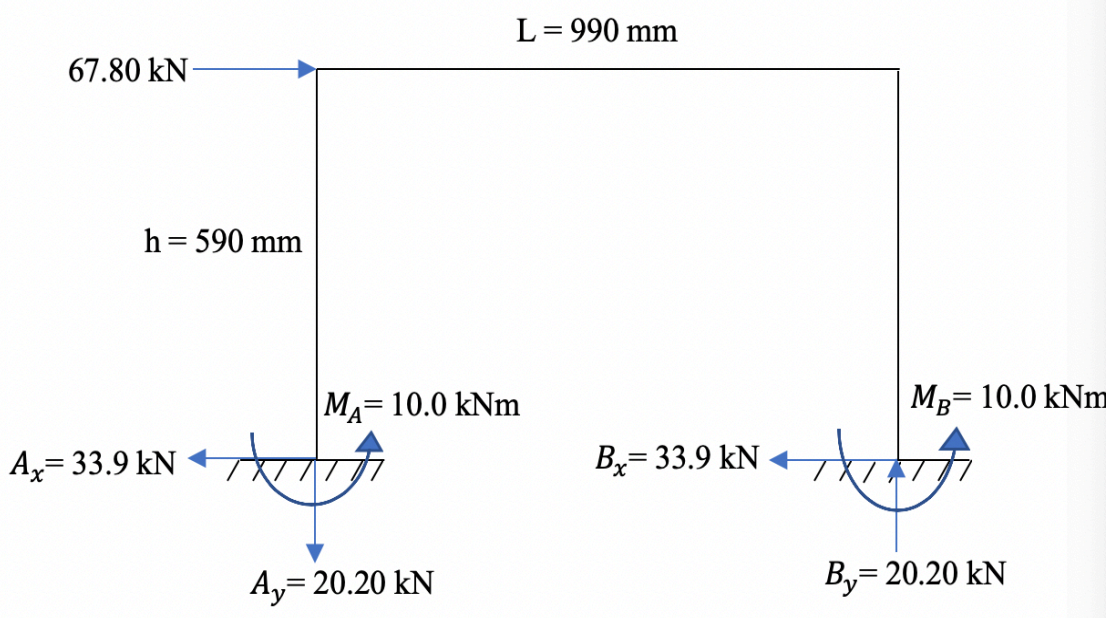

Figure A- 7: US Reactions 


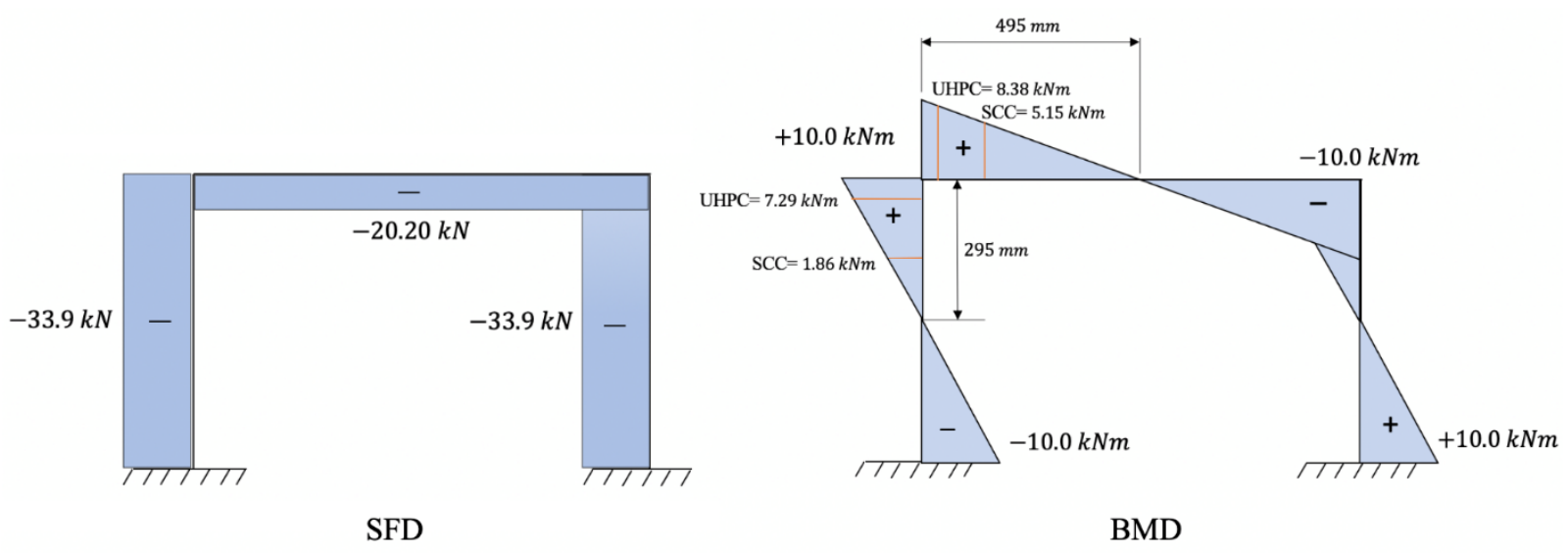

Figure A- 8: US SFD \& BMD 


\section{References}

Özbay, E., Karahan, O., Lachemi, M., Hossain, K.M.A., \& Atis, C. D. (2012). Investigation of properties of engineered cementitous composites incorporating high volumes of fly ash and metakaolin. ACI Materials Journal, 109(5), 565-571.

Abbas, A. N., Ali, S. K., \& Waryoosh, W. A. (2018). Behavior of reinforced concrete frames with different beam-column joints types. International Journal of Applied Engineering Research, 13(11), 9450-9456.

ACI-ASCE Committee 352. (2002). Recommendations for Design of Beam-Column Connections in Monolithic Reinforced Concrete Structures . ACI .

ASTM International. (2018). ASTM C78 / C78M-18, Standard Test Method for Flexural Strength of Concrete (Using Simple Beam with Third-Point Loading). West Conshohocken, PA.

ASTM International. (2020). ASTM C39 / C39M-20, Standard Test Method for Compressive Strength of Cylindrical Concrete Specimens. West Conshohocken, PA.

Candido, L., \& Micelli, F. (2018). Seismic behavior of regular reinforced concrete plan frames with fiber reinforced concrete in joints. Bull Earthquake Engineering, 16, 4107-4132.

Changwang, Y., \& Jinqing, J. (2010). Seismic performance of steel reinforced ultra highstrength concrete composite frame joints. Earthquake Engineering \& Engineering Vibration, 9(3), 439-448.

CSA. (2014). A23.3-14 - Design of concrete structures. CSA Group.

CSA. (2016). Concrete Design Handbook- 4th Edition (Vol. 4th Edition). Canada: CSA.

Fehling, E., Schmidt M.I., \& Walraven, J. (2015). Ultra-high performance concrete (uhpc): fundamentals, design, examples. Germany: Ernst \& Sohn.

Gencturk, B. (2013). Life-cycle cost assessment of RC and ECC frames using structural optimization. Earthquake Engineering \& Structural Dynamics, 42, 61-79.

Hossain, K.M.A. (2014). Behaviour of ECC link slabs for joint-free bridge construction. Structural Faults + Repair, European Bridge Conference. Imperial College, London, UK.

Hossain, K.M.A. (2018). Bond Strength of GFRP Bars Embedded in Engineered Cementitious Composite using RILEM Beam Testing. International Journal of Concrete Structures and Materials, 12(1). 
Hossain, K.M.A., \& Anwar, M. (2014). Strength and deformation characteristics of ECC link slab in joint-free bridge decks. Istanbul Bridge Conference, 1-12.

Hossain, K.M.A., \& Lachemi, M. (2010). • Fresh, mechanical, and durability characteristics of self-consolidating concrete incorporating volcanic ash. ASCE Journal Materials in Civil Engineering, 22(7), 651-657.

Hossain, K.M.A., Ametrano, D., \& Lachemi, M. (2017). Bond strength of GFRP bars in ultrahigh strength concrete using RILEM beam tests. Journal of Building Engineering, 10, 6979.

Hossain, K.M.A., Attarde S., \& Anwar, M. (2019). Finite element modelling of profiled steel deck composite slab system with engineered cementitious composite under monotonic loading. Engineering Structures, 186, 13-25.

Hossain, K.M.A., Ghatrehsamani, S., \& Anwar, M. (2015). Flexural fatigue performance of ECC link slabs for bridge deck applications. Sustainable Bridge Structure, Chapter 22, 247 260.

Hossain, K.M.A., Gladson , L., \& Anwar, M. (2017). Modeling shear strength of medium to ultra-high strength steel fiber reinforced concrete beams using artificial neural network. Neural Computing and Applications Journal, 28(1), 1119-1130.

Hossain, K.M.A., Hossain, M., \& Manzur, T. (2020). Structural performance of fiber reinforced lightweight self-compacting concrete beams subjected to accelerated corrosion. Journal of Building Engineering, 30, 101-291.

Hossain, K.M.A., Mak, C., \& Ametrano, D. (2012). GFRP reinforced UHPC composites for sustainable bridge construction. Canadian Civil Engineer, 29(1), 12-15.

Hossain, K.M.A., Samani, S.G., \& Anwar, M.S. (2018). Regression and artificial neural network models for strength properties of engineered cementitious composites. Neural Computing and Applications, 29(9), 631-645.

Hussein, H. H., Walsh, K. K., \& Sargand, S. M. (2016). Interfacial properties of ultrahighperformance concrete and high-strnegth concrete bridge connections. American Sociate of Civil Engineers, 28(5), 1-10.

Hwang, S.-D., Khayat, K. H., \& Bonneau, O. (2006). Performance-based specifcations of slefconsolidating concrete used in structural applications. ACI Materials, 103(2), 121-129. 
Issani, R. A. (2012). Flexural behaviour of ECC coupling slab in coupled shear wall structure. Master's Thesis, 1-135.

Issani, R., \& Hossain, K.M.A. (2013, May 29). High performance ECC floor slabs in coupled shear wall structures. 3rd Specialty Conference on Material Engineering \& Applied Mechanics.

Köksal, F., Altun, F., \& Yigit, I. (2007). Combined effect of silica fume and steel fiber on the mechanical properties of high strength concretes. Construction and Building Materials, 22(8), 1874-1880.

Kang, T. H., Kim, S., Shin, J. H., \& LaFave, J. M. (2019). Seismic behavior of exterior beamcolumn connections with high-strength materials and steel fibers. ACI Structural Journal, $116(4), 31-43$.

Kassimali, A. (2011). Structural Analysis- 4th Edition, SI. Illinois: Christopher M. Shortt.

Khalil, W. I., \& Tayfur, Y. (2013). Flexural strength of fibrous ultra high perofmrance reinforced concrete beams. ARPN Journal of Engineering and applied sciences, 8(3), 200-214.

Khayat, K. H. (1999). Workability, testing, and performance of self-consolidating concrete. $A C I$ Materials Journal, 96(3), 346-353.

Lachemi, M., Hossain, K.M.A., Lambros, V., Nkinamubanzi, P., \& Bouzoubaâ, N. (2004). Selfcompacting concrete incorporating new viscosity modifying admixtures. Cement and Concrete Research, 34(6), 917-926.

Lepech, M. D., \& Li, V. (2009). Application of ECC for bridge deck link slabs. Journal of Materials and Structures, 42(9), 1-11.

Li, M., \& Li, V. C. (2011). Behavior of ECC/Concrete layer repair system under drying shrinkage conditions. 1-10.

Li, M., \& Li, V. C. (2011). High-early-strength engineered cemenititous composites for fast, durable concrete repair-Material proeprties. ACI Materials Journal, 3-12.

Li, V. C. (2003). On engineered cementitous composites (ECC) A review of the material and its applications. Journal of Advanced Concrete Technology, 1(3), 215-230.

Long, W.-J., Khayat, K. H., \& Lemieux, G. (2014). Performance-based specifications of workability characteristics of prestressed, precast self-consolidating concrete- A North American Prospective. Materials, 7, 2474-2489. 
Lotfy, A., Hossain, K.M.A., \& Lachemi, M. (2016). Durability properties of lightweight selfconsolidating concrete with three aggregates. ACI Materials Journal, 113(5), 679-690.

Melnikov , R., \& Hossain, K.M.A. (2017). Numerical modeling of reinforced ECC building frames. Leadership in Sustainable Infrastructure, 1-10.

Ouchi, M. (n.d.). Self-compacting Concrete Development, Applications and Investigations. Japan: Kochi Univeristy of Technology.

Paultre, P., Khayat, K., Cusson, D., \& Tremblay , S. (2005). Structural performance of selfconsolidating concrete used in confined concrete columns. ACI Structural Journal, 102(4), 560-568.

Sahmaran, M., \& Li, V. C. (2009). Durability properties of micro-cracked ECC contaiing high volumes fly ash. Cement and Concrete Research Journal, 1033-1043.

Said, S. H., \& Razak, H. A. (2016). Structural behavior of RC engineered cementitous composite (ECC) exterior beam-column joints under reversed cyclic loading. Construction and Building Materials, 107, 226-234.

Sherir, M., Hossain, K.M.A., \& Lachemi, M. (2017). Development and recovery of mechanical properties of self-healing cementitious composites with $\mathrm{MgO}$ expansive agent. Construction and Building Materials, 148, 789-810.

Slater, E., Moni, M., \& Alam, M. S. (2011). Predicting the shear strength of steel fiber reinforced concrete beams. Construction and Building Materials, 26(1), 423-436.

Tawfik, A. S., Badr, M. R., \& ElZanaty, A. (2014). Behavior and ductility of high-strength reinforced concrete frames. Housing and Building National Research Center, 215-221.

United States Department of Transportation. (2019). Ultra-High Performance Concrete.

Retrieved from U.S. Department of Transportation- Federa Highway Administration: https://highways.dot.gov/research/structures/ultra-high-performance-concrete/ultra-highperformance-concrete

Xu, L., Ye, H., \& Feng, N. (2012). Brief introduction on the application of high-performance concrte preparation technology in ultra-high rise buildings. Applied Mechanics and Materials, Vol. 193-194, 633-638.

Yeganeh , A. E., \& Hossain, K.M.A. (2019). High-Performance Reinforced Concrete Flexuralcritical frames under lateral cyclic loading. Toronto: Ryerson University. 
Yeganeh, A. E. (2015). Structural behaviour of reinforced high performance concrete frames subjected to monotonic lateral loading. Master's Thesis, 1-95 .

Yeganeh, A. E., \& Hossain , K.M.A. (2019, June 12-15). Experimental investigation on the bending behaviour of exterior beam-column connections made with Engineered Cementitious Composite. Proc. CSCE Annual Conference.

Yoo, D.-Y., Sohn, H.-K., \& Borges, P. (2020). Enhancing the tensile performance of ultra-highperformance concrete through strategic use of novel half-hooked steel fibers. Journal of Materials Research and Technology, 1-12.

Yu, K., Li, L., \& Yu, J. (2018). Direct tensile properties of engineered cementitous composites: A review. Construction and Building Materials Journal, 165, 346-362.

Zdeb, T. (2013). Ultra-high performance concrete- properties and technology. Bulletin of the Polish Academy of sciences Technical sceineces, 183-194.

Zheng, Y., Zhang, L., \& Xia, L. (2018). Investigation of the behavior of flexible and ductile ECC link slab reinforced with FRP. Construction and Building Materials, 166, 694-711. 